Portland State University

PDXScholar

Dissertations and Theses

Dissertations and Theses

Spring 6-20-2013

\title{
Queer! Narratives of Gendered Sexuality: A Journey in Identity
}

Kym Bradley

Portland State University

Follow this and additional works at: https://pdxscholar.library.pdx.edu/open_access_etds

Part of the Gender and Sexuality Commons

Let us know how access to this document benefits you.

\section{Recommended Citation}

Bradley, Kym, "Queer! Narratives of Gendered Sexuality: A Journey in Identity" (2013). Dissertations and Theses. Paper 1069.

https://doi.org/10.15760/etd.1069

This Thesis is brought to you for free and open access. It has been accepted for inclusion in Dissertations and Theses by an authorized administrator of PDXScholar. Please contact us if we can make this document more accessible: pdxscholar@pdx.edu. 
Queer! Narratives of Gendered Sexuality:

A Journey in Identity

by

Kym Bradley

A thesis submitted in partial fulfillment of the requirements for the degree of

\author{
Master of Arts \\ in \\ Sociology
}

Thesis Committee:

Randy Blazak, Chair

Peter Collier

Lindsey Wilkinson

Portland State University 2013 
(C) 2013 Kym Bradley 


\begin{abstract}
My project looks at current conceptualizations of identity relating to gender and sexuality in order to understand how queer individuals enact gender as connected to their non-normative sexuality. I will use the notion of "desire" through Butler's (1990) notion of performativity as a part of iterability that reproduces an opposition between what is intended and how it is perceived. This approach creates space to problematize the status of identities that posits the conception of fluidity and dialectic as attached to notions of gendered sexualities - the understanding that sexuality interacts with gender and that these two notions are not compartmentalized. The construction of these systems of categorization allows for an assumption of the role of sexuality as connected to gender that can then be read through discursive practices and performances.

This research is placed within a post-structuralist and queer theory discussion that is used to understand identity as separate from an isolated core self and is rather comprehended through a particular connection of gender, sex, desire, and performance. By entering into a queer theory and post-structuralist discussion, this project aims to highlight ways in which gender and sex are not necessarily "intelligible" - in which one's gender enactment follows their sex, which then leads them to be attracted to the "opposite" sex/gender - and by doing so I will be able to understand how nonheterosexuals understand their own sexualized gender. The categories of gender and desire are not mutually exclusive nor are they dichotomous. According to Butler (1990), the heterosexual matrix addresses the power structures associated with hegemonic modes
\end{abstract}


of discourse and thought; therefore, my project embraces this approach to gender and sexuality and how these understandings create a unique performance of repetition that further constructs an identity.

This study specializes in the reformulation and re-articulation of a distinct consciousness of compounded identities that are comprised of a sexualized gender involving the performative interplay of sexuality on gender for queer individuals. In addition, this project seeks to understand how queer individuals form, understand, perform, and enact their evolving gender identity as connected to their sexuality. Specifically my research asks: 1) How do queer individuals narrate the construction of their particular identities? 2) How do queer individuals enact their gender as connected to sexuality? and 3) How do queer individuals describe their identities as marginalized?

In order to answer these questions I conducted 20 interviews with queer individuals in Portland, OR aged 18-35 in order to get a broad range of life experiences. The use of one-on-one interviews allowed me to get at the interpretative perspective of the participant such that they can clarify the connections and relationships they see between their own sexualized gender enactment and the world around them. This also allowed access to acquire information about the social interplay of gender, sex, and desire and how these individuals may or may not place importance on their queer identity and the processes involved. 


\section{Dedication}

To all those who have faced stigma and marginalization and were brave enough to stand up for their beliefs and for themselves. I also dedicate this work to those who were kind enough to open their souls and histories for me to be able to conduct this research.

Additionally I dedicate this thesis to those who enabled me to be the strong, motivated and passionate person I am today, thank you! 


\section{Acknowledgement}

I thank the members of my thesis committee Dr. Randy Blazak, Dr. Lindsey Wilkinson, and Dr. Peter Collier for their participation within this project and their helpful yet critical feedback throughout the process. I specifically thank Randy, my advisor, for slaving over the pages of my writing and his willingness to dig into a familiar yet new subject area and for dedicating his time and his generosity throughout the past year working on this project together.

Additionally, I would like to send my gratitude to Dr. José Padin who pushed me to re-evaluate my thought processes, and though he was not intimately involved in this project, he gave me suggestions and support. I know the project would not have been the same without him. I was lucky to have him as the theory professor who not only piqued my interest in the transformative power of education but also taught me humility.

I thank my friends in the department, and those outside of academia, who listened to me process through the writing and providing regular support and feedback and spent hours being that second, or third, or fourth pair of eyes looking over my work. Especially April, Patrick, Jeff and Daniel, they encouraged me to recognize my own strengths and abilities and picked me up on those hard days.

Mostly importantly, I give my undying thanks to my partner, Jenn Becker, who has been by my side through this whole project and has been the de facto research assistant and transcriptionist extraordinaire. She has encouraged me through the hard times, celebrated in the high times and is willing to stay by my side as I continue in my journey in academia. I could not ask for a better partner! 


\section{Table of Contents}

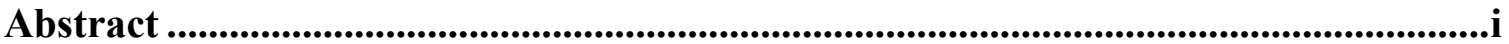

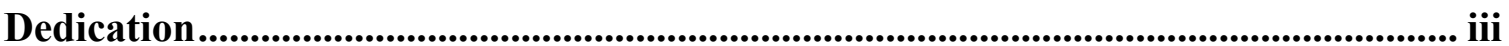

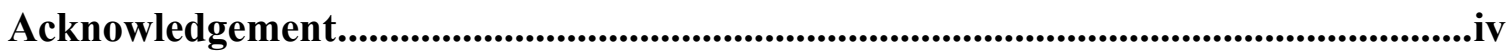

Chapter One: Introduction...........................................................................................1

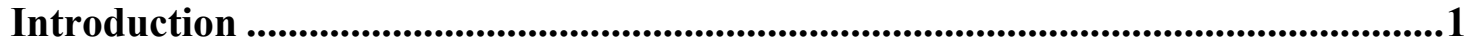

Post-Gay/Post-Closet Discourse ...................................................................................4

Importance of Linguistics and Discourse ....................................................................7

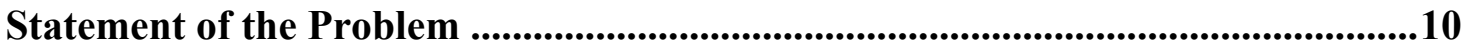

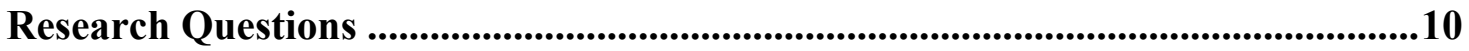

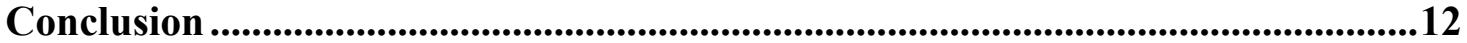

Chapter Two: Literature Review .........................................................................13

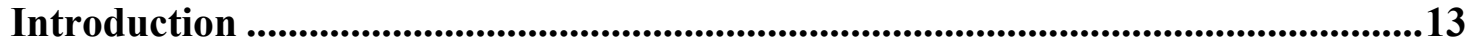

Linear Constructivist Models and Identity Theories ..........................................13

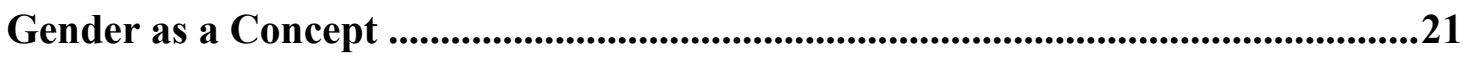

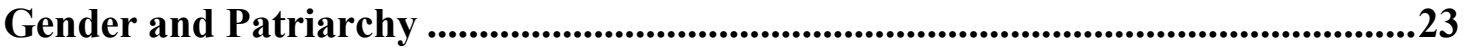

Hegemonic Masculinity and Emphasized Femininity .........................................26

Doing/Being Gender(ed) ....................................................................................................26

Beyond Gender into Performativity ................................................................29

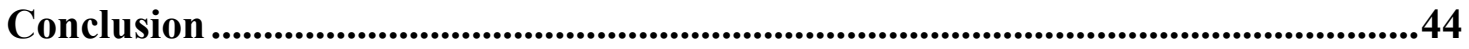

Chapter Three: Methodology ................................................................................................46

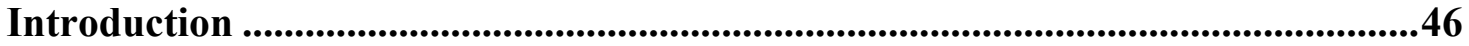

Research Design ..........................................................................................................................46

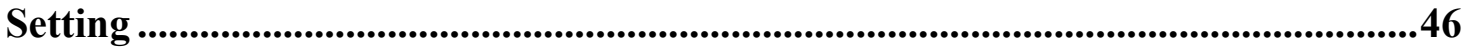

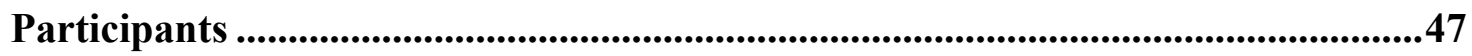


Interview Background.......................................................................................................50

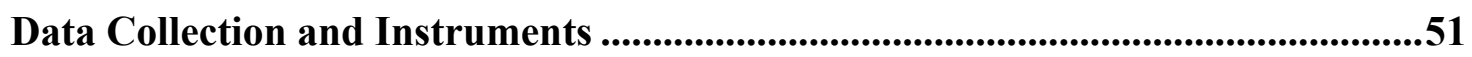

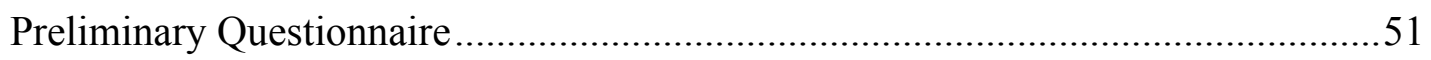

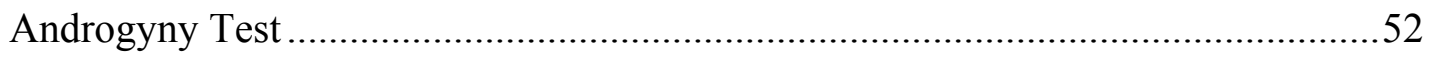

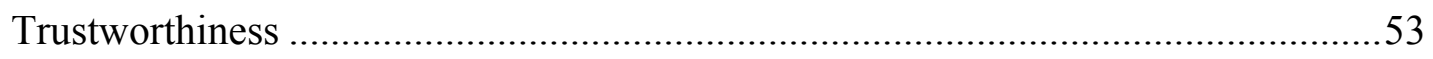

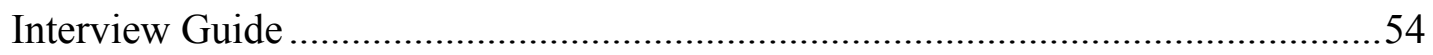

Confidentiality and Information Security ..............................................................56

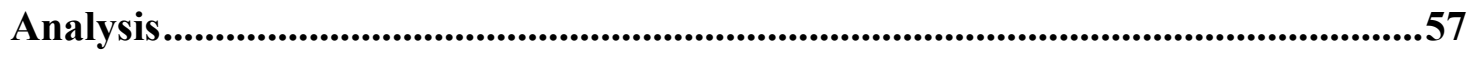

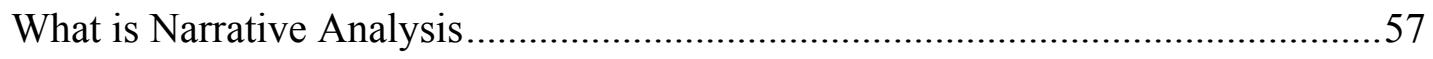

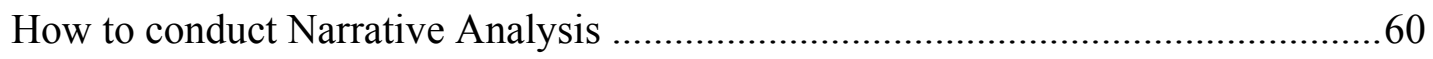

Realities and Limitations to Narrative Analysis........................................................61

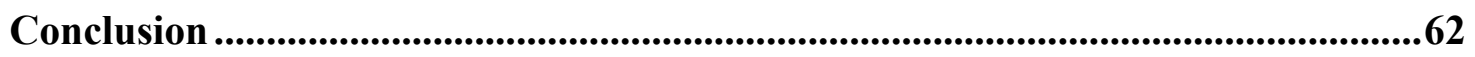

Chapter Four: Race, Gender, and Sexuality......................................................................64

Introduction ....................................................................................................................64

Participants .............................................................................................................................64

Race, Gender, and Sexuality ......................................................................................65

Brandon and Jay - Living Between the Spaces.........................................................66

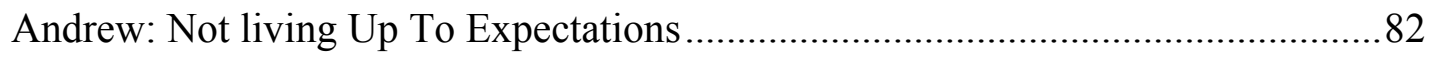

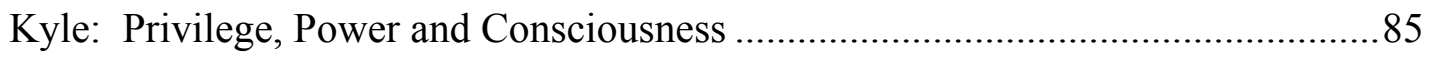

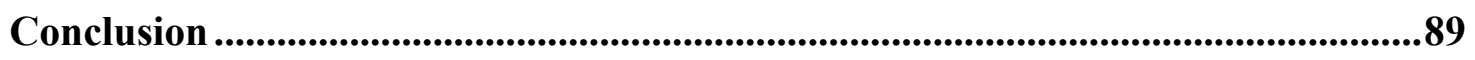

Chapter Five: Sexual Experiences ........................................................................................90

Introduction ......................................................................................................................90

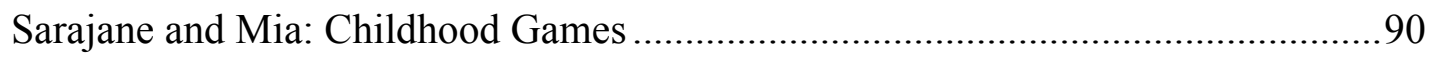


Lauren: Butch in the Sheets and Femme in the Cuddle

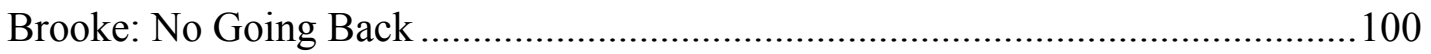

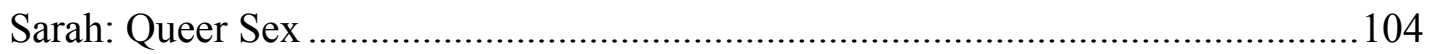

Jennifer: Conformity and Expectations ..............................................................111

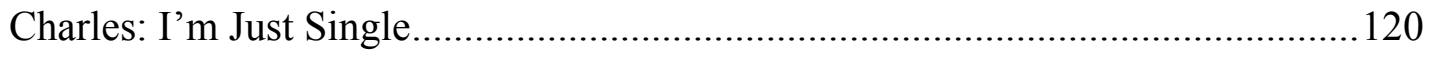

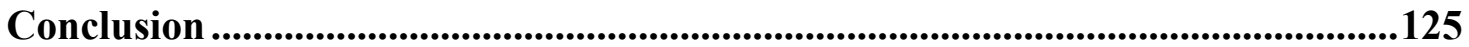

Chapter Six: Connections of Gender and Sexuality .....................................................126

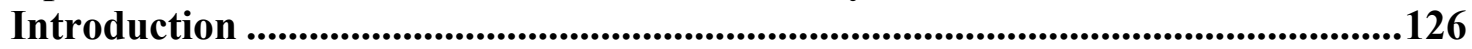

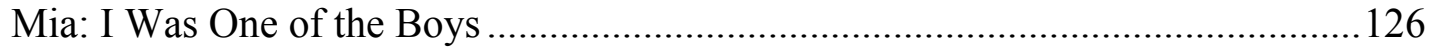

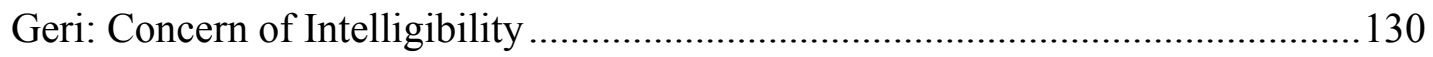

Lauren: Part of Being a Woman is Loving Other Women.......................................135

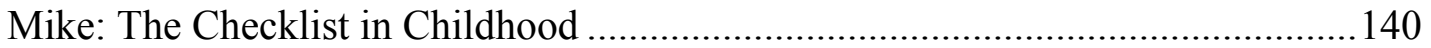

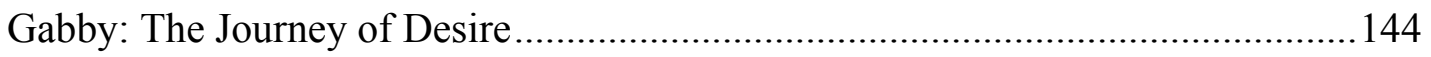

Sarah and Audrey: Dyke Conceptualizations .........................................................147

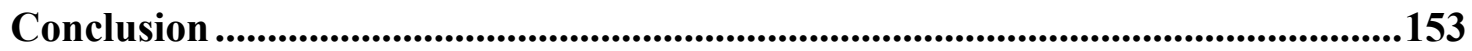

Chapter Seven: Discussion..................................................................................................155

Introduction .........................................................................................................................155

The Deconstruction of or Resistance to Traditional Labels and Hegemonic

Discourse .............................................................................................................................156

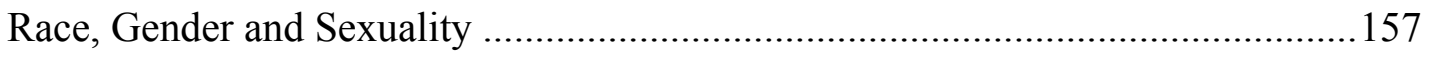

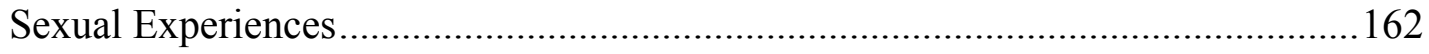

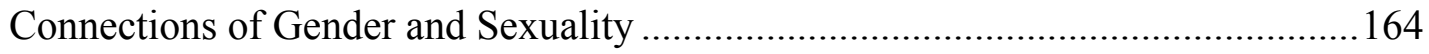

From a Linear Constructivist Lens................................................................168 
An Interplay of Resistance and Linear Constructivist Lens

Chapter Eight: Conclusion 175

Performativity and Gendered Sexuality .............................................................175

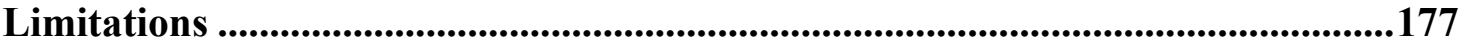

Suggestions for Future Research ....................................................................179

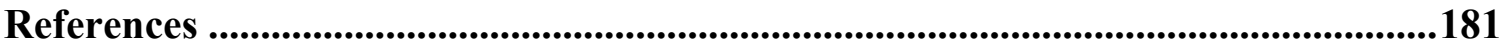

Appendix A: Recruitment Flyer..................................................................................191

Appendix B: Preliminary Questionnaire..........................................................................192

Appendix C: Bem Androgyny Test ................................................................193

Appendix D: Interview Guide ...............................................................................194 


\section{Chapter One: Introduction}

\section{Introduction}

Discourses of gender, sex and desire are contested and negotiated through multiple conceptualizations of identity and the self. Gender is defined as the cultural/social assumptions based on physiology. This definition illuminates the idea that there are biological differences between women and men, which are then taken as given or natural (Lorber 2004; West and Zimmerman 1987). Early feminist theorists suggested differentiating between gender and sex so that gender was constructed as cultural while sex was anatomical and natural (DeBeauvoir 1952).

The current cultural understanding of gender is understood as a dichotomy in which an individual is either seen as one category or the other, but cannot hold a place in both categories. This conceptualization fails to address the existence of multiple genders or understanding gender as behavioral. A similar dichotomous categorization of sexual desire - that of heterosexual versus homosexual - has emerged from this approach to gender, with each category being seen as mutually exclusive and tied to gender. One consequence of this dichotomization is the creation of a hierarchy of both gender and sexuality i.e. masculinity as superior to femininity and heterosexual as superior to homosexuality, based on these differences.

The separation of gender and sex speaks to how structural arrangements produce certain understandings to the role of biology and culture. West and Zimmerman (1987) present the idea of doing gender that involved complex socially guided activities. They add to the academic discussion of a core sense of self that is then reproduced through social interaction with others, subsequent perceptions and social structures. This notion 
of doing gender can be reworked in which the order of construction is a repetitive notion of performance - or more appropriately as Butler (1990, 1993a, 1993b) would say performativity - that recreates/re-constructs a particular gender. In looking at how gender and sexuality can be repetitive performances, I employ sexual desire and explore how it has been constructed as a signifier of identity. The use of desire will be queered through Butler's notion of performativity as part of iterability that (re)produces an opposition between what is intended and what is perceived. This approach creates legitimate space to problematize identities that incorporates conceptions of fluidity and dialecticism in regards to sexualized genders and gendered sexualities. The construction of these systems of categorizations allow for an assumption of the role of sexuality as connected to gender as well as other matrices of identity that can then be read through discursive practices and preforms.

Post-structuralist and queer theorists have imagined new ways of thinking about gendered and sexual identities that allow for a divergent approach. These methods can then be used to understand identity as separate from an isolated core sense of self but is rather comprehended through the connection of gender, sex, desire, and performativity (Butler 1990; Case 1993; DeLauretis 1993). These theorists argue that traditional conceptualizations involve an imposition of (hetero)sexuality on gender in the form of what Ingraham (1994) calls "heterosexual imaginary" and Butler (1990) describes as a "heterosexual matrix." Ingraham's heterosexual imaginary is the symbolic order of the world through the use of verbal and nonverbal communication that defines and individual's sexuality as heterosexual. Butler's heterosexual matrix is the hegemonic way of thinking that creates an epistemic model of gender intelligibility that assumes an 
individual's gender as feminine or masculine which matches their biological make-up and simultaneously is connected to an oppositional partnering through the practice of compulsory heterosexuality. Both the heterosexual imaginary and the heterosexual matrix focus on how the cultural conceptualizations of gender and sexuality "conceal the operation of heterosexuality in structuring gender and closes off any critical analysis as an ongoing institution" (Ingraham 1994: 3-4). Traditional conceptions of gender and sexuality can be linked to heteronormativity i.e. the cultural bias in favor of opposite sex/gender sexual relationships, and therefore is implicitly against same-sex relationships of a sexual nature (civil liberties 2012.) In a context where institutional constructions of both gender and sexuality are favored it is difficult to fully explicate the processes involved in understanding an individual's gender enactment as connected to sexuality or the fluidity of identity categories.

Social scientists have understood gender to be the performative expression of the biological make-up/sex of an individual. At the same time it has been conceptualized as the (re)presentation of the self that is visible to the social world that follows a predetermined structural alignment in which gender and sexuality are explicitly connected in one way. This intrinsic link of gender, sex, and desire addresses the modes in which a particular gender is replicated to express the dichotomous categories of feminine or masculine as connected to female and male respectively. This connection therefore informs an individual's understanding of her/his desire/attraction to the opposite gender and hence sex. By acknowledging the pairing of opposite genders with one another heterosexuality becomes the expected form of desire. Those that deviate from the dichotomous construction of gender (and sex) and heterosexuality are then perceived 
to transcend all three categories, no longer fit into the "normal," and no longer receives the benefits received from heterosexuality.

\section{Post-Gay/Post-Closet Discourse}

Previous research in relation to the "homosexual" question acknowledged homosexuality as similar to a disease (McIntosh 1996). It was either you are. Or you are not, with out possibilities of "in between." However some psychiatrists acknowledged the notion of bisexuality in the mid twentieth century and even some social scientists such as Alfred Kinsey and his partners, Wardell Pomeroy and Clyde Martin $(1948,1953)$ denoted a continuum that was not purely entrenched within biological, social, or psychological factors. In the mid twentieth century there was an emergence of "gay societies," stemming from the birth of the gay liberation movements as well as a change in the political scene with anti-sodomy laws, and, in general, anti-gay laws being repealed (D’Emilio and Freedman 1997). Scholars have addressed an emergence of the "new gay identity" stemming from identity politics and capitalism. Specifically, D’Emilio (1993) attributes the homosexual identity to the urbanization and the dominance of a capitalist economy, within western society. Wilson (2004), additionally, addresses the rise of the "Tom" and "Dee" identities, specific lesbian identities that may mirror the butch/femme relationship, to the commercial boom in Thailand and the new infrastructure that emerged in the end of the twentieth century. Both D'Emilio and Wilson connect this new identity to changes in the political and economic sphere. At the same time Lisa Duggan (1993) addresses the historical legacy of the lesbian subjectivity emerging in the end of the $19^{\text {th }}$ Century, but still connects it to structural inequalities from the economy. Duggan (1993: 
793) states that "stories of identity are never static, monolithic, or politically innocent" thus acknowledging the importance of social power and inequality in relation to identities, in the case of her work on lesbian identities. In other words the gay/queer/homosexual identity is not constructed in isolation, nor remains static.

Historical presentations of a "gay identity" have largely been analyzed by social scientists in relation to deviance (Weeks 1996); however society has also placed arbitrary constructions around the meaning of queer or gay and as such reproduces a particular discourse when describing the queer/gay experience. Stein and Plummer (1996) have focused on how the queer identity has been conceptualized along the racial/ethnic models in a relatively "identity politics" movement however they point to how the queer identity can be invisible comparatively to a racial/ethnic identity. According to Warner (1991:

15) the identity of a lesbian or gay man is
Ambiguously given and chosen, in some ways ascribed and in other ways the product of the performative act of coming out...In many respects, queer people are a kind of social group fundamentally unlike others, a status group only insofar as they are not a class.

This addresses the multiplicities of identities, not the lack of possible homogeneity within this group; however during the mid twentieth century, during the height of the gay rights struggle, there was an attempt to unify the vastness and diversity of this group under one similar identity to create visibility. Since the late 1980's queer discourses have emerged within society and these discourses react to a change in policies and culture. The rise in queer visibility can be specifically linked to the response to AIDS activism and an increasing visibility of homosexuals in the media (Dow 2001). 
Seidman (2002: 6) has suggested that in Western Society gay/queer life is moving "beyond the closet" even though heterosexuality is privileged in almost all aspects of life. A post-gay or post-closet discourse arose in the mid-nineteen nineties in both the U.S. and Britain (Ghaziani 2011). Specifically the post-closet discourse was started in a New York Times article that claimed "we should no longer define ourselves solely in terms of our sexuality - even if our opponents do. Post-gay is not UN-gay" (found in Ghaziani 2011). This is key in looking at how individuals construct identities around sexuality, but not solely sexuality. Though the acknowledgement of an emergence of a post-gay discourse, individuals no longer have to remain "ghettoized" even though some still feel the unequal positionality or subjectivity in their lives (Ghaziani 2011). Some queer researchers have argued that the post-gay discourse focuses on assimilationist values of some gays (Bullough, Eaklor, Meek 2006; Vaid 1995) and is specifically focused on a "normative" gay ideal - such as the white middle class "gay" (Duggan 2002; Valochi 1999a; Warner 1999). This post-gay/post-closet rhetoric has been both accepted and critiqued but came out of the changes in the perceived social acceptance of homosexuality, as well as the assimilationist ideas that appear to be sweeping gay culture (Ghaziani 2011). Assimilationist values are seen to be "muting" the identity that was once created by "difference" and struggle (Ghaziani 2011). However, identity needs difference (Gamson 1997; Seidman 1997) but at the same time "creating exclusion is an inevitable consequence" of that need for difference (Armstrong 2002: 178).

The exclusion of queer or gay culture from the mainstream created a community that was formed by an "Us versus Them" rhetoric (Tajfel and Turner 1979; Taylor and Whittier 1992). According to others (Chauncey 1994; D’Emilio 1983) this exclusionary 
"us versus them" framework created the construction of an identity in the time of the closet and during the era of coming out; additionally, Seidman (2002) considers the closet to be a tool that can be used for safety and protection from social, cultural, and familial discrimination. The closet has become synonymous with hiding, but not all queer individuals utilize the closet in the same way - those that have more or less social, cultural and/or institutional power may or may need to employ the closet in the same manner. Specifically when looking at other aspects of identity, how does race, gender, class, etc. shape and interact with sexuality and the closet? Do these matrices of identity require the use of the closet or not? The closet can be a tool but in post-closet rhetoric and perceived rise of acceptance, what was an "us VERSUS them" slogan has slowly shifted to an "us AND them" (D'Emilio 2002; Ghaziani 2011) rhetoric in which sexuality is no longer the defining aspect of an identity. But to be careful, I am not suggesting and neither are post-closet scholars, that heteronormativity and discrimination against queer individuals is obsolete, but rather in comparing times in history, sexuality has moved into a more open arena in which an individual can be more than just "gay" or "queer." The conception of the post-gay/post-closet is important in understanding the social climate that this research has been conducted in, and how some of the narratives expressed may be constructed in what can be considered this "post-closet world."

\section{Importance of Linguistics and Discourse}

Discourses are understood as "structured and structuring structures" which are involved in shaping/molding experiences (Keller 2005). In fact an individual's experience can be mediated through the language s/he utilizes to express, explain and define that experience. 
Language and the analysis of it, is commonly used in understanding both kinds of speech and types of speakers "who produce and reproduce particular identities" (Bucholtz and Hall 2004). Language can be utilized to understand how hegemony can be created by focusing on "sameness" and "difference," which offers complimentary lenses to identity (Bucholtz and Hall 2004). This allows an individual, by comparing, to construct an us/them as found in the post-closet discourse whether it be the previous construction of "us versus them" or the perceived current "us and them." Language analysis is linked to a post-modern turn in academia, influenced by Foucault, Derrida, Lacan, Irigaray, etc. and in this vain, focusing on discourse requires, as Derrida calls it, "double reading and writing” (Armour 1999.) Derridean language analysis involves deconstruction of existing systemic conditions that interfere with what remains to be thought (Armour 1999) and the understanding that language or rather speech represents itself - it is its own representation or re-presentation (Derrida 1991). Nothing exists prior to the naming or (re)presentation of the object/subject being named.

Derridean understandings of language and speech rely on the basic understanding that language is both the signifier and the signified. It both represents and constructs the possibility of existence. An individual's understanding of her/his identity is structured through language and as Bettie (2003: 195) states: "Experience is mediated by the discursive frameworks for understanding ourselves that are made available to us." As understood by discourse or linguistic theorists, discourse constitutes both society and culture, does ideological work, is historical and is a form of social action (van Dijk 2001; Fairclough and Wodak 1997). Utilizing linguistic or discourse analyses to focus on language and gender has a history in a divergent range of fields and it is as 
"interdisciplinary as they come" (Tannen 1994: 2) and can be traced to sociology, education, anthropology, women's studies, psychology, speech communication, literature, etc. Discourses outside of the basic linguistic nature moves beyond phonology, or words, or lexicon into the focus of language "beyond the sentence" (Tannen 1994). Similar to what Derrida considered the "double reading" focusing on discourse, specifically in relation to interaction and as connected to systemic structures of power, one is able to illuminate structural implications through language (for more work on gender and discourse see previous work by Tannen; Gumperz 1982; Maltz and Borker 1982). Language can be understood through a discourse lens in which language is power (Foucault) and works to disadvantage members of groups who are stigmatized in society at the same time advancing those in positions of power. This focus on discourse and language is useful in conceptualizing the ways in which marginalized individuals come to narrate their identities that must navigate the world of language.

Linguistics as a field, or subfield, has made assumptions that "roles are not given but are created in interaction" and "context is not given but is constituted by talk and action," therefore no language has meaning except by how it is framed (Becker 1979, 1984; Gumperz 1982; Tannen 1994: 10). This understanding of language is key in setting the background for the focus of this research, since language structures experiences, is structured itself and is created through interaction it is only necessary to highlight the role that language plays in how individuals utilize language to construct identities that changes over time. 


\section{Statement of the Problem}

Queer identities have been explored in a multitude of ways in social research, specifically looking at the development of sexual minority identities. In many cases the use of identity theory can be applied to look at the processes involved in forming a nonheterosexual identity. By focusing on the process and having a starting point, midpoints, and a final point research follows the existing model that paints development as linear and progressive. Though this research focuses on queer identities - specifically the construction of gendered sexualities in relation to interaction and other axes of identity it is not meant to be another study on coming out narratives. Coming out research has been explored in a multitude of ways and queer theory is starting to "queer" the traditional constructivist models in analyzing identity (Abes and Kasch 2007). Queer theory is born out of feminist and post-structuralist critical thought, which includes both queer readings of texts and the theorization of "queerness" itself. What does it mean to be queer? Though there are feminist scholars who influence queer theory it is different from feminism. It critiques the essentialist claims about gender, sex, and sexuality and questions the dichotomous structures within our society, male $\mathrm{v}$ female, homosexual $\mathrm{v}$ heterosexual, white v black etc. In a similar vain it is important to see how new forms of analysis and theory can work in order to understand how individuals utilize the process of language choice in constructing identities based on experience.

\section{Research Questions}

In this thesis I challenge traditional linear constructivist models of identity and queer them by focusing on the importance of language in relation to constructions of identity. 
This research asks "How do queer individuals articulate their identities in relation to other axes of identity and their social experiences?" The stories presented in this research move beyond stories of coming out, and focus more on the ways that individuals are capable of articulating their marginalized identities. As similar to linear constructivist models there are events and processes involved in developing an identity but this research explores the process of mediating language and how understanding one's identity changes over time based on experiences.

This thesis will be organized by topic Chapter Two will present the theoretical foundation for this project, introducing the key terms that will be utilized within my analysis. This chapter introduces concepts such as gender, patriarchy, hegemonic masculinity, doing gender, and notions of performativity. Chapter Three focuses on the methodology utilized in this study, including a justification for qualitative research, descriptions of the setting, the participants, design, data collection and analysis. Chapter Four will present the narratives of these individuals as they focus on the importance of race in constructing gendered sexualities, Chapter Five presents the narratives of sexual experience as an impetus for claiming a queer identity. Chapter Six will combine narratives of gender and sexuality in how the individuals express and understand their identity as inter-related. Chapter Seven will highlight the theoretical aspects for analysis as well as the connection of identity theory to queer theory. The final chapter will place this study within the larger framework, the limitations of this study, as well as suggestions for possible research. 


\section{Conclusion}

This first chapter has introduced the general background for this research including the separation of gender, sex, and desire, as well as set the stage with a discussion on postgay/post-closet discourse and the importance of discourse and linguistics. In addition this chapter presented the research question along with the plan for the organization for remaining chapters in this thesis. 


\section{Chapter Two: Literature Review}

\section{Introduction}

This thesis takes an intersectional approach in understanding how queer individuals narrate their journey to their current gendered sexualities. For the purpose of this research queer is being utilized as an umbrella term in place of the individual labels such as lesbian, gay, bisexual, questioning, and queer itself. The fields of language and sexuality have gained importance in studying identities, particularly within queer theory. Identities are constructed with interlocking systems of privilege and domination (Collins 1990, 1993, 2004; King 1988) and it is important to understand how individuals narrate their conceptualizations of their compounded identities - specifically around the notion of a gendered sexuality. Gendered behavior can be utilized as a way to construct an understanding of sexuality (Bradley 2013; Hatfield 2010). This research goes beyond narrating "coming out" stories, and because there is plenty of research on sexual minority development, I only provide a brief overview of that literature, and then move on to research related to gender theory and socially constructed conceptions of gender. This chapter will finish with queer theories as related to sexualities and identities.

\section{Linear Constructivist Models and Identity Theories}

This section addresses the linear models of sexual minority development as well as places that research in connection to identity theories understanding that identities are not constructed in isolation. Scholars in both the humanities and social sciences have focused on identity - a stable, fixed and essential form of being - for some time. Some have argued that existing identity theories and identity models are not capable of properly 
accounting for the true diversity and fluidity of sexualities across spaces, time and lives (Sedgwick 1990; Weeks 1977; Weiss 2006) however it is useful when connecting to other theoretical perspectives. Others have suggested linear theoretical frameworks for describing identity development for sexual minorities (Atkinson, Morten, and Sue 1979; Cass, 1979, 1984; Coleman 1982; Minton and McDonald 1984; Sophie 1985/1986; Troiden, 1988). While still others have provided critiques (Weber 1995; Weinberg 1984) and suggested that research should focus on the relations of "self" (Mead 1934) and symbolic interactionism (Kaufman and Johnson 2004). Bilodeau and Renn (2005) present an overview of existing psychosocial models, and life span approaches to provide an alternative approach to looking at sexual minorities; however, their approach remains to address solely lesbian, gay, and bisexual identities that appear to have similar outcomes to the linear models. Social science, especially the social psychological models, have presented a range of identity theories, however they address the inception of identity and whether or not in connection to the self or to broader structural implications. Therefore it could be beneficial to take these broader sociological theories and place them in connection to ideas of sexuality (Weiss 2006) or notions of desire (Butler 1990).

Most of the research on sexual identity formation focuses on sexual minorities and is presented in a linear format that focuses on how individuals identify or recognize their non-heterosexual attractions (Atkinson, Morten, and Sue 1979; Cass 1979, 1984; Coleman 1982; Minton and McDonald 1984; Plummer 1975; Sophie 1985/1986). For example, Cass (1984) discusses the role of "coming out" as a life-long process of exploring an individual's sexual orientation; however, this "exploration" appears to end in the sixth and final stage of her model. The exploration ending in the final stage leads 
one to believe that upon the formation of salient identity there is no need for further exploration or discovering of the self. For Cass (1984) the coming out process consists of six linear stages in which the first step is identity confusion. Step one addresses the personalization of information regarding sexuality. The middle steps address anger at being a minority, connecting with other LGBQ individuals to learn build a sense of community that can be both positive and negative and than emersion into the LGBQ subculture - which typically involves activism. The sixth step is reached when there is no longer a separation of the homosexual identity with other aspects of the individuals' lives and their sexual identities recede from the forefront and spotlight. However, this is just one of the many variations of the linear, stage-sequential model focused on the coming out ritual. Nevertheless, it reveals the assumption that coming out is fundamentally a linear process that does not follow multidirectional or alternative pathways; and does not address intersecting identities.

In a study of conceptual models of multiple dimensions of identity, which addresses some of the limitations of Cass's model, Jones and McEwen (2000) believe that there is core sense of self to all individuals and they sought out to understand what makes up a personal identity. Jones and McEwen (2000) interviewed 15 undergraduate women and created an identity model based on the participation of these women. They found that there are multiple intersecting circles surrounding the core identity that represent significant identity dimensions such as race, sexual orientation, and religion these categories are all interconnected and cannot be isolated from others. Though their model is not directly connected to queer individuals, it does bring in the aspect of 
"multiple oppressions" with sexuality as one of the oppressors and how it is not compartmentalized from other aspects.

Jones and McEwen (2000) found ten key themes that emerged from their data; however of the ten themes found, three are of particular interest to this study. The categories that are helpful are: 1) multiple layers of identity, 2) the braiding of gender with other dimensions, and 3) current experiences and situational factors. These three themes speak to the ways in which gender is apparent in multiple aspects of the individuals and is not compartmentalized off and experienced as an isolated aspect of the individual. Jones and McEwen (2000) found that gender is one of the key "contextual influences" that arose to be important for individuals. Specifically they found that identities have a fluidity in which they are under "ongoing construction" and there is an “influence of changing contexts" (Jones and McEwen 2000: 408).

In a study that focuses specifically on the processes of identity for lesbians and gay men, Kaufman and Johnson (2004) conducted ten interviews utilizing theoretical approaches to identity, symbolic interactionism, and stigma. They use utilized symbolic interactionism and how it impacts the self (Gecas and Burke 1995); additionally they employed research on "reflected appraisals" to demonstrate the role of the active individual to the appraisals (Felson 1985, Franks and Gecas 1992, Gecas and Schwalbe 1983). They found that reflected appraisals are fundamental in affecting the initial encounter of stigma and for the progress of a stigmatized identity. Participants in Kaufman' and Johnson's study (2004) expressed the significance of perceived information from others in the social context about "self" and homosexuality in general. 
There was a variance amongst the participants in regards to when they experienced samesex attraction.

When individuals are actively involved in the construction of their identity, stigma does not problematize the social basis for their identity. This is a key element of Kaufman and Johnson (2004) because it shows that individuals are active, and not passive, can have a solidified identity that is not interrupted. This interrupted identity stems from Burke's (1991) understanding of identity processes and social stress that plays a large role in the construction of an identity. However, on the one hand for Kaufman and Johnson their findings were key because it conflicted with these previous understandings of identity in which sexual minorities would have stigma and therefore interrupt their development. On the other hand what was congruent with these identity models was that all of the participants had a "first awareness" about their difference. This awareness is important in understanding how the notion of sexuality (if nonheterosexual) may impact other aspects of the self for it will/may take the forefront of an individual's thoughts.

Sexual minority development models can work with identity theories to broaden the understanding of identity. A majority of identity theories are placed within the context of society and examine the interactions between the individual and institutions, or other individuals. Stryker and Serpe (1982) regard the "self" as a product of society in which social interactions underlie structured relationships between the individual and social roles. In such a case, the individual in question knows who s/he is based on the role that s/he occupies. In these roles, the social context has a way of structuring the behaviors of how an individual is expected to interact with those around them. 
Identity Theory, itself, utilizes Mead's (1936) notion of the self in which sociology focuses on the hierarchical arrangements of multiple identities within individuals (Owens, Robinson, Lovin 2010). However, Identity Control Theory (Burke) can best be utilized to understand the continual processes - not just a state of the person that may lend itself to the analysis of the journeys involved alternative sexual identities in relation to gender. Nonetheless, if one is interested in how situations - not individuals shape the behavioral cognitive and/or emotional reactions of individuals than one must use a different lens. It has been suggested that Social Identity (Ashforth and Mael 1989) or Status Characteristic Theories may provide a good approach; however there are other theories focusing on the collective identity of groups - which may be useful as a wider range of literature such as feminist, cultural and/or cognitive sociologies. Nonetheless, I argue that by separating out the many forms of identity theories there is a gap in understanding individuals who may live further on the margins of society, which is why it is pertinent to combine aspects of multiple theories and bring in alternate understandings.

For those on the margins there is a pause as to how their location (within society) interacts with their identity. By recreating themselves through what Stryker and Serpe (1982: 206) consider "role behavior" individuals can understand who they are. It is this self-reflection that is important to examine when looking at those on the margins and how a sense of self interacts with the rest of the world and how is role used as a tool for agency in understanding the self and expressing an identity. The idea of role expresses the notion that the role an individual possesses is more than a bundle of expectations but rather allows individuals to pass certain "cultural tests" in which the individual is tested 
by society based on interaction to see of the role they enact is "believable" (Callero 1994: 228). Roles allow individuals to have specific discourses which they can enact in order to be able to better relate to others and social structures. Nonetheless, the use of roles does not explicitly mean that these roles are constructed free from regulation, for social roles can contribute to the production of the social structure while at the same time the social structure can contribute to the performance of said roles (Callero 1994).

Callero's (1994) understanding of role posits the choice of role as being first before the enactment of that role occurs. However, for some there may not be an obvious decision for "choosing" a role that relates to their current identity as is consistent with performativity. These individuals learn what it means to be apart of this marginalized sexual community and how this may cause certain rules and stipulations to script how they interact and enact their identities. It may also lead to a deeper understanding of how sexuality may be deeper than just a role and yet not the entire self. Furthermore, roles can be understood through a lens of power, where power is realized in the control or domination of others, in this case connected to dominant forms of sexuality (monogamous heterosexuality). However, this conceptualization of power does not explicitly address issues of being labeled as "other."

Furthermore, Stryker and Serpe (1982) explain how individuals know who they are based on the roles they hold within society - the role provides a script for interactions with others. The use of role behavior is pertinent in the analysis for Stryker and Serpe (1982) or Callero (1994). Social Identity Theory focuses on the relationship of the individual and society (for a critical review of Social Identity Theory see Brown 2000). Despite its name it does not focus on identities as a collective group, but more how 
individuals have identities based on in-group and out-group behaviors, group participation, membership and interactions which can be, in the case of this study connected to the post-closet/post-gay rhetoric of "us/them.” Both Identity Theory and Social Identity Theory utilize the notion of identity "salience" but they have different meanings and identity theory's version of salience differs from sexual minority development model's conception of identity salience.

For example, if utilizing Social Identity Theory's notion of identity salience, an individual's social identity becomes salient when it starts to hold the standards for selfregulation in particular contexts. These regulations will match the norms of the group from which the identity is derived. In such individuals on the margins having a "salient" identity will act as what Foucault (1977) considers "disciplinary coercions" in which they will follow regulatory discursive patterns that are the social norms for their particular identity. Furthermore, by categorizing to the extent that social identities are constructed it sharpens the boundaries between groups by creating "normative perceptions and actions, and assigns people including self to the contextually relevant category (Hogg, Terry, and White 1995 p. 260). This then creates the need for boundary work, which highlights in-group and out-group differences. Therefore, individuals may group together based on certain identities and as such, for example, an individual's marginal sexual desire (or identity) may be constructed through the ability to recognize behaviors, connections, and interactions that these individuals have within certain social contexts.

In an essence, individuals have come to know who they are based on those around them. However, theorists have tried to conceptualize models to create coherent identity models that can be utilized to understand the varying processes of identity formation 
whether it is sexual, social, or essential. Conceptions of the self have been theorized in order to grasp a firmer hand on comprehending individuals. Nonetheless, they do not always address the true diversity and fluidity that exists within society. Identity has been conceptualized in relation to sexuality, socially and psychologically; however, in an attempt to broaden the scope, it is important to note that the existing models and theoretical conceptions do not necessarily address all enactments. In fact most of the existing models appear to present a linear idea, which upon reaching identity salience, the development of the self is completed. This ignores alternative pathways, or alternative identities - for example those on the margins.

\section{Gender as a Concept}

The social construction of gender, sex, and desire - as categories - leads an individual to understand the categorizations of subjectivity that are constituted through exercises of power (Kerfoot and Knights 1994). The conception of power as linked to such categories can inform personal identities, genders, sexualities, and even how one experiences desire. There are specific cultural understandings that provide "appropriate" discourses available to conceptualize how one identifies and experiences their gendered sexuality.

A gender order usually exists within most societies, in which one gender is constructed as more powerful and prestigious than other(s) (Lorber 1990). Specifically western society, specifically the United States, is structured around patriarchy in which

masculinity and males are placed above all else on the gendered hierarchy (Bradley 2013; MacKinnon 2003). As a way to maintain this order social sanctions are put in place (Butler 1988; Lorber 1990). At the same time, a dichotomous understanding of sexuality, 
as stemming from this gendered order exists - which orders types of sexuality on a similar hierarchy as gender with heterosexuality on the top (Bradley 2013; Butler 1988, 1990, 2004; Lorber 1990; MacKinnon 2003). However queer theorists have subverted traditional understandings of gender, and sexuality in which a denaturalization project occurred and according to Epstein (1996: 145) "sexual meanings, identities, and categories were inter-subjectively negotiated social and historical products - that sexuality was, in a word, constructed." As part of the queer project this research looks at how identities are constructed through the use of power, discourse, and interactions with others and are therefore fluid and dynamic (Gamson and Moon 2004).

There are specific cultural understandings that provide appropriate discourses available to conceptualize how an individual identifies and experiences her/his gendered sexuality. Though this discourse creates an understanding of an individual's experience, it is the socially constructed subjectivities of masculine and feminine that are associated to behaviors and practices (MacKinnon 2003). Kerfoot and Knights (1994:71) believe that these subjectivities are "fractured, historically shifting, constantly unstable and potentially multiple" which speaks to a precariousness of identity.

Since this research focuses on gender enactment, it is pertinent to theoretically understand aspects of gender. Gender identity and gender behavior/enactment differ in an individual's understanding of her/himself. An individual's core gender relates to how an individual understands her/himself as matching her/his sex - cisgender - or being different from their sex - transgender. Gendered behavior is actions of femininity, masculinity, and androgyny. Since this project will focus more on gendered enactment/behavior, not on whether or not the individual sees their gender as woman or 
man, it will not address transgender theory (for a brief introduction look for Susan Stryker's or Judith Halberstam's work). Femininity and masculinity differ from an individual's identity or her/his sense of self though gender is part of what makes her/him who $\mathrm{s} / \mathrm{he}$ is. Gender identity refers to the degrees in which an individual sees her/his self as feminine and/or masculine, based on how society constructs those categories. In each society there is a communal understanding of what characteristics demarcate female as passive, caring nurturing, etc. and male as brave, aggressive, independent, etc. These conceptualizations construct, preform, and assume that females will align and define themselves as feminine and males as masculine (Bradley 2013; Butler 1990; Hatfield 2010; Lorber 1990, MacKinnon 2003). This ordering allows for a certain understanding of gender, but also easily leads to oppositional pairing of sexual partners so that "opposites attract," in this sense feminine with masculine and therefore females with males (Johnson 2005).

\section{Gender and Patriarchy}

Feminist conceptualizations of gender link the unequal treatment of gender to the existence of a patriarchal system. Patriarchy exists as a way to order and structure individuals on the basis of gender, but at the same time individuals within a particular gender are not created equal. Gender is racialized as well as classed and therefore further constructs a divided and classified system (Anzaldua 2007; Collins 1988; Espiritu 1999; Johnson 2005). Patriarchy prioritizes males over females and thus rewards masculinity and manhood while placing females and femininity as the position of "other." Additionally, the male acts as the "norm" or the standard that all else is compared to - 
and since gender is both classed and racialized it is a particular white male who is that specific “norm” (Collins 1993; King 1988; McIntosh 1988). Patriarchy, as a social system in society, renders invisible the power, privilege, and dominance given to men and thus particular forms of masculinity.

Patriarchy is not a stand-alone institution, but it functions based on its relationship to heteronormativity, capitalism, race relations etc. (Brown 2011). Heteronormativity as based on Rich's concept of "compulsory heterosexuality is "that institutionalized, normative heterosexuality regulates those kept within the boundaries as well as marginalizing and sanctioning those outside of them (Jackson 2006); it is the assumption that heterosexuality is natural and is the only legitimate form of sexuality and this understanding seeps into most, if not all, social institutions. As sexuality is linked to gender, heteronormativity brings in ideas of gender intelligibility in which those with certain "appropriate" gender behaviors are connected to sexuality as connected to social institution which then they too become gendered and sexualized shaped by patriarchy. Lives become gendered and how an individual presents her/his gender will invariably affect how s/he relates to the social world.

In a study that focuses on the role of racialized identities in connection to institutions of power Pyke and Johnson (2003) look at the implications of racialized individuals as they "traverse interactional arenas with conflicting gender expectations" (34). They analyzed the ways in which second-generation Asian Americans navigate their gender identity amongst changing social contexts, specifically the different levels of patriarchy within different cultures. Pyke and Johnson found that many Asian American women felt their gender presentation change across social settings, and women in their 
study noticed the different ways people treated them based on different locations and groups of people. They analyzed the role of culture for second-generation Asian Americans and the particular struggles the individuals faced with living in different worlds - that of modern "liberal" America and the other of their patriarchal Asian families and communities.

Pyke and Johnson (2003) examined the changes of gender performativity based on social context and who surrounded the participants. For example, one participant in their study mentioned how when she is with her family she feels she needs to be more submissive and quiet and feels as though her opinion does not really matter because she is female. But when predominately white people surround this same participant, she feels as though her "opinion counts" and she can "be loud" (Pyke and Johnson 2003: 43). This example addresses the ways in which cultural or social context plays a large role in not only how an individual understands her/his own gender but also the particular enactments and constructions of gender that individuals have. Pyke and Johnson's (2003) article helps expand the notion that social contexts are important in how individuals experience themselves, not only in relation to others, but to themselves as well. It highlights the ways in which gender enactment can change for individuals. Through this elucidation, I kept the relationship of gender enactment with social location in the back of my head when interviewing individuals. Additionally, my project replaced Pyke and Johnson's notion of race as connected to gender and highlighted the role of sexuality or sexual desire and looks at how queer individuals navigate multiple worlds in which their sexualized gender may come to the forefront or take a backseat. 


\section{Hegemonic Masculinity and Emphasized Femininity}

Notions of a gendered system have created the idea that there are appropriate ways in which gender is constructed. These "appropriate" gendered behaviors have been theorized as hegemonic masculinity and emphasized femininity. Hegemonic masculinity is based on the ideal or stereotype of a man, which values stoicism, aggressive behavior as well as competition (Connell 1992; Kimmel 2011; Lorde 1970). This construction of hegemonic masculinity is, according to Connell (1995:77) the "culturally exalted" type that is rewarded and aligned with hierarchical power. Furthermore, since patriarchy creates a dichotomous understanding of gender the unequal opposite to hegemonic masculinity is "emphasized femininity" (Connell 1987: 183) in which the ideal "woman" complies with her subordination by accommodating men's interests and desires. This dualistic relationship between the genders is asymmetrical and based on the dominance and subordination and sometimes marginalization of each group.

This cultural understanding of gender as a dichotomous categorization creates mutually exclusive categories of gender. A similar categorization of sexual desire, has since been bred from this distinction of gender, that of homosexual versus heterosexual. This creation of difference occurs with respect to categories of sex, but also more importantly it creates a hierarchy of gender based on these differences.

\section{Doing/Being Gender(ed)}

The collective understanding of what it means to be "female" or "male" is created socially (Stets and Burke 1988). West and Zimmerman (1987) and Lorber (2003) have theorized gender as a routine accomplishment embedded in every day interactions which 
is why it is important to conceptualize how genders are constructed through the narratives told by my participants. If gender is embedded in every day interactions and social institutions then it must also be entrenched in sexuality. Since gender is constructed, West and Zimmerman (1987:126) believe that "the 'doing' of gender is undertaken by women and men whose competence as members of society is hostage to its production." As linked to patriarchy, gender is also linked to power and privilege and can be key in understanding how it becomes interconnected with other aspects of an individual's identity - specifically sexuality. The differences between women and men, and girls and boys, are entrenched within the structural and institutional preforms of society (West and Zimmerman 1987). These differences are neither normal, natural, nor essential but since it is iterative and fully embedded, these differences are rendered as innate and natural and to the construction of both femininity(ies) and masculinity(ies) as intelligibly connected to the categories female and male (Lorber 2003).

Individuals are always held to be accountable for their genders to make sure it aligns with the cultural assumptions. Furthermore, individuals are "subject to evaluation in terms of normative conceptions of appropriate attitudes and activities" (Dull and West 1987: 140) and as such learn to adapt their behaviors and attitudes based on interactions. The connection of gendered behavior to particular sexed bodies reinforces the hierarchal arrangements of gender within society that continues the influence of heteronormativity and thus renders invisible alternative expressions of genders and/or sexualities specifically those that are unintelligible. The possible alternative expressions of genders as connected to sexuality is where this current project aligns itself in order to flesh out the impact of heteronormativity in constructing queer identities. 
Gender, as a structure, plays a major role in the paradox of human nature as a "manifestation of cultural meanings" and therefore can be a way to read and interact with sexuality (Lorber 2003:101). My project analyzes the way in which both gender and sexuality are connected to the formation of an identity and that the particular identity of the individual is narrated in a particular way. Utilizing both West and Zimmerman's (1987) and Lorber's (2003) understanding of gender as part of being and interacting with other social structures can be easily connected to Butler's (1990; 1993a; 1993b) notion of performativity which will be the lens I analyze the narratives: How are gendered sexualities being constructed through the narratives of my participants?

Specifically connecting these ideas and focusing on intersectionality, Trautner (2005) analyzes the performance of sexuality through a lens of doing gender and doing class. In her analysis, Trautner highlights the ways in which institutions are both gendered and classed through an ethnographic study of four exotic dance clubs. She builds on the conversation with West and Zimmerman, Lorber and Butler in the notions of both performance and performativity of gender. However, in the conversation of the interrelationship of gender and sexuality Trautner joins with Bettie (2000 and 2003) in which there are different versions of femininity, which are "integrally linked and inseparable from their class and race performances" (Bettie in Trautner 2005: 773). Through the use of ethnography Trautner is able to see how gender and sexuality are structured in two different class-based clubs. She found that there are two comparatively different forms of gender and sexuality that are structured through the physical characteristics of the clubs. Sexuality ranged from "voyeuristic [to] cheap thrills" as she moved from the middle-class club to a working-class club (Trautner 2005:776). 
As a way to measure sexuality, Trautner (2005) analyzes both the body sizes of the working women or as she called them "images of attractiveness" and what styles of dance were performed. "Stage performances: constructing the gaze" entailed how often and how the dancers touched themselves, what style of music played when they were dancing and whether or not they interacted passively (middle-class dancers) or actively (working-class dancers). There were key differences presented through the sexualized gender performances of the women working in these bars that also spread to a obvious distinction between the middle- and working-class clubs. Additionally, she found that the rules of tipping changed between the class-based clubs and the ways in which the rest of the staff, the non-dancers, would dress. She argues that women's performances are both a "reflection and an interpretation" of organizational cultures and that sexuality is more than just an individual attribute that individuals holds. Though this study utilizes a different methodological approach to my project it provides great insight into the ways in which "doing gender" and performativity can work hand-in-hand in order to analyze the role of sexualized gender as it also connects with other axes of identity.

\section{Beyond Gender into Performativity}

Kerfoot and Knights (1994) believe that ideas around the social construction of gender, sex, and desire as identifying categories lead to an understanding that these categories of subjectivity are constituted through exercises of power and used to hierarchically arrange groupings of people. The conceptions of power as linked to such categories can inform personal identity, gender, sexuality, and even how individuals experience desire. By analyzing gender as performative an individual can recommend alternative pathways to 
examine how queer individuals construct identities around gendered sexualities that break down existing categories. The use of performative theory emphasizes the role of language and discourse in which there are particular discourses for individuals as relating to their gendered sexualities (Eves 2004). Gendered sexualities, or sexualized genders, highlight the intersection of these to axes of identification and how identities are constructed and discussed through a particular lens. This project will utilize this understanding in order to analyze the narratives of the participants.

Understandings of performativity speak to the ways in which discursive conditions of intelligibility "precedes and conditions the formation of a subject" (Butler 1993a: 18) so that they are based on the replication of a socially constructed category of social or sexual practices. This concept is entrenched in a discourse that has a history that performs contemporary understandings of gendered sexualities. These discourses create boundaries of exclusion and inclusion through the claiming of an identity that is highlighted in the narratives of some of the participants. There is an erasure of agency despite the inability to choose freely constructions of gendered sexualities and Butler's notion of performativity enables a thorough understanding of gender and sexuality as connected to the heterosexual matrix.

A queer discourse of performativity allows the invisibility of categories of identities to be elucidated in which certain enactments of sexualized genders rise to the surface. Queer, according to Jagose (1996: 4) "is always an identity under construction, a site of permanent becoming: utopic in its negativity, queer theory curves endlessly toward a realization that its realization remains impossible." In this instance queer theory brings to light the ever-evolving identity for queer individuals in which individuals' 
understandings of their own identities of gender is confounded with sexuality. This theorization of queer seeks to complicate the categorical simplicities within culture to show that there is a continual movement to challenge the hegemonic ordering of the sex/gender binary. Queer theory sheds light on the importance of highlighting current conceptualizations of individuals' sexualized gender enactments. It has been connected to the opening up of new "pathways for self-development and life satisfaction that were previously unimaginable or unforeseeable" (Green 2010: 317). Nonetheless, it has been critiqued at the level in which its endeavor to deconstruct the existing categories at the same time constructs those same categories. Queer individuals can utilize the discourses available in order to constitute an identity entrenched in the processes of discursive subjectification that are regulated by "disciplinary coercion" (Foucault 1977).

Green (2010), adding to queer theory's discussion on identity, attempts to propel taxonomic discourse as a way to expand upon subjectivities this research aligns with a similar attempt to expand notions of the self that revolve around sexualized gender. Green (2010: 317) highlights the ways in which post-structuralist and queer theory emphasizes power in discourse while "promoting a politics of transgression anchored in parody and deconstruction." Though my project emphasizes discourse it veers from Green's continued theoretical approach in that it does not necessarily aim to deconstruct the existing dichotomous boundaries of gender and desire, but rather may lead to an expansion on the way to think about how these two concepts relate and interact with one another. In doing so I believe that it can open up important sociological inquiries into understanding sexualized genders that, according to Green (2010: 318), are "obscured by too heavy a reliance on a thesis of self control." But rather the goal here is to explore 
new ways in which gender and desire discourses can expand current modes for selfdevelopment and satisfaction. Queer theory, in this instance, understands that in a postmodern world individuals are subject to "disciplinary coercion" (Foucault 1977) in which bodies, and thus identities, are scrupulously produced and structured. What is key is understanding how queer individuals understand the ways in which their sexualized genders are produced and structured.

My current project is centered on unfixing sexualized and gendered bodies so that instead of being understood through a heterosexual lens the existing categories of identity may be (re)formulated or (re)conceptualized. In a similar attempt Green (2010) highlights the ways in which individuals internalize categories around sex, gender, desire, or race and hence organize their identities around the category itself; and Diamond (2003, 2008) discusses the fluidities of the role of desire in the formation of sexual identities. These views lead to a broader understanding of how individuals may begin to think in particular ways about their connection to identifying categories and brought into this research. In looking at queer individuals it is important to understand the ways in which queer discourses have offered divergent possibilities for individuals who have participated in same-sex desires and has structured the ways in which queer individuals are capable of understanding themselves but also how they are understood by society. However not all of these discourses allow for an authentic experience since experiences are structured by our language and the current language system is constructed by and through a heteronormative lens. By linking post-structuralist and queer theories to the ethnographic understandings of doing gender, this connection aims to fulfill Green's (2010) request to open up taxonomic discourses around gender and desire. 
Through the use of Green's theoretical assumptions within queer and poststructuralist theories, my project aims to take sides with Green in such that even though discourse and identity categories are not natural, they come to represent what is natural or a natural ordering of human beings. Through the use of interviews this research is able to explore these caveats within identification categories as they relate to the lived experiences of queer individuals. Specifically, this project addresses the question: How does constructing an identity around gender and sexuality address the "unnatural" aspect of identities through the use of discourse?

As a way to further understand the ways that sociological concepts attempt to understand the ways the world is structured, Ingraham (1994) utilizes queer theory as a way to critique the sex-gender system. Ingraham asks that feminist sociological understandings of gender need to be reexamined so that they do not further the “heterosexual imaginary.” Ingraham's (1994) work critiques the current heteronormative system within dominant culture through acknowledging the ways in which the universality of subjects renders invisible current structures and players involved. In such, her work highlights how current configurations of gender are "inextricably bound up with heterosexuality" (Ingraham 1994: 204) and therefore need to be destabilized in order to analyze the ways in which sexualized genders are not necessarily intelligible and heterosexual. These categorical orderings of sex, gender and desire need to be analyzed as a form of critique since according to Ingraham (1994: 208) this is a practice that "exposes the textual boundaries and the ideologies which manage them, revealing the taken-for-granted order they perpetuate." This is the underlying groundwork that informs the ways in which categories of identity are understood in this research and though 
dominant discourses are used, it is acknowledged that they are connected to hegemonic structures within society. By interviewing individuals it is possible to get the stories of, not just labels and identities, but the intricacies involved within the journey of identity.

Butler (1990), in an attempt to trouble preexisting conceptualizations of gender, utilizes a theory of iterability and performativity in order to emphasize a different and broader foundation for gender that can be extended to sexuality. Butler, adding to a French philosophical conversation, looks to the role of linguistics and discourse as a way to represent the ways in which subjects are subsequently formed. She may be one of the first in this arena that allows for a movement away from structural or ethnographical understandings of gender and sex, and rather agrees with Foucault in which "juridical systems of power produce the subjects that they subsequently come to represent" (Butler 1990: 4, emphasis in original). Though there has been a transfer of Butler's thoughts from "juridical systems" to a broader identity field, this analysis creates space to restructure the ways in which sexualized genders are considered. This restructuring is attempting to take place in the current project by looking at the specific narratives of queer individuals that revolve around the construction of their identities as connected to the interplay of their gender and sexuality. Butler acknowledges that individuals are controlled by social structures; additionally, they are "formed, defined, and reproduced in accordance with the requirements of those structures" (Butler 1990: 4). In an attempt to better understand these structures it is necessary to understand what helps construct the structures. For Butler, language is the secret in understanding how gender performativity not only structures, creates, and performs one's sexualized gender, but also highlights the 
ways in which there is no essential gender or sex that an individual IS but rather gender is impossible to be separated out form other regulating modalities.

An individual may only be understood in relation to gender intelligibility and whether or not s/he adheres to this standard (Butler 1990). Under this analysis, identity and gender appear to be normal ways to structure individuals, but by disregarding the processes involved in gender intelligibility, the "regulatory practices of gender formation" are rendered invisible and it is precisely these processes that need to be brought to light (Butler 1990: 23). It is important to shed light on the processes of how "being" a gendered person is achieved through a "performative twist of language and/or discourse that conceals the fact that 'being' a sex or gender is fundamentally impossible" (Butler 1990: 26). This is key for Butler, which brings forth the ways in which individuals use discourse as a ways to discover their gender or explain their gender or sex. In fact, it is a "performative twist of language and/or discourse" that comes to play an importance in understanding sexualized genders for queer individuals. This linguistic twist is important in understanding the interplay between gender and sexuality.

Sexuality is postulated as a normative form (heterosexuality) such that a sexuality that is “'before', 'outside,' or 'beyond' power is a cultural impossibility and a politically impractical dream" (Butler 1990: 40). In such, Butler acknowledges that heterosexuality is posited as normal and natural and within this construct disregards alternative forms of desire. Though her "heterosexual matrix" attempts to denaturalize the current conceptualizations of sex, gender, desire, and power, further analysis is still needed to bring into question the so-called heterosexual original that is also the status quo. 
Therefore it is important to analyze the ways in which alternative sexualities interact with genders that may or may not be intelligible.

The discourses available to individuals, especially those with non-heterosexual identities or unintelligible genders, can be utilized to express a sexualized gender. Individuals, though the choice may not be free from structural or cultural implications, can utilize traditional modeling of identity and incorporate it into a form that fits. For instance, when looking at the formation of identities surrounding butch/femme within the lesbian community it can be interpreted as though femininities and masculinities have been queered to fit the lesbian relations within certain individuals' lives. Butler (2004) theorizes the parodic inscriptions of a corporal heterosexual signification. This corporal signification makes fun of the ideas of an original that is being imitated on the bodies, in this case butch and femme lesbians. They can be seen as queering an original heterosexual signification and utilizing it for their queer bodies in a way that seems "true" for their "self" as it relates to their sexuality. Butler's notion of butch/femme will be utilized in order to understand the way in which the participants, specifically the female participants, construct their identities around hegemonic terminology that enables the particularities of discourse to be shared through narratives. The construction of desire, sex, and gender leads to the constant deconstruction of a core identity into an understanding of fluidity (Butler 2004; Diamond 2003, 2008) based on a cultural understanding of false stability within the gender hierarchy. Butler (1990) argues that though this notion of butch/femme seems to reinforce dichotomous masculine/feminine ways of gender, it is instead an expression of a sexualized gender that is produced on the surface of bodies. 
Performativity acknowledges the histories associated with discourse and therefore when an individual invokes the terms feminine or masculine, gay, queer, or straight etc., there are certain histories that are also invoked, which is why it is important to understand the ways that individuals come to their own understandings of their sexualized genders. Performativity allows for the (de)construction of identity categories that precede current understandings of the "self" and in such highlights certain structural power arrangements. Butler (1993b: 21-22) states:

gender is performative insofar as it is the effect of a regulatory regime of gender differences in which genders are divided and hierarchized under constraint. Social constraints, taboos, prohibitions, threats of punishment operate in the ritualized repetition of norms, and this repetition constitutes the temporalized scene of gender construction and destabilization. There is no subject who precedes or enacts this repetition of norms.

Therefore through the use of performativity an individual may be able to further break down the processes of these "repetitive norms" that are structured by constraints that lead to expectations that follow an announcement of queer or a particular gender. However, these expectations are currently conceptualized as separate just as desire and gender, but as with before, there is a lack of acknowledgement about the interplay between the two.

In an attempt to critique the social constructionist claims about gender, Butler (1993b) clearly differentiates between performance (doing gender) and performativity in which "performance as bounded 'act' is distinguished from performativity insofar as the latter consists in a reiteration of norms which precede, constrain, and exceed the performer and in that sense cannot be taken as the fabrication of the performer's 'will' or 'choice"' (24). Therefore there is no "self" that comes before the sexualized gender but rather the individual is understood through her or his sexualized gender but not before it. 
In such sexualized genders may currently be understood through gender identification, which is why it is important to understand how queer individuals narrate and describe their own gendered sexualities. However, this current acknowledgement renders invisible the relationship between gender and sexuality and it must be critiqued in an attempt to bring attention to the interplay between sexuality and gender, and not just gender or sexuality. It is through the performative lens of sexualized gender in which "heterosexuality can be said to operate through the regulated production" (Butler 1993b) of either man or women; nonetheless these performances may be compulsory whereby individuals do not necessarily choose these versions but are forced to navigate through them.

According to queer theorist Valocchi (2005) there must be an understanding of the relationships between sex, gender, and sexuality in which there is "a focus on the performativity of gender and sexuality in the formation of identities; and a refusal of the easy conflation of sexual identity with the whole range of sexual desires, dispositions, and practices that constitute sexuality" (751). Sociology has previously assumed that each individual has one gender, one sex, and one sexuality that is static and fixed through life. Separating gender and sex reaffirms this notion of a fixed core self that is isolated from others. When utilizing a queer theory approach, it has been demonstrated that the dimensions of identity overlap each other in which gender can become racialized and race can become sexualized. However, it has been noted (Valocchi 2005) that queer theory tends to fall short on broadening its analysis. It has previously focused on the deviant cases and an alignment of the failure of dominant taxonomies to address the 
"complexity of individual gender and sexual subjectivities and practices" (Valocchi 2005: 753).

An example of a queer empirical analysis comes from Rupp and Taylor's (2003) study of a drag club in Florida. Their analysis defied categorizations of gender and sexuality in which they synthesized multiple theories in order to (re)imagine the relationship of cultural production to contentious politics. They found that drag queens, through a strategic use of comedy, irony, illusion, and sexuality bring the audience into an interactive space in which boundaries between gender and sexuality are blurred, disrupted, and played with. Through a discussion of the deconstructing of the gender/sex binary Rupp and Taylor (2003) create a new lens in which the drag queen can create and fill a new gender and sexuality - that of "drag-queenish" (61). The drag queens, in this sense, are not all feminine, but rather they inherently act in profoundly masculine ways and therefore they are neither one nor the other as the existing system suggests. This analysis creates space to see the ways in which gender and sexuality interact with one another in a multitude of ways. Individuals may not necessarily be solely feminine nor solely masculine, but somewhere in the middle or beyond. The sexuality of the drag queens is alluded through performance of "straight" however since these individuals are queering gender they, in a similar manner, are queering sexuality. What appears, upon first glance, to be a simple form of categorization of gender and sexuality is actually more confounding than originally believed. Therefore, through this analysis it sheds light on the ways in which one's enactment of sexuality interacts in a way that blurs traditional understandings of gender. 
As a way to analyze the transgressive discourses that the drag troupes presented, Rupp, Taylor and Shapiro (2010) compared gender between drag queens and drag kings. The participants in both troupes ranged from 17-34, which is similar to the population (18-35) in my project. Their data analysis consisted of interviews, analysis of taped performances, and focus groups of audience members, as well as an annual conference the International Drag King Extravaganza. They utilized this data in order to look at the use of drag, which they termed a "gateway drug for gender" (Rupp, Taylor, and Shapiro 2010). This study, as well as the previous Rupp and Taylor (2003) article, speaks to the ways in which drag can be a means to create new gender and sexual possibilities through their challenge to hegemonic gender and heteronormativity especially when thinking about the difference gender makes in "intentional performances of femininity and masculinity and the acting out of complex sexual desires" (Rupp, Taylor and Shapiro 2010: 290). This conceptualization aids in the understanding that particular implications of doing gender and sexuality have in everyday interactions which allows for a challenge to the traditional gender and sexual system. In such their analysis lends itself easily to a further adaptation of performativity as a way to analyze sexualized genders.

In order hone in on the ways that gender may or may not make a difference in drag kings and drag queens, Rupp, Taylor and Shapiro (2010: 277) explore how both the drag queen and drag kings had "divergent routes to performing drag." These performances of drag constructed the sexuality of the participants that were further defined through different contexts and styles of the shows. In their analyses, Rupp, Taylor and Shapiro (2010) highlighted the ways in which both the groups - the Disposable Boy Toys and the 801 Girls - have similar critiques of hegemonic gender and 
heteronormativity that surfaced in their performances. This leads to the use of performativity because when coupled with queer theory its analysis undermines the "assumed connections among gender, sex, and (hetero)sexuality (Rupp, Taylor and Shapiro 2010: 277). Their assumptions further rely on the somewhat theatrical performance of gender and sexuality for the drag queens and kings. However, Butler (1993b) in "Critically Queer" explicitly states that gender performativity is not the theatrical performance of gender or sexuality and that it is not necessarily a form of resistance that undermines the connections between the two but rather is a notion of forced management of some of these connections through a repetitive intelligibility of gender.

Some queer theorists (Valentine 2003, Valocchi 2005) warn others to not break apart the connection of gender and sexuality. Rather queer theory believes it is necessary to look at the compounded identities and the impact that this has on the individual. Not so much as one's gender is read as intelligible, in such gender stems from sex which leads to sexuality, but Rupp, Taylor and Shapiro instead look at the idea of a gendered sexuality or a sexualized gender which is key.

Furthermore, in an example of queer theory in a non-textual analysis, Eves (2004) interviewed 31 lesbian/queer women from the United Kingdom across the butch/femme spectrum. Eves's study focused on the intersection of discourses with everyday practices and the ways in which discourse are actively negotiated. Eves adds to the discussion of Esterberg (1996) that focused on the discourses and practices of butch lesbians. In Eves's interviews, she focused on the production of narratives in identity work and as well as on individual stories and intentions as they relate to safe spaces. For example, one 
participant, Jan, said she was no longer "going to pretend [she] was something [she] wasn't' she left her marriage and came out as a dyke (Eves 2004: 485). Jan is a femme who came out later in life and speaks of her sexualized identity in connection to gender. Her narrative fits in the western discourses of liberalism (Plummer 1995) and utilizes normative discourses in order to face homophobia in which butch/femme relationships were seen as imitative of heterosexual ones (Eves 2004). Eves found that butch and androgynous lesbians told narratives of estrangement and ostracism in public restrooms based on interactions with heterosexual women. These narratives fit in the discourses of heteronormative understandings of gender and sexuality in which atypical gender representations are marginalized.

Additionally, Eves (2004) focused on the marginalization of female masculinity and the performance of normative femininities - both are absent from Esterberg's (1996) analysis. In doing so she found that there were strong boundaries created between butch/femme in which there were constructions of femininity as understood through the hierarchy of heterosexuality. Furthermore, it became clear that certain practices might be subversive. She argues that those situated within a queer location can use "heteronormative structures to challenge that positioning" in order to construct new butch and femme subjectivities (Eves 2004: 491). These constructions are created around "aesthetic repertoires" that enable specific lesbian spaces and visualized desirability. The stories of butch and femme as gender representations spoke about personal histories of non-conformity, ambiguity and difference; however, for sexual identities these butch women spoke more of fluidity and choice than did the femme women who were interviewed (Eves 2004). 
These findings overall speak to the ways that inform the idea that gender and sexuality have a distinct relationship with each other, but they are not necessarily the same. For Helen and others who identified strongly as butch: "I don't necessarily choose to be butch, I am butch. But then it also might be something cultivated, it's complicated" (Helen in Eves 2004: 489). Helen's conceptualization of her butchness is not just a role, like gender has previously been defined, but is related to sexuality for the butch identity is tied to gender and sexual desire through the possibility of action with femme women. These findings help inform the constructions of butch and femme and how individuals may see their own performativity as relating to the connections of sexual desire. Additionally Eves's study (2004) gives light to ways in which I will formulate questions about butch and femme and constructions of walking style, haircuts, clothing etc. Her study provides a useful foundation to analyze the use of performativity when studying a particular set of sexualized genders because it not only provides a framework but also helps shape the ways to construct questions about gender and sexuality as interrelated.

Gendered sexualities will remain framed by the conventions of identity (Kopelson 2002) and though there has been a plethora of theoretical understandings of gender, sex, and desire, I will use Butler's (1990, 1993a, 1993b, 1995) performativity as the foundation for this project. It will be reconfigured to analyze gendered sexualities as a way to highlight the powers of discourse in constructing understandings of queer identities that takes a broader lens than previously utilized within queer theory to focus on the particular narratives. By highlighting the narratives of these participants it will provide explicit examples of how dominant discourses are both involved and negated in the performative construction of queer identities. 
In conclusion, queer theory provides a unique framework that allows for a more nuanced analysis of an individual's sexualized gender. It has previously been used to analyze butch/femme constructions, which allows for the interplay of gender with sexuality, to look at the performance of lesbianism, as well as the analysis of drag performances. In a textual way queer theory has been conceptualized through an emphasis on discourse and the importance of language as a way to (de)construct the lived experiences of individuals. It works well when paired with notions of "doing"; however, performativity according to Butler and other queer theorists provides a deeper more personable way to study those on the margins.

Additionally, as a theoretical lens, queer theory's performativity provides space to look at the ways language is used by individuals to relate their experiences of their sexual desire and gender enactment to other axes of their identities. It is important to be able to have a theoretical standpoint that not only allows for the emphasis of the participant, but also prefaces their experiences above what existing literature says. Therefore, queer theory, enables my research to explore the ways 18-35 year old queer Portlanders experience their own gendered sexualities and how that shapes their lived experiences in this world.

\section{Conclusion}

Overall in this chapter I have presented the theoretical and empirical foundation for the upcoming analysis. As this project focuses on gendered sexualities, performativity and queer theory provides a foundation; however at the same time, as it reaches only a small audience this research also utilized linear constructivist models to look at identity itself. 
Therefore this chapter started with a brief overview of identity work since it will join performativity and queer theory in my final analysis, as well as addressed gender and sexuality in a myriad of ways and ended with empirical work within queer theory that helped frame the design of this current work. With this theoretical background in mind the following chapter discusses the methodology and design of this project. 


\section{Chapter Three: Methodology}

\section{Introduction}

This chapter presents the justification for qualitative research, the research design, which includes description of the setting and participants, data collection and instruments, and data analysis. This chapter also addresses participant confidentiality, information security, and preliminary information about myself in the role as the researcher.

\section{Research Design}

This was an exploratory, qualitative study that utilized in-depth one-on-one interviews designed to explore the lived experiences of self-identified Lesbian, Gay, Bisexual, and/or Queer (LGBQ) individuals living in Portland, Oregon. It focused on individuals between the ages of 18- to 35-years old. It also created space for a deeper understanding of how queer individuals conceptualize their gendered sexualities. Because this study was exploratory it was important to use participants' information and impressions as they understand themselves. Through the use of the participants' understandings I was able to analyze how the participants connected their identities to the rest of their life histories.

\section{Setting}

The setting for this study was Portland, Oregon, a midsized city in the Northwestern United States. Portland is the largest city in the state of Oregon with a population of about 594,000. The city has a relatively equal number of females and males. Portland is the most ethnically and racially diverse city in the state of Oregon. White/Caucasian persons make up 76\% (and White non-Hispanic is $72.2 \%$ ) of the population in Portland, 
with persons of Hispanic or Latino origin representing the largest minority at 9.4\%, followed by Asians at 7.1\%, Black persons 6.3\%, and then American Indian and Alaskan Native persons at $1.0 \%$. There was $4.7 \%$ of the population who reported being of two or more races. As of 2010, about $55.2 \%$ of the residents claimed home ownership, with an additional $37.3 \%$ of residents reported living in housing in multi-unit structures. The average household income was $\$ 48,831$; however $16.3 \%$ of Portland's population reported living below the poverty level (Census 2012).

Portland has a reputation for being a haven for queer youth and queer culture; it has been rated one of the top "gay cities" according to the Advocate, one of the top gay and lesbian news magazine in the US. There are even a handful of services dedicated to the queer community. Additionally, Portland is known for its sustainable outlook, recycling, biking, and outdoor activities.

\section{Participants}

Due to the nature of this project, participants were recruited through the use of purposive and snowball sampling utilizing Portland State University and its resources - such as the Queer Resource Center and class lists from professors who teach gender and sexuality classes to distribute to their students. Flyers were placed at the Q Center - a LGBT Community Center located in North Portland - and Pivot - a gay male support group - as well as passed around at the 2012 Gay Pride parade, festival, and subsequent events. Furthermore personal networks such as Facebook were utilized in order to access queer groups and communities such as Latino Pride Committee and Queer People of Color in 
Portland. I used both institutional sites and personal networks to ensure a wider range of participants.

Recruitment flyers and announcements were distributed that asked interested individuals to contact the researcher by email or phone (Appendix A). Participants were self-selected through purposive sampling meaning that individuals who volunteered and met participant criteria and were interviewed (Marshall and Rossman 2011).

I conducted 20 interviews with self-identified lesbian, bisexual, gay and/or queer individuals or those who have a non-heterosexual understanding of their sexuality who live in Portland, Oregon. The participants were of various ages between 23-35, though my recruitment flyers said 18-35, with the average age of 27. Slightly more than half of the participants were cisgender females, which means an individual's gender identity agrees with their societally recognized sex, at the time of the interview. This age range was selected due to the possible life phases being experienced by this cohort of ages. All of the participants, except one, are either currently in college, or have already attended college and/or received a four-year degree. This distribution is not surprising due to the percentage of college graduates or attendees in that age range who live in Portland, Oregon. Additionally, all of the participants have had some experience in the "real world" (being independent in a non-scholastic environment), which allows for the blossoming and solidification of their own identities. This age rage also gives access to participants who may have an established career that does not necessarily accommodate nontraditional gender enactments, such as working in a corporate job that reifies traditional understandings of gender. 
Participants who responded to the notices, announcements, and flyers almost racially matched the racial/ethnic demographics of Portland. However there were no Hispanic/Latinos participants. The self-defined racial/ethnic distribution of the participants is as follows: 16 White/Caucasian, 1 Korean, 2 half-black half-white, and 1 half-Asian/half-white individuals. In regards to sexual orientation there were 7 lesbians, 1 lesbian/queer, 2 pansexuals, 6 gays and 3 queer individuals, and 1 undecided. The gender distribution as self-identified by the participants is as follows: 8 females, 8 cisgendered males, 1 cisfemale dyke, 1 queer gay boy, 1 queer female, and 1 gender queer female. Since this study is based on the lived experiences of queer individuals it is important to not erase the chosen identities of the participants and therefore I have kept their orientations the way in which they identified on the preliminary questionnaire.

The participants have lived in Portland ranging from their entire life to as little as 9 months, some of have also moved away and come back which allowed for the experience of new social locations and communities, either by moving away from home for the first time, or from moving around the country for experience/growth or possible job placement. There was also participants in and out of long-term committed relationships.

I acknowledge that transgender individuals are typically grouped within the category of LGBQ, however for this study I did not include self identified individuals with "T" since I was particularly interested in looking at the interaction between nondominant sexuality (non-heterosexuality) and one's gender enactment. However, a transgendered individual who does not identify and/or disclose their transgender identity could/would have been included in this study. By focusing explicitly on LGBQ 
individuals, I am not saying that I believe transgender individuals are not queer, but rather I do not want to further conflate their gender with sexualized desire since it does not apply to this project. Furthermore, being transgender adds another layer of complexity that this particular project could not give sufficient attention. In such, I believe trans needs its own study since being/identifying with trans is mostly a gender identity and not a sexual identity and therefore trans is not always under the queer umbrella and this project is intentionally only studying queer individuals as it relates to sexuality.

I understand that due to the current climate and advances within queer theory and post-structuralist research there has been an acknowledgement of the constrictions associated with the existing labels of lesbian, gay, bisexual (LGB) and therefor I use "queer" in the analysis when talking about the participants in general; however, I will use the label participants identified with when talking about the participants specifically.

\section{Interview Background}

Twenty interviews were conducted with self-identified LGBQ individuals who live in Portland, Oregon, during summer 2012. Seventeen out of the twenty interviews were conducted in the Portland State University Sociology Department, in a meeting room in order to ensure an environment that was free from distractions. The remaining three interviews were conducted at the participants' residences due to scheduling and availability issues. In order to address possible sensitive topics, I have found it is important to be in a comfortable setting and creating a friendly rapport with the participant in order to gain access to the truest form of her/his narrative. The participants 
were asked to fill out a consent form as well as an androgyny test before the interview began. The participants were given as much time as they needed to complete the androgyny test. One-on-one, face-to-face interviews were conducted, and lasted anywhere from 45 minutes to 120 minutes. The interviews were digitally recorded and the files were then transferred onto the researcher's computer.

\section{Data Collection and Instruments}

The use of one-on-one ethnographic interviews provided the proper data to answer my research questions about how LGBQ individuals narrate their journey into a sexualized

gender. It permitted me to hone in on the interpretive perspective of the participant such that they were able to clarify the connections and relationships they saw between their own sexuality and gender enactment and the world around them (Marshall and Rossman, 2011). This allowed me to answer my research questions by acquiring information about the social interplay of gender, sex, and desire. It also enabled me to elucidate whether or not these individuals placed importance on their identity as non-heterosexual.

Additionally, a preliminary questionnaire and an androgyny test were given in order gain background and demographic information about the participants.

\section{Preliminary Questionnaire}

Individuals who contacted the researcher were sent a preliminary questionnaire that asked potential participants to verify their age, disclose their gender identity, sexual identity, and their racial/ethnic identity. They were also asked where they live, how long they have lived in Portland (if they live in Portland), if they have attended college, and if so, 
where. Additionally the questionnaire asked whether or not they were currently in a relationship with someone of the same-sex, or had been so in the past (Appendix B).

Androgyny Test

After participants signed the consent form, they filled out the Bem Androgyny Test before being interviewed (Bem 1975 and 1981). The Bem Androgyny test is designed to use self-report data to assess individuals' relative levels of femininity and masculinity. Participants answered a list of questions about how well a series of gender-associated terms fit them, using a 7-point Likert scale, with $1=$ Never or almost never true, $2=$ Usually not true, $3=$ Sometimes but infrequently true, $4=$ Occasionally true, $5=$ Often true, $6=$ Usually true, and $7=$ Always or almost always true. The questions were arranged in six columns. Each column has a corresponding column for answers so that an individual's response to each question is in the same column configuration. After a participant filled out the initial analysis portion of the Bem Inventory, the interview was conducted. After the participant completed the interview and left, the researcher scored the androgyny test.

In order to gauge the person's femininity or masculinity, according to the individual's own ratings of personality traits, each of the six column of answers were added up. Columns 1 and 5 questions capture traditionally "masculine" characteristics such as "dominant" or "unsystematic." Columns 3 and 6 are the stereotypical "feminine" traits such as "affectionate" or "cheerful." Finally columns 2 and 4 are associated with "neutral" traits," such as "adaptable" or "conceited." After each individual column is added up, then the totals of column 1 and 5 are combined to yield a masculine traits score. 
Then the totals of columns 3 and 6 are combined to yield a feminine trait score. The Feminine traits score is subtracted from the masculine traits score, which then results in the individual's "Bem score." The interpretation of the Bem score is based on comparing the individual's Bem score to a set of parameters provided by the Bem Androgyny Test. A score of $<=-20$ is feminine; $-19--10$ is "nearly feminine"; -9 to 0 to +9 is Androgynous; $+10-+19$ is "nearly masculine"; and $>=+20$ is Masculine. (Appendix C)

The Bem Androgyny test was utilized as a tool to better grasp the participants' understanding of their gender enactment. This research tool validated participants' gender conceptualizations by triangulating the Bem test results with the responses to the initial questionnaire, and the ways in which the individuals talked about their own gender(s) in the interviews. Participants' locations on the Bem scale, based on the interpretations of their test scores, provided a framework for understanding these individuals' ideas about their own sexualized gender. Using the Bem test also allowed the researcher to move beyond the traditional gender binary and locate possible divergences for individuals who enact a non-heterosexualized gender.

\section{Trustworthiness}

After the interviews were completed I gave the opportunity for participants to ask me any questions that they would like to know in reference to the study, my own history and how my queer identity has shaped who I am today. This was offered up, as consistent with feminist research, to create a horizontal approach to research instead of reifying "patriarchal scholarship" which creates and maintains a power differential between those being studied and the person doing the studying (Bowles and Klein 1983). Additionally, 
I gave participants the option to use their real name, choose an alias, or have me choose one for them for confidentiality reasons. I also asked if participants wanted to be kept up to date with the research process and if they wanted to see copies of the analysis to verify proper analysis of their stories.

\section{Interview Guide}

To best capture of the lived experiences of the 20 participants semi-structured interviews with open-ended questions were utilized. Since the purpose of this research was not to prove a point or an argument, as consistent with narrative analysis, the structuring of the interviews was key in capturing how the participants (re)tell their lived experiences. The purpose was to focus on the reality and language used by the participants and so each interview was unique to the stories being (re)told. This construction is similar to grounded theory (Charmaz 2006) or ethnographical approaches which means that the analysis and collection of data informed the findings throughout the research process. The semi-structured interview questions format allowed me to tailor specific questions to the life stories that participants shared with me. Since this research is focused on what and how the individuals are saying, each interview addressed major milestones in their lives as they interpreted them.

I asked participants to take me on a journey of their lives and their histories. I asked these individuals to start in childhood and dependent upon the story they told, together we explored aspects of their life relating to gender, race, class, social interaction including sexual interaction, and constructions of their current identity. The participants shared coming out stories as it related to their current identity and the importance that 
family, fear, and the internalized homophobia they had in acknowledging and admitting same-sex desires and claiming an identity around it. As part of the narrative sharing process, a conversation was created that explored similarities and differences in experiences between them, and others as well as myself. As this project is about understanding how these individuals construct gendered sexuality, as the researcher, I relinquished control on what subjects would be discussed and allowed the participant to be active in this process and define the topics or talking points that $\mathrm{s} /$ he wanted to include, which is consistent with some forms of narrative sharing (Brown 2011, Ewick and Silbey 2003).

We discussed what their gender meant to and for them, what their sexuality meant and how they experienced these aspects of their identity on a day-to-day basis. Individuals shared stories of compounding identities that addressed stories of childhood, race, family, or sexual experiences. These stories were intertwined with their gender and their sexuality, which was further tied to their identity. I followed the individuals on the journey that they wanted to share with me whether or not it explicitly shared an experience in relationship to their gender and sexuality, because as true with intersecting identities, individuals experience interactions and the world around as gendered, sexualized, classed and racialized (etc.) beings.

The interviews ended with questions that asked the participant to explain/describe her/himself both in regards to their gender enactment and sexuality. After the stories ended and questions were answered I gave the participants the opportunity to add 
anything else that they thought the interview had not covered, or to change or correct any story they had previously stated. (Appendix D)

\section{Confidentiality and Information Security}

Once participants were selected to be a part of the study, but prior to each interview, they were given a copy of the informed consent form that laid out their rights as participants. The consent form explained how the study was set-up to ensure the confidentiality of their responses and their safety as participants. The form also provided contact information, for both the researcher and the PSU Human Subjects Review Board in case any ethical issues or questions came up in regards to how the research was being conducted. Participants were informed that participation in the study was voluntary, at the time of recruitment, when the preliminary questionnaire was being filled out, as well again at the beginning of the interview. At the time of the interview participants were informed that the interview would be digitally recorded, and that any information that was obtained in connection with this study that can be linked to or identify the respondent was to be kept confidential. At the beginning of the interview, each participant was given the option to use their real name, choose an alias, or have me choose one for them for confidentiality reasons. Transcripts were labeled with the chosen name in order to ensure proper analysis. In order to further demonstrate the level of confidentiality provided in the way this study was being conducted, the researcher assured participants that any identifying information they might inadvertently provide during the course of the interview would be removed during the transcription process. Furthermore, any quotes 
employed in this thesis have had identifying information removed to preserve the anonymity of participants unless requested otherwise by participants.

Each subject was assigned a number that was used on the consent form and androgyny test as well as any other records to refer to participants. Throughout the research the digital copies and transcripts were stored safely and securely ensuring confidentiality and anonymity when desired.

\section{Analysis}

Oral histories have played a key role in shaping our past, our culture, and how we view the world today. They are autobiographical (Georgakapoula 2006) in that these histories not only share participants' own lives, but also their views and understandings of the social world. These histories are conformed by political, social, and cultural frames. According to Ewick and Silbey (2003) and Maines (1993) this approach conceptualizes narrative as a social act. This research explores the everyday lived experiences of 18-35 year-old self-identified queer individuals in Portland, Oregon and focuses on the narratives these individuals (re)told in constructing their own subjectivities. It focused on gaining a deep understanding of why queer individuals enact gender the way that they do and what influences their own understanding of their gender as connected to sexuality. Since this study is exploratory it is important to use participants' understandings of their life experiences in order to learn how they connected their identities to the rest of their life histories.

\section{What is Narrative Analysis}

A narrative approach allows the researcher to analyze stories in order to reveal certain 
pasts and constructions of the self, which is critical to action and interaction (Blumer 1969, 1979, Gubrium and Holstein 1999). Narratives describe events from the past that have structure imposed on them. This structure is used to elucidate the plot and setting of the stories and enable a temporal order to be placed on events which in turn creates a causal process (Bridger and Maines 1998) that is ripe with social interaction, the individual's own meaning/analysis to the importance of events, which makes it perfect for understanding individual's own conceptualizations of the interplay between their gender and sexuality. Narrative explains actions through stories about every day life (Brown 2011). It provides "the incursion of value and evaluation into the research process" (Daiute and Lightfoot 2004: $\mathrm{x}$ ) which is key when the goal of the research is to highlight the lived experiences of individuals - especially those living with a marginalized status. According to Daiute and Lightfoot (2004: $\mathrm{x}$ ) "narrative discourses are cultural meanings and interpretations that guide perception, thought, interaction and action" which is why narrative analysis can give insight into individuals own perceptions and conceptualizations of their lives.

Stories and narratives can contribute to sociological knowledge qualities that focus on the sharing of cultural and hegemonic assumptions and ideologies (Blumer 1969, Ewick and Silbey 1995). Although narratives are a (re)telling of histories, events, interactions, and experiences Ewick and Silbey (1995) address how the act of (re)telling these stories is a performance and can be connected to the performance of a particular "self." Narratives present an alternative way to reveal an individual's understanding of social relationships specifically in a context of matrices of power and resistance. I have 
adapted narrative analysis into my feminist approach in order to better distribute the power between the researcher and the participant, by placing equal importance on the role of the participant as with the researcher. I am cognizant of how institutions of power can enter into the relationship and according to Foucault (1978) power enters various interactions and locations with multiple meanings and interpretations. Power can be read on the body and how an individual relates to that power can be through the sharing of knowledge or stories that then in turn constructs a particular self; the self is constructed in relation to power (Foucault 1978).

Narrative allows the ability to understand actions, both one's own and others, the ability to organize events and objects in a way that is intentional and meaningful and whole, and connecting the consequences of actions over time (Bruner 1986, Chase 2005, Gubrium and Holstein 1997, Hinchman and Hinchman 2001, Laslett 1999, and Polkinghorne 1995). Narrative researchers view the narrative as action within itself and emphasizes the narrator's own voice instead of that of the researcher (Gubrium and Holstein 1997). Through focusing on voice, the researcher is able to move away from the fracturing of narratives and instead highlights versions of self, reality and experience that is produced through the act of story (re)telling (Chase 2005). The setting and style of the narratives are important in understanding the type of narrative that comes out.

Chase (2005) has outlined five approaches to narrative in contemporary narrative inquiry. These approaches are split between disciplines but I have focused on the second approach which was developed by sociologists who focus on "identity work" and understanding that people construct selves within specific institutional, discursive, 
organizational, and local cultural contexts (Chase 2005). The narrative becomes the "lived experience" and focuses on the hows of story telling while in the what of story telling. This approach has been linked to ways of knowing how the individual constructs her/himself across a wide range of institutional, organizational and social settings. The movement across these diverse settings highlights the possible constraints that these individuals construct their "selves" within (Chase 2005, Holstein and Gubrium 2000). Furthermore it shows the options for narrating the self in a postmodern world (Holstein and Gubrium 2000). As detailed in Chase's (2005) experience with interpreting narrative analysis it is important to focus on how organizing transcripts into themes about specific topics on work (aspirations, competence, and confidence etc.) or themes about inequality (discrimination, barriers, responses etc.) splits up the narrative or the conception of self that an individual has. In order to present a cohesive narrative and interpret the data, the researcher must focus on connections among the stories, from a storyteller, and thus present a cohesive narrative about a single individual rather than separating her/his stories into themes (Chase 2005).

\section{How to conduct Narrative Analysis}

The researcher collects a narrative, or narrative transaction (Ewick and Silbey 1995). The story is gathered in its entirety with connecting plots, sequence of events and characters. In collecting this data, it is important to pay attention to how, what, when, and why: How is information being exchanged, what is being said, when do events take place, and why is this particular story being told - what is its significance. According to Coffey and Atkinson (1996) how an individual organizes her/his story can provide insight into 
wider social groupings or cultural settings that s/he belongs to; therefore it is important to minimize the impact analysis might have upon the individual's own story. As the researcher, I have chosen to keep large portions of narrative in tact even though the story may cross multiple axes of interest for this study.

Previous researchers in the field have outlined narrative analysis so that it can be used in further research. It has been recommended (Brown 2011, Chase 2005, Labov 2001, Ozyildirim 2009) that narrative analysis have six steps in order to create the entire scenario or history of the individuals. These steps are: 1) abstract, 2) orientation, 3) complicating action, 4) evaluation, 5) result or resolution, and 6) coda. Abstract- has been described as a summary of the whole story that has a few quotes/stanzas to introduce the narratives. The orientation - offers information about characters, place, the situation, and activity that follows; this focuses on the "who, what, where, and when" of the narrative. Complicating actions - are long narrative clauses that paint the story of what happens next, it provides the pinnacle of the story that makes it important. The resolution or the result - provides information to the reader about how the previous step - the complicating action - was resolved. In other words, what the final outcome is. Finally, the coda - or final clauses are statements at the end of the narrative informing the reader that that particular narrative is over. Some suggest a summary can be provided during coda, which allows the present and the past to be connected.

\section{Realities and Limitations to Narrative Analysis}

Narrative analysis requires a shift in role as the researcher, it requires the researcher to reframe the point of the interview and to make the acknowledgement that the participant 
has control and that they are the narrator in their stories (Chase 2005). This does not mean that through narratives there is an "authentic" or "unmediated" self being portrayed but rather is saying the interest is placed on how the individual constructs narratives and her/his interpretation of the story. As such narratives are social matter and as such only have as much as power as allowed or permitted and is a transaction that is socially conditioned, experienced, and produced. In utilizing narratives it is important to address how stories have no beginning or end and thus are constantly linked to the present and the past. Each narrative has multiple narratives relating to consequence or response or reward and shows the multiplicities of subjectivities especially when focusing on identities.

According to Brown (2011: 73) narrative analysis "makes it difficult to draw conclusions across cases" and therefore it is about presenting people's stories as “cohesive and whole." Narratives must not and should not be generalized because its purpose is to present a unique story that is significant; but the researcher is challenged to find emerging concepts within each narrative that act as data related to the participant. Since narratives involve reflections of the past or interpretations of events, interactions, behaviors, feelings, etc. they are not free from personal bias and are constructed within the hegemonic framework that is grounded with social inequalities which causes limitations (Ewick and Silbey 1995, Gramsci 1971).

\section{Conclusion}

In conclusion this chapter has presented a justification for qualitative research, introduced the research design that included a description of the setting and the participants, data 
collection and instruments and tools, and description of the interview. It also addressed participant confidentiality, information security, and the process for analyzing the data. It will now address my role as the researcher.

This research was informed by my own personal history as a queer individual that had a significant journey in coming to my current conceptualization of my gendered sexuality. My own gender and sexuality were shaped within a world that does not always address fluidity within the categories and as such I worked on this project as an "outsider within" (Collins 1986, 1990). My identity was formed in the face of stigma and that stigma came to represent how I view myself today. This lived experience has led me to the understandings of gender and sexuality as something, which is compounding and interconnected, but not the same. In trying to explain identities to individuals I struggled with finding proper labels that truly addressed these particular aspects of myself. Growing up with a very hegemonic understanding of gender and sexuality, and never feeling comfortable, my curiosity of "Otherness" has infiltrated my research in trying to understand how other queer individuals experience their own gendered sexuality. Additionally, my research explores what aspects of gender are transferred into an assumption of sexuality in which female masculinity is read as lesbian and feminine masculinity as gay. Gender performance can be linked to sexuality whether it be homosexual or heterosexual and thus it is important to understand the lived experiences of individuals who come from a position of marginalization, especially since both societal constructions of gender and sexuality are shaped by patriarchy and other forms of power. 


\section{Chapter Four: Race, Gender, and Sexuality}

\section{Introduction}

This chapter presents the overall description of the participants including their demographic information as well as introduces the participants and their stories as they relate to the first chapter of my findings. The stories of these 20 individuals revolve around a non-normative sexuality and the journeys they have travelled in their life to get to their current sexualized identities however it only (re)presents a snapshot of their lives. Though there is a range of identities claimed, all participants discussed a nonheterosexual identity that affected their lives in different ways. These individuals shared stories about their lives and how conceptualizations of their genders and sexualities were pivotal and weaved their way through their own histories. The narratives arose out of conversations about race, sexual experiences and the intersections between gender and sexuality. Specifically this chapter addresses the experience of race in connection to their gendered sexualities.

\section{Participants}

The participants in this study ranged from 23-35 and had varying ways of identifying their sexual orientation and their gender. Some claimed "cisgender" while others explained characteristics such as being a hardcore femme or a female with strong masculine tendencies, or a queer gay boy. Participants' scores on the Bem Androgyny Test ranged from masculine to feminine and had the following distribution: 6 individuals were "masculine," 1 person was “nearly masculine," 8 participants were "androgynous," 4 individuals were "nearly feminine," and 1 person was "feminine." 


\section{Race, Gender, and Sexuality}

Queer theory utilizes an approach that acknowledges that identities are multiple "or at best composites with literally an infinite number of ways in which identity-components can intersect or combine" (Seidman 1996: 11) in which there is no single identity or construction of identity. Moving away from identity politics, this research acknowledges the multiplicities of identities and this chapter focuses on race as it intersects with understandings of gender and sexuality. Since our society is socially constructed differences between racial/ethnic groups become intimately connected to identity. The racial politics that exist came out in the narratives that some of my participants shared about their identities. They talked about how they feel a double, double consciousness in which they feel a double minority status - they are both a racial and sexual minority, while others had stories of privilege as connected to race. In such sexuality becomes racialized and these individuals told stories that focused on the racial aspect of themselves as it was intertwined with their sexuality and gender.

As compared to dominant society, race was explicitly connected to these individuals' constructions of their gender and sexuality, while those who are white told similar stories with the absence of acknowledging race, except in a few instances. The absence of narratives around race for white individuals continues to put forth the power and privilege associated with whiteness (McIntosh 1988). Hegemonic constructions of masculinity and sexuality are based on the belief of racial stereotypes. Espiritu (1999, 2010) acknowledges that racial patriarchy scrutinizes non-white bodies and holds them to particular behaviors and expectations, as similarly with gendered and sexualized bodies. 
Our language used to discuss gender and sexuality creates hierarchies based on moral boundaries and politics (Seidman 1996).

\section{Brandon and Jay - Living Between the Spaces}

Brandon is a 25-year-old half-black/half-white gay male who grew up in Texas. As someone who identifies as biracial he says he is very cognizant of the discriminatory treatment between people of color and white people. Brandon's narrative discusses the intersecting identities of race, gender and sexuality, and how his current identity is still connected to those specific constructions of gender and sexuality from his past. Brandon has experienced the expectation that as someone who is white and black he is the liaison and representative for each group. However, systems of oppression, especially those surrounding the African-American community assume that all African Americans share a unified identity that was constructed through a racialized world of oppression and marginalization. However, according to Cohen (1996: 368) “even as a unifier, blackness, or what qualifies as indigenously constructed blackness, has always been mediated or contested by other identities" in which other matrices of identities such as class, gender, sexuality, religion etc. are intrinsically tied to an individual's identity (Collins 2000; Crenshaw 1991).

As a child, Brandon attended private Christian schools and his earliest memories of gender were connected to the school's expectations of what "a boy could do, versus what a girl could do...girls play with dolls, boys play with trucks." This was very clear for him because he never fit into the hegemonic construction of those two boxes. He said that the male/female binary was very clear that that was the only option, there was 
nothing outside of that dichotomy. Brandon did not realize he was gay until his senior year of high school - he says it is because of the "conservative" and "religious household" he grew up in. He said when asked to describe himself that he has always been more creative and artistic and never really athletic. However, as an adult he spent some time in the ROTC. Though he believed that his years in the ROTC really exacerbated his lack of masculinity and gave away his homosexuality. Since the military is not known for being open and affirming for gays, he told me how he tried to hide his sexuality by performing a particular type of masculinity - one that better matched people's ideas of what it means to be a black man.

In discussing options for identity Brandon shares a story that highlights the prevalence of heteronormativity:

When I was younger like in grade school... it was just that I was a creative person. I was more of an artist and that sort of thing. I don't remember much conversation about my sexuality ... I didn't know any gay people. I didn't know what gay was. So that as an option didn't really present itself until senior year of high school when I started to realize 'Oh this is maybe why I'm different!' It all started making sense at that point.

For Brandon his religious background and his experiences within his family continue to shape his understandings of gender and sexuality. Brandon acknowledges the powerful role the church had on his upbringing; however, it was not just the church, but also the impact of being bi-racial. A strong and exaggerated sense of masculinity coupled with theologically driven-homophobia mediated by black nationalist ideology has a significant role on the individual, particularly those at the crux of racial and sexual matrices (Ward 2005). This is not to say that all black churches are homogenous, however they are acknowledged to be the "central, oldest and most influential institution in the black 
community" (Ward 2005: 494) and this is seen to be true in Brandon's narrative of developing his sense of self. The influence of homophobia within the black community, as it relates to Brandon's narrative addresses what Kimmel (2011) believes as the conflation of gender and sexuality. To be properly read as masculine is, at the same time, to be properly read as heterosexual, and since Brandon is not heterosexual his narrative addresses how he constructed his gender within the "normative" construction of masculinity in attempting to adhere to the black church's, his family, and the larger society's view of what it means to be a man.

As is similar with the hegemonic constructions of what it meant to be a "boy" or a "girl" there were just as prevalent stereotypes for race. Brandon commented on how those values were enforced upon him by his family. His family acted as a strong socializing institution, and was able to be the first introduction of social expectations and stereotypes (Lorde 1970). The values of femininity and masculinity are not treated the same, and as society is structured in a patriarchal and heteronormative way, hegemonic masculinity is favored and held to be the standard (Connell 1995, 2005). Cross-gendered behavior is generally not rewarded specifically if an individual in a "higher" position enacts characteristics associated to the lower counterpart (Bradley 2013; Connell 2003; and D'Augelli 2008). Since masculinity is rewarded over femininity, females attempting to assert "masculine traits" can achieve some of the privileged status traditionally awarded to males, however, it is at the expense of being read as homosexual (Bradley 2013; Hatfield 2010).

Brandon currently works predominately with the African-American community and at work he strives consciously to embody his own subject position as male by 
exaggerating masculine characteristics and behaviors. In doing so, he "downplays" his sexuality. Brandon states:

I guess I'm still very conscientious of how people view me. It doesn't bother me if people have an issue with the way that I dress or the way that I live. But I'm super aware of how I present myself. And there are some times where I purposively try to conceal my sexuality. Particularly in professional environments. I need to downplay that issue. I work primarily in the African-American community and acceptance of homosexuality is, there's just not that level of acceptance in that community. So there are occasions where I have to downplay that so they can get to know who I am, where I'm coming from, and what I'm doing. Before they necessarily recognize that I'm gay. I don't want them to write me off as "oh here's some gay kid."

Kym: How do you downplay your sexuality in those instances? What do you do?

Brandon: In some ways I'm not as personable. I'm very to the point, my posture is different. I'm much more rigid. They were, there are some times where I take a look at my calendar when I am getting ready in the morning to figure out: 'What am I doing today? Who am I meeting with? Am I going to be any issues if I'm wearing this super low cut pant? Or do I need to wear something more boxy/conservative?' I mean I really only speak to the African-American community and the Latino community a little bit. But I myself am -black and half-white and work within the African-American community, and they think, they often think that there is the experience, is very traditional gender roles that we were talking about, like boy/girl, man/woman. Certainly not everyone is that way, particularly amongst different generations. But the 'established community, ' which is who I usually work closely with, they are still beholden to traditional visions of gender and sexuality. And that, you know, church and religion is a huge part of black culture and so I think all of that plays into it.

Brandon's own constructions of identity and acknowledgement of the interplay between his gender presentation and his sexuality is confined by the traditional beliefs of gender within the African-American community that he works with. Though he is half-black and half-white, he generally only discusses how he takes into account the views of the African-American community, and not necessarily the white community, when figuring 
out how to present himself. Race, for Brandon, has a large part in his life and interacts with his gender and his sexuality. However he also acknowledges that religion and race combine to create the standards of gender for the "established [black] community." Brandon has struggled with how to present himself and which gender characteristics to hide via clothing and aesthetics. Part of Brandon's need for micro-managing his gender stems from his understanding of the racial constraints on his gendered and sexualized identities. His involvement in religion is intrinsically tied to the African-American community and together these aspects of his life create structural limitations on possibilities for identity. Specifically the "established [black] community" for Brandon regulates his identity through regimes of power and structure.

As someone who works and spends most of his time surrounded by the AfricanAmerican community, he is cognizant of race and the complications of being bi-racial in a world that has strict boundaries on identity. In fact, as similar to others I interviewed, he talks about living his life between the spaces and how being "half-black and half-white" plays a large role in his life. Brandon states:

I mean everyone has their own experiences. It has been a challenge for me to navigate the world, occasionally, and a challenge to kind of affiliate myself with different groups because well I'm half-black and half-white. I'm not really white enough for white people to identify me as white, or black enough for black people to immediately identify me as black. And so, also I feel that way with my sexuality, sometimes. Where there are times where I can choose to be straight, to present myself as straight or present myself as gay. And so navigating those four corners of what, what makes up 'me' has been a challenge at times and try to relate to people. ... Occasionally there's some hostility, I wouldn't go so far as say hostility, there's, I just have to prove myself in way that I don't think that others, who are not caught in the middle of those four issues/areas do on a regular basis...yeah having to prove yourself, yeah I do know what discrimination is, I do know what 
that looks like and feels like.... And just having to come out all the time as "gay" and as "bi-racial" even. And doing a lot of education, not formally but informally developing those relationships and letting people know what they have in vision as what a gay person is or what a biracial person is, are not necessarily true.

Brandon discusses his experiences as "being caught in the middle of those four issues/areas" - white/black, heterosexual/homosexual - his identity may not be as simple as initially thought. The African-American community not only plays a role, but Brandon also makes an acknowledgement of conflict of his other "half." The AfricanAmerican community that he speaks about is unwilling to recognize or accept alternative forms of sexuality or gender roles beyond the prescribed hetero-genders (Ingraham 1994/2004, 2008). It is this understanding that Brandon finds his identity amidst the matrix of marginalization, or a marginalization within marginalization. He sees himself within the black and the white worlds, in which he is fighting to have his experience heard and seen as valid, but since his gender presentation, at times can present within the authority to "pass" as straight, he recognizes the multiple intersections that he resides within. Since Brandon enacts gender in the "normal" way his gender is perceived to be intelligible and thus given the privilege and status of being heterosexual. At the same time his racial identity is often rendered invisible unless he is "educating" someone about "his race." Which further elucidates two of the "four" areas that he seems to be caught in the middle of.

In a more explicit conversation about the history of the hyper-sexualized black sexuality, Brandon discusses how he has not experienced the prescription of having his 
sexuality racialized. On the other hand, he knows people who have experienced this and talks about the role of race on sexuality. Brandon states:

Not personally, but I have to some extent, some black gay friends and we've talked about this issue and I do feel like gay men, mostly gay white men are not really any better talking about race than straight white men. I've experienced, I've been privy to conversations with gay white men and they speak very flattedly [sic], even ignorantly about race, um, black people, and that has been uncomfortable because I'll remind them, "excuse me I'm biracial, what you're talking about is my people too." ... they forget that I'm biracial. I've heard people talk about we're not just a stereotype, we are real people too. And I hear some really stereotypical things, comments being made about black culture and African Americans, and to me, it is such a double standard! And even the conversations about "gay is the new black!" As a social justice, there are very obvious parallels between the two struggles for equality, but I don't think people are completely familiar with the unique experiences that black people have versus what the unique experience that gay people have, and even the more unique experience of a gay person of color.

Brandon's existence in the spaces of multiple worlds addresses how dominant narratives have the ability to construct identities and inform people's thoughts about identities. In fact, Brandon, as a way to try and deconstruct these narratives elucidates the lack of authenticity that stereotypes have. He acknowledges that there is a unique lived experience by people of color, and also gay people and though there may be similarities the differences are important and there is even a more unique lived experience for queer people of color, because not only are they marginalized in one axis of their identity but in multiple axes.

Brandon acknowledges how in the African-American community, as well as with the Christian community, gender becomes something that is policed, in order to restrict and construct particular behaviors and practices. This constriction, in turn, constructs a hierarchy of gendered behaviors in which certain 
characteristics/actions, if they match one's gender, become rewarded. At the same time, those that do not match get disciplined and demonized. It is through both familial and religious discourse that Brandon's identity was created. Collins $(1989,1990,2004,2008)$ addresses how both the roles of the family and the church, as institutions, have been pivotal in shaping constructions of identity with the Black community. When sexualities, i.e. non-normative sexualities, challenge the "traditional" understanding Brandon feels as though the Black community can feel threatened and continue to push for traditional understandings of gender and sexuality. Brandon comments how his family and his experience within the African-American community sheds light on how conceptualizing a 'normative' gay identity is unconceivable; for his family believes that being gay is still a death sentence and is marked by outlandish behavior and public nudity.

Brandon's upbringing and historical understanding of what it means to be gay is constructed by the normative views of sexuality. There is a pedagogical tool that is embraced by the mainstream that delegitimizes non-outlandish forms of queer sexuality. In fact the belief that traditional understandings of gender and sexuality continue to push forth the "queer" subject as something that is nonnormative. Brandon states:

I think they don't know what "GAY" is. I think that their version of gay is what they see in the New York Pride Parade Party, with the very extremes of gay culture. So public nudity, promiscuity, heathenism as they would probably call it. They don't see, it's not something they're exposed to, gay people who are professionals, who have families; you know you are "normal." "Normal" you know, not being crazy all the time. 
Brandon understands that part of his identity is to break free from the 'controlling image' that constructs black gay sexuality. He is aware that not only is his identity a mixture of queer sexuality, but also at the same time, the impact that his family background as connected to religious beliefs and racial constructions that the dichotomy of male and female has on him. He has decided to consciously try and break these stereotypes, and through a management of enactment and dress, Brandon believes that he can get past the stereotype and reach members the African-American community, in which he can try to relate as being "normal."

Jay is a 27 -year-old gay male and shared a similar narrative to Brandon. Jay is also half-black and half-white, grew up in a religious and socially conservative family. However, his parents divorced when he was a child, and with their divorce Jay's life was split in half - the world of his father, a Baptist pastor in an African-American church, and his white mother, who was described as "hippy-ish" and socially more liberal. Jay described them as complete opposites, which placed him in the middle of two opposite and different worlds. Jay grew up in Southern California and attended a private religious college in a conservative area.

Throughout Jay's narrative, he shared similar struggles to Brandon, with his experiences in the African-American community and their strict constructions of gender and sexuality. According to Jay, he "grew up" in the church, similar to Brandon, in which constructions of gender are sexuality were strict. Since his father was a pastor in a Baptist church, and held many of the values close to his heart Jay struggled with his relationship with his father. According to Jay that is part of why he "came out" later in life, at the age of $22 / 23$. The following is his coming out story: 
Mine's a little complicated than the typical story. ... My dad is a pastor; I grew up in the church. My parents are divorced. My mom is very hippy-ish, [and] my dad is very religious. So I was literally caught right in the middle between my mom being crazy, smoking, drugs, and my dad being really religious. So I didn't come out, and the reason I didn't come out at an earlier age is because my father's influence on me. I, he was my world. And I looked up to him. And I knew he would not approve and I knew the church would not approve. ... I truly, wholeheartedly believed that I could for the lack of better phrase, "pray the gay away." I was very uptight, rigid, structured person, up until I came out; because I had to, I had to keep myself in line. And obviously there were slip-ups, there were tons of stuff. So that was the reason why I didn't come out until later. I was attending a Christian college at the time too and that was really hard. (grimaces)....So it was around my birthday ... Well [my dad] had swung by (deep breath) and we were just talking and he asked me, "what do you want for your birthday?" and I was like "I don't know. I don't care" and he was like "you know, son, you can tell me what you want" and in my head I'm thinking "oh now you've done did it now" (laughing). So it wasn't until I think June or July that I had build up enough courage and built up enough gall to be like I need to tell him what I want. I've never, I've always fallen in line with him. I've never disagreed with him, and if I had, I'd kept it to myself. I'm coming of age where I need to tell him. "So I asked him out to dinner... and then came "Dad I, I, I asked you here to talk about something, and I know you know that I struggle with the attraction to men, but I've chosen to, I've chosen to just be me. And if that means that I have an attraction to men and I'm a gay than that is what it is. Because what I am doing currently is literally killing me. Like I would have these breakdowns, these emotional breakdowns where I would just shake, I would cry and I would just, I was soo disoriented, so penting up all these things. So yeah obviously he said, "Well I suspected that this is what you wanted to talk to me about and your mother (my stepmother) he said your step mother and I are very disappointed that this is your decision." He equated sexuality to dribbling a basketball...

As Brandon had previously discussed his parents beliefs about gender and sexuality Jay's narrative tells a similar story of the rigidness of his father's belief. Jay talks about the role of the church, and his dad's side of the family being African American, and the traditions of family. These regulatory discourses for Jay were "literally killing" him. Jay 
continued to talk about the choice he made and having to confront his father, because he was "of the age" where he needed to do so. Though this rhetoric of "choice" is not necessarily what sexuality essentialists would discuss when commenting oh how "being gay was a choice" for Jay it was very clear that the choice for him was to be himself which is gay - or to continue to "pray the gay away" which seemed like suicide.

As is often the case in queer communities of color, "gayness" is equated with AIDS and people's fear often lead to queer individuals of color living deeply in the closet. As with other marginalized groups the problem with living in a society based on hierarchy is the fact that individuals often find ways of "Othering" those who are different as a way to try and lift themselves up on the ladder of indifference. In the case of the African-American community or at least Jay's experience gay and lesbian individuals were stigmatized and those he surrounded himself with utilized a language based in patriarchy and homophobia. The belief that "gay" is a choice, was something that Jay highlighted by stating that his father was "disappointed" in his choice to be gay. However, what Jay was trying to tell his father was that the only choice he had was to whether or not to live in a closet, for he was gay and by trying to adhere to normative constructions of gender and sexuality he experienced panic attacks and emotional breakdowns. Living in the closet was "literally killing" Jay, and destroying his health.

Jay associates "traditional" notions of gender and sexuality to his father, which at the same time is connected to religion and being black and the way in which the two intersecting parts of his identity are in direct conflict with his queer sexuality. The role Jay's father plays, according to Jay, upholds the idea of "racialized patriarchy" (Espiritu 1999). The racial construction of the patriarchal figure further maintains hegemonic 
understandings of, in this case masculinity and sexuality. The patriarchal subject of Jay's father further renders invisible the institutions of heteronormativity and hetero-genders; however, Jay tells us that he finally faced his dad and faced the oppression associated with him and the church in relation to his sexuality.

The church was significantly connected to Jay's understanding of gender, and in a later discussion about his masculine characteristics he shared how many people were surprised that he was gay. He discusses how he constructed his identity deliberately, hiding his sexuality through the portrayal of normative masculinity.

I got accused of being gay up until high school [he was a very caring kid] pretty much. Up until like my junior year of high school, was because, I kind of looked around and was like "I need to fit in" I went out and bought clothes that they [his peers] were wearing. I'm very observant and I use that for my survival and that is what I came to survival was that I was very observant so I could blend in. I learned how to "walk the walk" and "talk the talk." I am half-black and hung out with the black kids. Their definition of gay, is different, it is definitely more feminine than other versions of what gay means. ... So because I wasn't super feminine they never really caught on. ... I was masculine. Typically in the Black community, gays tend to be in the choir, I was generally pretty musically gifted and so I was drawn to the choir, but never in the flamboyant choir director way, clapping and grooving. I do that now, but not back then. So it just, it never really clicked or caught on. I hung out with a lot of athlete that were in my church. I played basketball, so there was just not opportunity to be "GAY" really. It's uh, different. It is very, very looked down upon in the Black church. However, which is really interesting is more than half of their music directors and their choir is gay. And that tends to be where gays gravitate towards when they are like in a Baptist setting, or yeah a church that is more African American. My, the gays that my dad did know in Jersey had died of AIDS in the 80's and 90 's. So obviously that is what he is picturing. I guess the gay, or "alternative lifestyle," queer lifestyle is, but he has completely no idea of anything.... It's a complete death sentence. It's, it's all about partying and fornication, and lust, there's not commitment. ... all the typical stuff. So it's the black community, it's different, it's a little different. It is not as accepted. It is not talked about. 
Things like "pray the gay away" don't really exist. It's kind of like

"don't ask, don't tell, but also don't let anyone find out either"

(laughing) because they will probably kick you out of the church

and will be pulled in to the pastor's office and will be prayed over

and put on Pray Watch 3.000. It's not fun, not enjoyable.

Jay in this narrative talks about where he falls in relation to the church, his father, his gender, and how the African-American community conceptualizes the "alternative lifestyle." The fact that being gay is less accepted in the African-American community was apparent in Brandon's narrative as well. However the connection of being gay to a death sentence, or more of "not in our community" relates to multiple phenomena within black communities. Jay acknowledges the "place where the gays are" in the Baptist church which is in the choir, and since he was aware of this, he ignored his musicality and instead played basketball with the other black guys in order to adhere to "proper" gender roles (Bradley 2013; Connell 2003, 2005, 2011; Hatfield 2010; Kimmel 2011; Lorber 2004)

There is also this acknowledgement that homosexuality within the Black community is something that is not accepted, or in Jay's words: "It's different, it's a little different.... It's not talked about." Though Jay himself is "out," his understanding of his own sexuality and masculinity within this world addresses some of the secrecy that comes out in the "Down Low" communities. The dominant constructions of masculinity, are often that of the "normative white heterosexual male" however, black masculinity is something that has been racialized and constructed through a lens of hyper-sexuality (Collins 2004). The typical construction of black masculinity does not leave room for alternative forms of black masculinity; heterosexuality plays a large role in this ideal. Since alternative forms are marginalized there was an emergence of the Down Low 
subculture amongst Black gay and bisexual men. Black men who live in the "Down Low" live perceivably heterosexual lives, generally with wives or girlfriends, but at the same time have secret sexual relationships and intimacies with other men. The normative construction of black masculinity as inherently tied to fatherhood, heterosexuality and patriarchy renders invisible the possibility of black homosexuality. This construction of black masculinity coupled with heterosexuality upholds the idea that homosexuality as "a white man's perversion" (Denizet-Lewis 2003).

In an explicit conversation of black masculinity Jay explains what he calls his “black face." Jay states:

If I feel frightened by anybody I definitely (breaths deeply in through his nose and puffs up his chest), I put on my "black face" I guess. Just because, I don't know what, or I think it's more aggressive, and less negotiating, I guess. I don't know. It's I don't know. It's, it's just what happened when I was in high school that you know someone got in your face, you got in their face back and you did, you did your thing and I guess I finally stopped being different people in different situations and obviously when I came out, it was harder to figure out who I am. I think I need to accept that I'm all of them. But there is definitely a lot of, I'm going to choose this person today, and I'm going to choose this person in this social context and this and this and this. Learning to deal with that, it's definitely something I think about it.

Jay's masculinity and presentation adjusts based on the location and social context, which he is aware of. However, as living in the spaces in the middle, where most minorities are not able to choose what side of them is presented, Jay's narrative shows agency and privilege in being able to construct his own identity. Though he participates in the every day society, Jay's narrative addresses how his construction of his identity is by choice, or rather the identity that he presents. He can pass in a multiple of ways and therefore is not constricted by the typical controlling image of black sexuality. Jay's narrative points to a 
particular performance of race, sexuality, and gender in which he is addressing how these may be fluid categories and he chooses which part of his identity he will "let shine" in particular social contexts. He is doing Jay differently based on the context. Although it is important to note that what Jay calls "black face" upholds the image of the black masculinity as aggressive and "less negotiating" or as something to be feared, his narrative does not seem controlled by this image, but rather he is acting out a particular form of masculinity.

In a further discussion about changing in social context, Jay discusses his ability to "code switch." Jay states:

My biggest struggle with pretty much everything is, and even coming out. I never really sought out gays because I felt like I was way too busy always playing the liaison because I am half-white, half-black. I can code switch, I don't know if you know what that means. Like if people that are I guess in different mixed families that are ethnically different, obviously if I hang out with my dad's side of the family, who is black, I'm going to talk and act different. And as soon as you get me around my mom's side of my family, I'm totally different. It's because the cultures are different, does that make sense? I just code switch, back and forth, back and forth. So I'm pretty much the same way with being gay, being black, um I guess... politically, I'm kind of in the middle you know I see both sides, and you know I was, I feel like I'm always playing the liaison so I never really had an opportunity to really seek out gays because I was too busy telling people that "not all black people are the same" and "Not all gays are the same." ...

Quick story, I was driving to my friends to go to a concert, and my sister called me and I was talking and I hung up the phone and my friend was just looking at me. And they were like "Wow you sounded BLACK DUDE" (emphasis included) and I was like "yeah I am half-black THANKS!" yeah it really does surprise people because I turn into different people, my vernacular changes, my mannerisms, my body language, it's just because I grew up in two different cultures and two different environments. 
The notion of code switching is something in which Brandon spoke of as well, however for Brandon there was not the explicit comment of changing vernacular, but he did mention changing appearance and mannerisms as a way to "fit in." Code switching for Brandon, and similarly for others, becomes an instance in which the individuals change their behavior, characteristics, etc. on the basis of those around them. It is a way for them to enact gender, race, sexuality etc. For Jay specifically it comes into action when talking about enacting black or enacting white and if he does not switch at appropriate times he is sanctioned by others in which part of his identity is set up, through interaction, to be less than the hegemonic structure, and therefore learns "appropriate" ways of being. Code switching, can relate to micro-managing oneself in order to try and fit in but at the same time talks more specifically about how individuals change their behaviors based on the situation. Jay's performance of himself is mediated and calculated by the structures around him in which he puts on a different face based on this surrounding. The narratives that Jay shared show notions of Goffman's "backstage" performance of the interactions of individuals. Jay, additionally, in this narrative talks about the impact that living in multiple worlds has on him and how he is constantly having to defend, or explain his actions based on who "witnesses" the differences within his presentation. Explicitly, he feels as though, he does not seek out a "community" of his own, for he lives in multiple worlds and spends a majority of his time "playing the liaison" between the communities that he lives amidst.

As has been exemplified in the narratives of both Brandon and Jay, their identities were amidst multiple axes and not only were there the racial aspect, but they were also coupled with religion and its influences over constructions of gender and sexuality. Jay 
and Brandon both, when talking telling their narratives about the African-American communities they grew up with, discussed the role of the church and how the strict and rigid understandings of gender and sexuality came to be important. The heteronormative constructions of both gender and sexuality shaped the ways in which Jay and Brandon had to overcome this background in order to who they are today.

\section{Andrew: Not living Up To Expectations}

Andrew is a 30 year-old gay male. He self identifies as Asian/Caucasian, his mother is Asian and his father white; however, according to him he grew up in an "Asian household." As a child Andrew always felt slightly removed from everyone else around him, and was also incredibly shy. When talking about his household and growing up he talked about how there was "The Tiger Mom" that broke down his self-confidence. He saw it as a way to control his behaviors and made sure he "stayed in line." He grew up in a house in which homosexuality was wrong and though he knew he was attracted to the same sex at a young age, he would tell himself that it "couldn't be that case, because that is bad." He started to "come out" to his friends in high school; however, he is still not out to his mother, but he is to his brother and father.

Andrew's high school years were shaped by the influences of his family and being in an Asian household. In high school when his peers were dating one another, Andrew never had a girlfriend, though as he says his mom, "being the typical Asian mother," tried to set him up a couple of times with girls. He felt pressure by his mom to date girls, but he was not interested. His Asian background was key in his narratives about how he came to be who he was. He feels that he is expected to adhere to all the 
"good" stereotypes about Asians, but hates the expectations placed on him because of his identity. These stereotypes may have some truth to them but no one individual, or group of individuals can uphold the model minority stereotype all the time. This stereotype is constructed by the dominant group and has infiltrated into how individuals think and as such minority groups can/are rendered invisible in creating their own identities (Collins, 1986, 1991; Shankar 2008).

He discusses with me his frustration with how dominant narratives end up constructing his own identity. He states:

I identify as "gay" but at the same time, I've thrown terms around. "Queer"- I've identified that way as well. Do I like to? Not necessarily, I mean not because I don't like the word it's more just that's not how I identify. I've always identified as "gay" and those people that identify as "queer," more power to them. I'm really personally pretty flexible... if that is how you want to identifyfantastic.... I've always... I identify as "gay" but people have, society as a whole has this idea about what "gay" means and while I use the label "gay" I'm always frustrated by stereotyping and um [pause] prejudicial thoughts of people based on their label, or what you perceive their label to be,.

While I may claim "gay" as a label or how, my identity, it frustrates me to no end when people expect me to act a certain way, because I'm gay... or Asian, or half Asian, as it were. I mean I, I was always everybody's "Asian Friend." Just labels in general, I mean, I'm half Asian. I don't know if I'd describe myself that way. I mean, I'm mixed...I don't know, it's hard to explain. When people use your label and your identifier and their view of that label and that identifier does not match yours, and they're not giving about it, then that's highly frustrating to me.

While explaining his identity and his frustrations with labels and the confines he finds himself in due to his "identity" it becomes apparent that the available "labels" whether it be gay or straight or queer are no more liberating than stereotypes that people have. Andrew is very cognizant of the role of language and how discourse shapes individuals 
understandings of the world around them. Andrew acknowledges that label "gay" or "half-Asian" place on him expectations that will direct how he is then expected to behave and at the same time constructs how individuals will interpret and interact with him. This idea is representative in the power of language and how what Foucault considers to be one of the effects of language on identity. Through understanding his compounded identity it is clear that Andrew still struggles with the traditional upbringing he had in his Asian household. When responding to my question about if being in an "Asian" household played a part in his childhood and his sexuality he states:

Absolutely it is. It's one of the things that really affected the way that I, I related with my family. Um, in an Asian household and in Asian culture, family is everything. You're raised - at least in my household and in several other households that I know of - in a very strict environment with these very, uh, hard expectations, these high expectations to live up to. And if you fail, you are punished for it. And my mother was no different than - and I hate to say it, these stereotypes that you hear about - she had very high expectations for me and there was a certain way that I was going to live my life. There was a certain way that I was going to have a future. I was going to find a nice girl who I would marry, have kids - preferably Asian - who would cook for me. Um, ... so yeah, I definitely, think that growing up in an Asian household with a very traditional Asian mother really was very difficult growing up gay. It was one of the most; it's probably THE most difficult thing I have ever had to deal with-EVER yeah.

The values that his mother held, took priority in his family, and as he said coming out and being gay as a child in his household was one of the most difficult things he has ever done. Not only was it about the fact that he was gay, but more or less how being gay contradicts the path laid out before him. His future of being successful and marrying a, preferably Asian, nice girl and have kids, has in a sense been taken away form him because of his gay identity. Being gay, is not necessarily something that Andrew that 
was "allowed" in his family and still does not address that aspect of his life to his mother. However the fact that though he upholds most of the expectations laid out before him, from his mom and the culture she brings, but is not accepted or because of his sexuality, lays heavy in Andrew's narrative.

\section{Kyle: Privilege, Power and Consciousness}

Meet Kyle, he is a 27 year-old queer gay male who moved around as a child. He was raised in the upper echelons of the military and always felt comfortable with adults as a child. He considered himself a very precocious child and did not notice differences between him and others except for maybe his "exceptionalism around being intelligent and well-spoken." He said how growing up on military bases abroad that the military tries to erase difference and create homogeneity and thus he did not face much diversity within the bases. Also because he lived abroad as a child, he never experienced the typical bullying that happens to children who are different. He shared how his father's position in the military landed him in a "really bizarre, politically correct place" and did not have the confines of the archetype patriarch. His family was really accepting of his non-heterosexuality and he grew up knowing that he could love whomever he wanted. However, in middle school, everything in his life changed. He moved to the United States for the first time when he was in middle school, his parents got divorced, and he interacted with people who had a different cultural background than him for the first time. According to him the military tries to "white-wash" everyone so there is homogeneity and uniformity, and so in middle school he had his first confrontation with inequality and the realization that not everyone is the same. Kyle struggled with going to school and 
being teased about "being like a girl," being overweight and just not understanding bullying because prior to middle school, he was never made fun of.

Kyle's construction of his own identity as a "white non-Hispanic" queer gay male comes with power and privilege as being part of the dominant population in one axis of his identity. Unlike others in his position, Kyle is very aware of the homogeneity and normativity of whiteness and his narrative is rich with Kyle's own analysis of the impact of having a white normative culture. According to Stuart Hall (1994: 394) "identities are the names we give to the different ways we are positioned by, and position ourselves within, the narratives of the past" which is pivotal in understanding Kyle's narrative around his own identity. He is aware of his position within the hierarchy system and analyzed his own decisions on why he chose to be where he is today. When talking about social expectations and his identity Kyle states:

That's really were this sort-of, a balance for me about who I am as a person, that "I don't really give a shit anymore how I come off to people," was realizing that I was being super rigid in my intellectualism and realizing what a privilege it was to consider myself an intellectual. Um, and then I realized that it was about giving myself a break, and that a break there was to be gender non-conforming - I about to do a drag show at my high school, to be a drag performer, to be a sex worker, things like that. All of those things sort-of broke down those fake walls about what it means to be successful as a male. Um, and obviously my parents were having a much harder time with the fact that I was combatting the social expectations they'd set for me which to be a hyper-successful compassionate white gay guy 'cause they were totally fine with the gay thing, or the most part. My mom had AIDS fears for years. Then when they realized there was no changing me being gay they wanted me to the best that I could be... a lawyer, a doctor. And then I realized that a lot of that wasn't going to be MY journey, because it would feed into that megalomania of being a white male and I didn't, I was just like, it was literally like I'm just getting so far away from that its' not even funny, so I did Women's Studies and Queer Studies and was an academic. And then I got 
into activism and sex work, and those were all things that were just gender for me. Activism is gender non-conforming, and it's not a masculine act. You know, now I know it really that way, but at the time I was like "this is rejecting the dominant paradigm" like to be involved in queer local politics and to be involved in monumental issues makes me a little bit of hippie, and a little bit of a ... a little bit more femme.

Kyle's narrative is one of privilege and power. Not only does he talk about the fighting the path that his parents set before him such as being a doctor, but also how he chose to study women/queer studies which for him was for him gender non-conforming. One thing that occurred a lot in his narrative was positing himself as white and talking about constructing his own identity - however there is a lack of acknowledgement about the power that he holds in these situations. Not only is he part of dominant society, racially, but also he has the ability to construct his own identity and not being regulated by the same controlling images, in relation to race. There is no real stereotype that controls his own concept of his racial self, but he acknowledges that he had a choice about what his future was going to look like, which does not happen to everyone. Whether they are white or black or Asian or middle class or lower class, or Christian, or Muslim, or Jewish, etc. wherever an individual lands in the matrixes of identities some are luckier than others and land in a particular position of power. For Kyle the intersections of his identity come from and are a source of power for him and he was able to construct his identity without the restraints of the dominant regimes of thought.

Race was something that was apparent in Kyle's narrative, but I would argue that it is a different story of race than some of the other participants in this study. He felt "Othered" at times in his life, but being white was never a reason for his "Othering," it had more to do with lack of traditional gender presentation and enactment. Kyle's 
understanding of his own identity was wrapped up in understanding dominant gay culture, but that was the world that was normative or white, in which alternative constructions of identities did not exist. At the same time this heteronormative gay culture was one that fit within the ideology of patriarchy in which femme was less than masculine and gender constructions around these forms of the dichotomy still structured dominant gay culture. Kyle understood that his culture was being commercialized and what he knew as gay culture was "white" gay culture. White became the normative, but also as Connell (1992) notes, white male and upper class status is what is valorized in Western society. Furthermore Kyle's understanding of the normative white gay culture acknowledges the disparity in representation and what dominant cultural narratives say about what is “normal" (Bonilla-Silva 2001, 2010; McIntosh 1988). Kyle chose to challenge these normative understandings of gay culture and to not continue to blindly follow what dominant society says. The ability to choose to turn one's back highlights her/his position of power and as such Kyle's whiteness has shaped his experiences. As a white middle class male, Kyle has had many opportunities to construct his identity without the same barriers or stereotypes. However, this is not to say that the white male is free from stereotypes. Kyle had been placed in a particular category and he chose to use his racial position in order to create his own form of masculinity, one that was separate from the mainstream idea of "hegemonic masculinity" but one that embraced femininity and exploring a range of gendered behaviors and enactments. 


\section{Conclusion}

Race has been a large organizing factor for society and as such has played a role in how the individuals constructed their journey for identity development. As we live in a racially segregated world, race is utilized as a basis for access to power, it is important to understand how race connects with both gender and sexuality in which they both become racialized. Regulatory regimes of gender and sexuality are influenced by hegemonic understandings of race. Whether or not the conversation of race is invisible, it plays a role in development. For those of racial minority status it may be easier to see how race is connected to other aspects of identity but those that hold a position of power and privilege (that of white) race may be rendered invisible and in their eyes not seen as existing. Many of the white individuals I interviewed shared similar stories to those who have a racial minority status, specifically the role of the church, but in the white narratives race was absent. The absence of race in these narratives highlight the ways in which "White" is seen as the "original" or "normal" and other racial categories are constructed as opposite of or different from "White."

The following chapter is going to move from the analysis of race in connection to gender and sexuality to focus on how sexual experiences are connected to these individuals' understanding of their gendered sexuality. 


\section{Chapter Five: Sexual Experiences}

\section{Introduction}

According to Weeks (1986:4) "sexuality is the most natural thing about us;" however what is the role that sex plays in relation to individuals and the construction of their identities. Many researchers have studied sexuality and in Western society there is a strict heterosexual versus homosexual binary that prescribes how people understand and do sex. Sex can play a large part in one's identity. It is often believed that sexual desire is more complex than an individual's sexual identity. A majority of my participants discussed how sex, for them, was a large part in understanding and (pre)forming their identities. For some, as similar to the literature, their first sexual experiences with someone of the same sex solidified their queerness, while for others, it was more about exploration and agency which led to their current identity. The exploration for some included the use of pornography and/or masturbatory aids. For others, still, their intimate relationships sparked changes in their identities; however, for all my participants sex played a large role in the journeys these individuals under went in constructing their current identities.

\section{Sarajane and Mia: Childhood Games}

Meet Sarajane a 34-year-old white lesbian female. She grew up just south of Portland, Oregon. Her parents divorced when she was younger and she mostly lived with her mother, until her senior year of high school she moved in with her father and stepmother. In recalling stories about her childhood sexuality, she expressed notions of "otherness" and same-sex relationships that she perceived mimicked heterosexual realities. 
Her family was poor living in the middle of a well-to-do neighborhood, comparatively, and Sarajane shared stories of how this affected her life. She told me how it was easier in her old school because she was similar to her peers; however after changing schools and moving neighborhoods with her mother she lived through experiences of extreme class differentiation. Her mother worked hard and all the time to be able to afford the new school and neighborhood. However Sarajane's memories of this time are fraught with depression and sadness, at least those that she remembers. As she told me in the beginning of the interview she does not remember most of her childhood. Sarajane grew up and faced the realization of her same-sex desire, her parents kicked her out upon high school graduation and she spent two years living on the streets in Portland. Homelessness is often a fear for those who are "coming out" to the their families at a young age, and sexual minorities often make up the majority of homeless youth (Cochran, Stewart, Ginzler, and Cauce 2002). Although the climate for acceptance is changing as we are coming to live in a "post-closet" world (Seidman, Meeks, Traschen 1999) Sarajane's story of homelessness is by no means an "outlier" amongst queer individuals.

In the following narrative Sarajane discusses what she remembers from her childhood and this narrative becomes key in her own construction of a gendered sexuality. Welcome to a retrospective glance at Sarajane's childhood.

I don't remember a lot of my childhood. What I do remember is I was a very angry, depressed child. I didn't have a lot of friends. I didn't have a lot... you know... people to play with or anything. I remember when I was younger I wanted to be a boy. I don't know. I had a fascination with it for many years. Um, the one thing that popped outta my head was that I really wanted to be a boy. I think it was because boys got to do more. Boys had more opportunities. 
They... my brother got away with everything. I just figured it would be easier if I was a boy. My mom's a single mom. Worked really, really hard so that we could live in a nice neighborhood. Which meant we lived in a nice, middle-class neighborhood, but we were extremely poor. So I'm going to a nice school where the kids have nice clothes and all this stuff, and I'm in rags... We moved in the middle of the school year... and from the get-go, the kids decided I was the kid to pick on. I was the kid that everybody picked on. All I know was that my brother and the boys at school had it so much easier than I did, I figured if I was a boy I could fight back or something.

Sarajane expressed wanting to be a boy, though for her it was not necessarily in relation to her later non-heterosexuality. The desire of wanting to be the "other" gender is something that is common for, particularly for queer women (Hiestand and Levitt 2005). Rather than expressing this desire as connected to her sexuality Sarajane's narrative focused on what she saw as the discriminatory treatment between males and females. At the same time she believed that if she was a boy she figured she "could fight back" when the other kids were picking on her. Her desire of wanting to be "a boy" as tied to the discriminatory treatment between the genders may also be connected to the conceptualization that individuals are raised with in this patriarchal society.

In heteronormative societies masculinity and maleness are rewarded or upheld as the norm compared to that of femininity and femaleness (Connell and Messerschmidt 2005; Kimmel 2011). In her childhood narrative she did not state outright feeling "different;" though she was cognizant of the difference her social class placed her in comparison to her peers. She expressed feelings of "difference" through the hardships she faced as a child such as being picked on by her peers, struggling for money, and then later her experience with homelessness. Sarajane's way of knowing "how to be" is expressed through the linguistic structuring of this gendered society. Her narrative 
brings into consideration Lacan's theory of language in which there appears to be meaning in being (Butler 1990), however what is true with Sarajane's narrative is that her identity was formed in the constrains of language and the structuring of those experiences. Though Sarajane was bullied due to her class position and her possible gender atypicality her narrative tells a story of how positions of hegemony come to play a large part in her the structuring of her lesbian identity - even in childhood, prior to the claiming of that identity. However the heteronormative structuring of society assumes and presumes individual's heterosexuality, which negates alternative forms and fluidities of gender and sexuality. Through language individuals come to understand what their experiences are and what they mean in accordance with the world around them. Language is the central representation expressed through communication. It presents opinions, views, and understandings and for Sarajane this structuring of language genders her experiences.

In retrospect, her desire of wanting to be a boy was connected her realization of same sex attraction at a young age. She discussed that she started to acknowledge her same-sex desires around 5 or 6 . Her desires to "be a boy" came out in her narrative of childhood games that was intertwined with her same-sex attraction. Although the awareness of homosexuality is out the closet, for many individuals the internalization of patriarchal and hegemonic values of sexuality play a large role in hiding their own nonheterosexual desires. Sarajane reflects back:

Sarajane: I fought it for a long time. I had a friend who was my babysitter's daughter. And she was my babysitter for maybe $1^{\text {st }}$ grade where we lived before we moved to the nicer neighborhood. And we used to play "boyfriend-girlfriend." And after we moved she would come over and spend the night. My mom caught us one time without our clothes on. Just got suppressed for many, many years, until I was a teenager. 
Kym: Did you talk to anybody about it?

Sarajane: No. It was swept under the rug and we never talked about it. Nothing came of it or anything for a long time. And I grew up in Salem, Oregon, which is not necessarily a small town 'cuz it's not. ...but it still has a very small town feel. It's not a very diverse city. There's not much in the way of role models for queer youth or anything like that. ... And I grew up in a very abusive, strict, homophobic, prejudiced household which is had a lot to do with my repressing how I felt. I remember liking girls when I was really young. Then I just kinda pushed that away for many years.

Sarajane expresses a common narrative about childhood same-sex attraction that becomes repressed due to the environment that one lives. For her, her same-sex attraction was pushed "under the rug" and she did not talk about it for a long time. In thinking about her past Sarajane believed that her refusal to acknowledge her same-sex desire had to do with where she grew up.

According to this narrative her household was not an open and inviting home, which can be a stressor for individuals (D’Emilio 1993; Kaufman and Johnson 2004). Environments are key in the process of sexual development - or any development - no matter sexual orientation. However, being in an environment that is homophobic can cause, in the case of Sarajane, the internalization and closeting of same-sex desires. Foucault (1978) acknowledges that current western constructions of sexuality were bred out of the Victorian era that not only created the linguistic modeling for sexuality, but also addressed how the repression of sexuality still exists. Sarajane acknowledges her positionality in her homophobic household and, as a way to escape the phobia, hid her same-sex attractions. This homophobic environment not only forced Sarajane into the closet but also structured how she understands herself. At the time, she may have had a 
different understanding of the impact on her identity, but at the interview she spoke about how those moments in childhood truly shaped how she sees herself today.

Mia's childhood experiences have similarities to Sarajane, in which denial was inter-twined with "playing games" such as "boyfriend/girlfriend." Sharing stories of prepubescent same-sex sexual exploration was a common theme amongst the individuals I interviewed however Mia narrated her story in terms of role-playing and denial. This narrative arose when answering the question: When did you realize you were attracted to the same sex?

It was weird, I never thought about it actually. But the things I did. I started experimenting with girls in like $7^{\text {th }}$ grade. You know we would play these games. "Games" [air quotes inserted] and we would experiment with each other. And I never thought about it, and you know one of my best friends, her name is Krista, and we are still best friends now. But um, she, I used to fool around with her the most. And she was like "I'm scared I'm going to be a lesbian." And I would be "what are you talking about? We're just playing around," and you know honestly I think I was just in denial. It felt normal, but it was, it was weird because when we played those "games" we role-played. And I was always a man. I was THE MAN, I was the dude and "oh you're my girlfriend and we are going to pretend to go on a date to the movies," kind of thing. (Laughing). It was like we were practicing for "heterosexual relationships." But I was not a man and I liked it.

Conceptions of same-sex attraction for Mia came through "role-playing" and are tied to feeling and enacting "like a man" or "a boy" with her friends during sexual experimentation. Though she still identifies as a tomboy today. The narrative of childhood same-sex games play into the hegemonic narratives of a history that can be (re)told to make sense of the queer identity claimed. Though both Mia and Sarajane discussed childhood sexual experiences they were loosely connected to their adult queer identities. In the narratives the childhood games were moments that took place in the 
past that had not been constructed into the current gendered sexuality that these women claim.

Lauren: Butch in the Sheets and Femme in the Cuddle

Meet Lauren, a 24-year-old self identified gay androgynous female. Lauren grew up in a small town and said that she knew most of the people in her hometown. She noticed the social pressures of heterosexuality when everyone started dating, and realized something was off. Though she never really knew why that was until later in life. She said it felt like “they were all into some secret that I didn't know." As a child Lauren was a "total tomboy" but said she did not realize it until she was much older. Lauren came out as "bisexual" when she was 17 years old, and it was not until after she broke up with her first girlfriend that she claimed a "gay" identity. As a child, she felt somewhat "Othered," though was not really sure why it was.

As Lauren informed me she never really thought about her sexuality at the time but it plays an important role in her own life and how she interacts with others. She had attended boarding school, in which there were out gay faculty and students, which provided a supportive and positive environment for her. During college she had become the "poster child for gayness" at her school, in which everyone knew who she was - she attended a small liberal arts college in New England.

In a discussion around her sexuality she starts discussing her gender presentation. Lauren states that she "dresses androgynously" which means for her that she wore:

Graphic T-shirts, skinny jeans, but I wear them baggy and sag them (laughing). I have a leg discrepancy by about 1.5 inches [which causes me to] have a massive swagger. I limp. I heard it looks like I put on an affect, but I just have a defective body. But I 
don't really like tight fitting clothes, that much. I'm starting to like

them more the older I get, but not uber-baggy. There's a line. I

like dressing like "gay boys" dress. H and M. and Top Shop.

As a child, Lauren never wore dresses and had a stint in middle school when she dressed in baggy jeans and Carhartt overalls. During the interview with Lauren her gender aesthetics and presentation often became a topic of conversation. This often arose in which she discussed how her presentation often leads to sexual relationships now; the ritual of socializing and reading each other's sexual cues is an important aspect of socializing and navigating sexualities. Later in the interview Lauren discussed the importance of sex and how that is related to the construction of her identity. Though she had had moment of dressing more feminine, she has typically always dressed more masculine. She makes an explicit connection of her gender presentation to her sexuality.

She states:

It's the clothes I've worn. I've always dressed more 'masculine-ly' my mom used to argue with me when I was 3 and she would put leggings and I would pull them down and sag them automatically. I never liked girly clothing on me. I don't know how much that is innate, how much of that is who you're around and the people you see. A lot of style, and what you decide to wear is the people you see, if I surround myself with a lot of gay people, I'm probably more likely to pick up style cues from that. But it probably has something to do with my sexuality. Probably a lot, part of that is I think gay people are, because you're outside the heterosexual gendered norm, they're more free to explore different clothing styles.

Lauren sees how her gender aesthetics and presentation is connected to her sexuality. She describes it as being free from hegemonic constraints of heterosexuality and how the enables gay people to "explore different clothing styles.” Her gender presentation as masculine is not only a way in which she can mark her sexuality but also is connected to 
her sexuality. As someone who is androgynous in characteristics and dress she connects

to how she relates sexually to other women.

The following narrative is the conversation Lauren and I had about her past

relationships and the possible sexual "roles" that she fills.

Lauren: I'm very dominant (silence) in that way I've, like I'm a "top," that's what they call it right? I prefer being the dominant one. That is probably why I like dating small girls, I always seem to find really teeny ones. I think that is because it's the only girl I can "hold down" well actually I pretend. I've like slept with people across the spectrum from Trans to actually very straight and not like flappable straight. So it's not an exclusive thing, but I've, I'm more comfortable being dominant. I'm actually fairly uncomfortable sleeping with people who are the more dominant one. Neutral-playing ground is also okay. I think I've slept with three people who are very, very "TOP" and out-topped me.

Kym: and be being dominant are you talking about sexually aggressive? Or penetration? Or giving? Or...

Lauren: Uhhhh...(awkward giggle) More probably in giving. I, like, really enjoy doing things to people Uh and if that like, I'm, uh I don't. So whatever people like I mean, like, I like penetration. Or both ways, like dominant in like, I like to be the one who says where things are going. I think, I like being physically stronger than the person I am sleeping with. In fact, I know I like being stronger than the person I am sleeping with (laughs). But in terms of sex acts, I like being penetrated just as much as most people. Well maybe I shouldn't say most people. I like it going both ways, in that realm. (Laughing). So that s even, but like behavior, and when I say people who are more "top heavy" I mean, like, people who wand to control where everything went. I like it not as well.

Kym: And by everything are we talking toys? Accessories? Or...?

Lauren: I've never really been into toys. But just like (thinking) positions and timing and the structuring of actual acts... Yeah and also I like, prefer beyond physically on top to, I used to be in with. Well AND I LIKE WAY PREFER, well not way prefer, but I really enjoy the pleasing of other people. 
This dominant construction Lauren has in her sexual relationships is part of her identity as an androgynous gay female. Her identity, sexually, plays out in wanting to be stronger than the women she is sexually and romantically involved with, and also with having more control over the intimate situations. However, in the discussion of actual sex acts, she enjoys and "prefers the pleasing of others." This pleasing of others is tied to the gendered construction of sexual activity for Lauren, as either the giver/active or receiver/passive. As a more masculine person, Lauren finds herself in relationships in which she is able to play out the dominant role of being, according to her, "Butch in the sheets." However, at the same time, does not like to be associated with "butch." Her sexual experience of "roles" and acts are interconnected to her identity and help shape the way she interacts with other women.

Additionally, Lauren, as a more dominant/masculine individual tends to be attracted females who are more feminine than she is - which allows her to continue to perform this particular identity of "top." This is based out of her sexual desires and experiences that play out in the desire to be stronger than the females she is sexually involved with. This narrative of preference in relation to her sexuality addresses the ways there are intersecting identities that exist within her and how they are connected to her sexual life. Furthermore, the way she describes sex or the acts/positions is through a dominant discourse that continues to reify her own iteration of sexuality. In fact, because she constructs her identity via terms of dominant and "butch in the sheets" the alternative iteration of sexuality in dominant discourse is feminine, and that is who describes she is sexually attracted to. However in the narrative, she discusses how both her and her girlfriend have fluid constructions of gender enactment and presentation. Lauren, utilizes 
dominant discourse in constructing her sexual desires, while at the same time understands the fluidity in identity that queer theory posits.

\section{Brooke: No Going Back}

Brooke is a 35-year old white self-identified sporty femme lesbian. She grew up in Portland and considers herself to be "pretty open-minded about most things." As a child, she was a tomboy but "always found other girls that liked to do boy things" and became friends with them and so never felt isolated. She had a supportive family and never felt pressure from them to act or dress a certain way. After high school Brooke attended a four-year university in the Pacific Northwest but transferred after a year to a prestigious military academy. It was at this point in which she started to realize the pressures that society puts in regards to gender norms and enactment. At the military academy there were certain social functions in which she felt most of the pressure to dress a certain way and conform to social pressures; she said she believed the pressures came from society as a whole, and not just the military.

According to Brooke, she took a long time to figure out herself in regards to her same-sex attraction, and she associates this to the lack of opportunities to explore sexually. She believes that having the opportunity later in life was influential in understanding herself and her own sexuality. This realization came though a long process of not having the opportunities pan out in her life earlier, but at the same time the opportunities arose after starting to surround herself with queer people. Although Brooke talked extensively about the importance of meeting and socializing with other gay women - her narrative focused more on the impetus that opportunities of sexual experiences with 
other women caused her. Having a community brought her the prospects to finally be comfortable with a group of women who in this case were gay, and she no longer had to pretend to be someone she was not. While discussing this new group of friends she states:

I remember going out to dinner with them once, with a bunch of lesbians and of course when you are a lesbian you can totally tell when that "straight girl" is gay, and you try and convincer her but it takes a long time and she needs to figure that out. They totally tried to do that to me, I remember they made some toast or something and were like "TO WOMEN!'”... So they were trying to encourage me, but I again, I didn't have any opportunity to have any girl that I was really interested in. I think that's a big catalyst.

Brooke mentions this community of friends as trying to help her get to the understanding of herself as a lesbian, but for her the lack of experience and opportunities were important to her in getting to that point. At the time that this story took place, she was unaware of the need for "the experience." She was on this exploration in her life and although she felt like if she had made alternative career choices - not going to military school and staying at the civilian university - her first "experience" may have come sooner.

Her first sexual experience with a woman happened a few years after this first narrative and a few years ago. When she discussed how she felt like she missed opportunities in her life and how that was key as to her not acknowledging her own sexuality. The story that she told about how she finally figured out her sexuality was as following:

I had just gotten out of active duty and I joined the Oregon Guard. And one of my subordinate's, his name is Charlie, has a very attractive wife and he kind of let it be known that he and his wife had an "open relationship." ... When we were flying one day, he kind of hinted that maybe if I wanted to do something like that it 
would be cool. And I was 'AH OKAY" whatever, I wasn't shocked, because I've had friends who have had open relationships and I consider myself pretty laid back when it comes to that. Yeah so I gave it some thought and then they invited me. I ended up staying at their house one Saturday. I was like "hey Charlie I'm ready to kind of do that. Sure let's do it! Let's have a three-some." and so I finally had my chance to sleep with a woman and I finally did and MAN it was like there was NO GOING BACK AFTER THAT! NONE!! And granted I fell madly in love with Bree and I haven't spoken with her in three years, but I mean she's my first love for sure.

This was Brooke's first experience and though it was a three-some and included a married couple, it was the moment that catapulted Brooke in to accepting and exploring her own queer sexuality. She had kissed a woman prior to this experience, but "it was not private and it was with someone I didn't really know. So NO! I hadn't had an opportunity" to explore sexual intimacy with other woman. For Brooke, it was the need of opportunity and experience that led to a new journey for her identity - that of lesbian. As was similar with other women, specifically, Brooke had thought about what it would mean for her as a person, but also her own sexuality and realized she was ready to take the leap.

Brooke's experiences in her life play a large part in her identity and had her experiences or past been different, she said that she was pretty sure she would have "connected the dots sooner." In this identity, she was able to explain her own understanding of categories such as butch/femme, lesbian, gay, etc. Part of her own hesitation in coming to terms with her lesbian identity was not having the opportunity to experience same sex relationships but also the societal construction of what it meant to be a "lesbian." Talking beyond her sexual experiences, and more about identity categories this is the conversation that followed: 
Brooke: This is also why it took me so long to come out because...those really butchy softball players, that are so prevalent when you think "lesbian" you think of them. I did not relate to that at all! It would just, disgusted me, so to think of that, to associate with that I was like "that is not me" you know, because I had never met a, well that's not true, but Melissa was "normal" lesbian or whatever you want to call it.

Kym: and by normal lesbian you mean?

Brooke: She (Melissa) wasn't 200 pounds, and didn't chew and didn't have a motorcycle and play softball. Yeah she's a half black, half white, you know tall track-star kind of athletic woman. Not "bull dykey." I think that stops a lot of young girls from considering that as a possibility. That image, although hopefully nowadays people you know. Don't have so much... nowadays girls have the L-Word, they have GLEE, they have all these pictures of what a "lesbian" could look like and when I was a kid my softball coach was definitely yeah. It's like what I like to call the "Title IXers." I joke now because have like the curly half-mullet and with their little visor. And they just dress with their t-shirt and jeans, and like you know. Thank god they were there, but I don't want to dress or be like them. So, you know we're the new generation.

In Brooke's narrative there is a strict understanding of how gender presentation and aesthetics addresses identity and because she did not want to identify with the particular image/aesthetic of a "lesbian" she struggled with coming to terms to her own identity as one. The "normative" construction of lesbian acted as a controlling image for Brooke which was at some point controlling her own destiny until she came to an alternative understanding and the power of self-identity as consistent with Patricia Hill Collins' (1990) or Jessie Daniels' (1997) thinking. They discuss how African American women’s constructions of their own identities were shaped for a long time by that of "Mammy," "Matriarch," "Welfare Mothers," or "Jezebel." As is similar with Brooke's understanding of lesbian, what she called "Title IXer," she thought it was the only option as a child and young adult in understanding what it means to be a "lesbian." Brooke had disregarded the possibility that she herself might be gay, which later played out as 
internalized homophobia, until later in life when she met Melissa, whom she considered to be a "normal" lesbian. It was upon meeting Melissa which helped her break past the controlling image of "lesbian" and after her first sexual experience with a woman, she was finally able to into her current identity as a sporty femme lesbian.

Part of Brooke's identity, now in her group of friends is the "new gay" because she is the most recently "out" person in her group of friends. Her friends nag her because she is just starting to get acclimated to "gay culture" and incorporating it into her own life. After her first sexual experience with Bree, she definitely "tried to make up for lost time" by throwing herself, full blown into the gay world and meeting women.

\section{Sarah: Queer Sex}

Sarah's narrative about her sexual experiences is intertwined with her queer identity. Sarah is a 27 -year-old pansexual queer who identifies as a gender queer hardcore femme. At one moment in her life, she held a lesbian identity but addresses how this identity did not fully encapsulate her internal feelings and how that identity affected the way she sexually connected to other individuals. She had been raised in a fundamentalist Christian household and was home-schooled until about the age of 15 . She says her father was extremely misogynistic and her mom was not the most mentally stable individual. Sarah has worked hard on getting past her childhood; however it plays a role in how she understands herself and interacts with people around her. She says that she knew she was gay when she was 11 or 12 , but it took a series of experiences to come into the identity she held at the time of the interview. A majority of those experiences relate to her own sexuality and how for her sex/sexuality is deeply connected to her own 
identity. Sarah's journey started with sexual attraction to women but she also

experienced stress with finding a label that fully connects to her own identity. The

following conversation gives insight into Sarah's thoughts about labels and their past.

I was pretty romantically oriented towards... effeminate malebodied people. And I was also very romantically oriented towards my best friend in high school but. But I didn't know that you could do both. You know, and I felt very stressed out by that...It was really a bit, it was a very intense struggle and I read a lot so I would pick up on stuff from books and be well this must mean I'm a lesbian... You know and being sheltered there is no social outlet to be with other people. Like all that sexual exploration stuff that kids get to do, I wasn't a part of, and I just learned how to masturbate on my own. Like my parents didn't talk to me about sex. It was really all this strange internal dialogue about how to $f^{* * *}$ ing figure out who I am... So yeah I felt really sad, because I wasn't a real lesbian. ... But I felt illegitimate because I was also attracted to male-bodied people and it made me really sad. So when I was 18 I was like "I'm a lesbian, I'm just going to go for it...I'm a lesbian. Make it easy on everyone, I'm just a lesbian" and what happened was I fell in love with an effeminate androgynous bisexual male-bodied person and then being "uh-oh" (heavy breathing, as to signify stressing out)... I never felt like I don't relate to it. ...And I was struggling...I was surrounded by a bunch of straight people and I didn't have a queer community until I was 26. So I'm like sitting in the middle, I was the only queer person out of all these straight people. And they were looking to me with all these expectations. And all these constraints on my gender and sexuality. And I can't fit in those boxes and I don't know how to feel belong, belonging.

This struggle of "both" is a huge aspect of Sarah's journey into the identity she holds.

Through an acknowledgement of her romantic tendencies towards women, she claimed a lesbian identity; however that is not her current identity and felt as though she did not belong with that identity. In describing the difference between "lesbian" and "queer" as identities, she talks about the role that sexuality played. Her childhood played a large role in her own conceptualization this queer identity, because she figured out her 
sexuality by herself, there was always something that did not always match up. She had taught herself how to masturbate, and never had the "sex talk" with her parent's and as such read a lot of books about romance in order to figure out her attraction to women and thus claimed the "lesbian" identity. However, as soon as she claimed that identity she fell in love with a male-bodied individual that just added to her own confusion.

Although Sarah talked about having a queer community, she explained more what being queer meant for her compared being a lesbian. In describing the difference between lesbian and queer as identities she talks about the role that sex played in her identity. In this discussion she states:

Ifeel like the queer potential opens up the consciousness during sex instead of roles, ... But the difference between, I know we are talking about individuals, but culture-wise, that queer culture is more about who you are, or like who, trying to deconstruct genitalia, trying to deconstruct hormones, trying to be the freest person you can possibly be. How free can I be, how free can I be and how, in which case sex becomes really, really interesting. I mean when you have sex out of pleasure and not roles, it's like really, a really interesting experience and my very first. I'll say this, my first "boyfriend" or whatever, we had queer sex, we have very, because I didn't want to be penetrated. And we would find very unique ways to have orgasms and I think that, that is part of the queer sex experience. How can I find different ways to have an orgasm? Yeah like it visibly looks heterosexual, but it is just not! ... You can be in a homosexual relationship and have heteronormativity in your relationship. Also you can be in a heterosexual relationship and have homosexuality in your relationship. And I think that is what queerness is about. You know, opening up the conversation in which you can have different genitalia operate in non-conventional ways, and to have it, but not be constrained by: "are you the same genitalia as me?" or "Are you opposite genitalia?”

Sarah tells this narrative about how sex, for her is a huge part in understanding her identity. She discussed how identities are connected to the sexual experience. 
Specifically how for her, as queer, that means there is a lack of boxes that she has to fit into, but it connects to how she sexually relates to people as well. She understands her queer identity to incorporate self-exploration. In addition, she addresses how queer involves rebelling against the heteronormative constraints that society places on sexuality - in which the socially constructed understanding of sex - even between two individuals of the same genitalia - is very heteronormative which involves penetrative sex. However, for Sarah, being queer allows her to explore her own sexuality beyond the constraints she sees society places on individuals. She utilizes the dominant discourses of sexuality and believes in the queer potential and how if you (de)construct genitalia sex can free yourself, but this in turn speaks to identities that one holds.

Sarah continues further in discussing how her journey of self-exploration involves having a queer sexuality. She shared how her queer identity has enabled her personal growth and she tells me the journey she has been on in her identity development. The following detailed narrative highlights the slight implications and recent transformations that are key in understanding Sarah's identity. It provides rich data that illustrates the struggles she has gone through in having a queer identity and how that has affected her sexual life. This is the story she told throughout our conversation:

Sarah: I would say that... I was a conscious individual who had social insecurity who had totally lack of context, had no relations with empowered people who were also exploring this like this and so I also fell into appearances of things, that I don't feel comfortable with now. And I was, I had things imposed upon me. I felt trapped. I just felt trapped

Kym: What was it that that enabled you to learn that what was trapping you was not the end all be all? 
Sarah: Yeah I also was trapping myself, I was with male-bodied people and that was like "I'm trapped, I'm trapped" I can't get past male bodies, I'll never be queer, or gay. I didn't identify as queer at the time, but I felt inferiority you know. I didn't see my relationships as the queer androgynous effeminate type of sex that it was. I only saw that it is the penis. And so I guess what really got me past was that I broke up with my ex. Who is male-bodied, who is androgynous and feminine, but I broke up with them and when I was with them, I started to have the turmoil again... I need to be with more female-bodied, I started having all these stressed out issues. And I would sit there and cry and I was like 'oh man something is wrong. I mean we are poly but it wasn't working out. '... I just went on this amorous slut fest. And I just explore the shit out of sexuality, ... and then Amelia moved here, and Amelia was very encouraging of me exploring and being queer.... We are going to queer it up!" and I was "oh thank god" and went on OKCupid, met some really cool people, put up my profile and put myself out there. ... I started having empowered, negotiated, queer, sexual relationships with people. And you know once I started doing that, I dated multi-gender queer people, had sex with gender queer people, felt like aligned with that, and that made a lot of sense to me. ... It legitimized me. ... And really having my relationship with Brandon...- they wanted me to fuck them and they are male-bodied. And I was like "wow" that really pushed it forward. ...You know sometimes, it just means so much...I'm going to start crying. (crying a little bit)I don't know why I'm so emotional (crying). Yeah it meant a lot to me. The fact that I could be queer and could still be with a male-bodied person was like, exceptionally queer, it was just so meaningful for me. ....

Sarah's journey was full of struggles until she could negotiate her queer identity;

however as is illustrated in the above quote having her queer sexual experiences really enabled her to connect and build a healthy and strong queer identity. Sarah's journey has been one of compounded identities and trying to understand how her sexuality, gender and identity all relate to who she is. Upon having sexual relationships with multigendered and gender queer individuals "made a lot of sense" to her and better fits with who she is. Her own understanding and the identity she claims are in direct connection to her sexual experiences because it allowed her to truly explore her gender through sexual 
exploration. Through this gender and sexual exploration and having support from her friends, like Amelia, made her feel "like a worthwhile queer." Feeling worthwhile, for her was connected directly to having legitimate experiences and one that was not constrained by the rigid boundaries of sexuality that she felt society had trapped her in. Sarah had constructed a life that, through a queer identity, was between the spaces. Her sexual experiences were a huge impetus in how she sees herself today.

There was an obvious struggle with the role of labels, specifically those of lesbian or bisexual, but after she embraced her queer label she felt legitimized. She went on to further explain why the label of lesbian was stressful for her:

It is STRESSFUL! You're dealing with the fact that I came from a sheltered household and pushing myself and finally having friends, like at 15 or 16, I don't want to go through that again. I don't want to go through a social group again and then be kicked out!

Because of, I can't help who I love. So being, that's what made it really, you know the gender queer friends, and then being with a gender queer male-bodied person. Because for me, that made it closer on my whole being queer and NOT JUST A LESBIAN.

In the beginning of this narrative Sarah saw herself as insecure and in a way floundering amidst social pressures trying to find who she is and how to identify. She felt trapped by the label of "lesbian" and faced a lot of internal turmoil based on the social understanding of what a "lesbian" is, as similar to Brooke who felt constrained by the "controlling image" of a lesbian. The identity label, such as lesbian, provided stress on individuals, particularly Sarah and Brooke, as the assumed heterosexuality of all individuals. However, through sexual exploration Sarah was able to "deconstruct genitalia" and acknowledge the queerness in herself and in her relationships. It was through her "queer sex" experiences that fully enabled her to not only accept herself but also be strong in 
claiming identity and acknowledging that she cannot help who she loves. Facing the stigma of homogenous groups she was scared of being kicked out for loving and having sexual experiences with male-bodied individuals. However, before she could fully claim her queer identity she went on an "amorous slut fest" which solidified her experiences and her identity. Sarah believes that the sexual experiences people have are a huge part of who they are, and feels a similarity with bisexual femmes in particular because of the real and perceived ostracism that they face based on their sexual attraction and experiences with both male- and female-bodied individuals. As she said "they very much invalidate the queer experience" if, in particular, she slept with those she felt an attraction to. Though she disengages from a bisexual label, her experiences of ostracism she believes are most similar to those who claim a bisexual identity.

Later in her narrative, Sarah discusses the differences between being bisexual and being queer. This is an important distinction in her own identity and as she stated earlier, she was not bisexual, but felt a similarity to other bisexual femmes. This is important because for Sarah queer has allowed her to be political, to be empowered, and to have healthy sexual relationships with all genders. Queer for her has enabled her identity to develop and change over time into something that is exploratory and at the same time highlights "her perspective about human freedom" and "sexual desire." For Sarah queer is not just sexuality, it empowers her and help creates the identity that she is currently living. Her sexual experiences play a large part in her own identity and with this queer identity she has been able to explore how being "sex positive" is a part of who she is and how it is directly connected to her sexual experiences. Her sexuality is a part of who she is and upon maintaining a queer identity she was able to feel positive about herself and 
the experiences she has had with others. She sees this identity as formed from her sexual experiences but also affects how she presents herself to the world.

Particularly, her sexual experiences allowed her to start having empowered, negotiated queer relationships that led her to overcome the stigmatism and thrive living as a queer. These experiences push her forward to no longer stand in her own way and let the power of sexual connection between two individuals, despite their genitalia, take a hold and be the center piece in her life which then further enhances and empowers her decisions and validates her queer experience.

\section{Jennifer: Conformity and Expectations}

Jennifer, a 26-year-old white lesbian female, shared stories of feeling different or "out of place" which confused her because she said she had an aesthetic of traditional femininity. Her internalized feelings were fraught with challenges of gender intelligibility and how it played out in her life. She was raised in the Pacific Northwest and her father was a pastor and according to her, she "grew up in the Church." She was predominately surrounded by males, including her three brothers, and shared how she felt more comfortable and relaxed around males. As a child she went "through the motions of 'being a girl." As she got older her outward appearance followed traditional gender norms, and she wore dresses, heels, make-up etc. and in most cases sees herself as "passing," in which based on her gender enactment and appearance people will assume her heterosexuality. "Passing" can come with certain power as individuals assume their heterosexuality and thus are granted with the privilege of hegemony, generally until those around them know 
their marginalized status. The linguistic use of "passing" is found amongst most minority groups, and not just sexual minorities.

Jennifer moved to Chicago to attend a university after transferring from a smaller Christian school in the Northwest. She spent her formidable "coming out" years in Chicago, building her community and transferring into an empowered and proud queer. Upon first coming out she chopped off all her hair and dressed "like a typical dyke," however, as time went on, she realized that when she looked into the mirror she looked good/'hot" but not herself. She was dressing to match what she thought was attractive that of the androgynous dyke lesbian. Shortly after moving back to the Pacific Northwest, she reverted back to her regular style of dress, but according to her it posed a problem.

She felt hat her queerness was rendered invisible and at the same time most people placed certain expectations and roles on her because of her outward femininity.

In talking about her previous relationships and going through the motions of fulfilling the "female" role Jennifer shares this narrative about the how sexual interaction or possible sexual interactions are connected to her identity. The following is our conversation:

My point is that I didn't, my relationships with men seemed to be what I was supposed to be doing. ...I never considered that I could be [gay]. I think the thing would be that I grew up thinking that you would know from birth that you were gay and it was something that 'oh I'm white, I'm female, I'm gay. '...I mean it's not like you get a letter from Hogwarts (laughing) that says 'Hey Welcome to the CLUB!' ... So then I went to Chicago, did an Urban Studies Program, that focused on all the different communities well that I'd never been exposed to back home because they aren't 'straight,' 'white,' 'Christian.' ...I was exposed to the gay community in a way that I really had never been before. And so I started questioning myself and that questioning took like two years, of a lot of burnt bridges with some dudes. Where I was just "okay, I'm 
just going to try this" and it, just, was like 'OH GOD' and so then

I met THE GIRL, that like changed everything, right? And

EVERYTHING started making sense. EVERYTHING. IT WAS

AWESOME! I was like 'Holy Shit sex is AWESOME!' okay!

(Laughing) ... But she [my mom] is like 'How do you know you're

gay' and it's 'Mom, I just know' and I think that's part of the

problem, is that I think that all those people who have issues with

the 'gays' its like, I don't know. There is part of me that wishes

that I could be like 'Hey mom! It's actually about the sex!' I mean

it's not just about sex, but that is sort of, that was my first clue, was the SEX! And that's okay that that was one of the first clues. And then it was a deeper relationship connection, who would of thought that communicating with a partner could be like a really great positive thing?!?

Jennifer discussed how her sexual intimacies with both men and women have been part of her understanding of who she is. Although this narrative addresses part of her coming out story, it focuses on the importance of sexual interaction and how sexual intimacies can be connected to identity. She had always wondered why people loved sex so much and why it was so important in her peers' lives, until she met "THE GIRL." As is similar with a lot of queer females, sexual relationships can be the impetus for a change in identity and their coming out narratives are deeply interconnected to that first relationship (Kaufman and Johnson 2004).

The narrative she shared addresses complexities within herself as someone who was not gender atypical, for most gender atypicality commonly leads to a homosexual identity (D'Augelli, et. al. 2008). As someone who is traditionally feminine in appearance it was not as obvious to her that she was attracted to other females, she never put much thought on sexuality, and went through the motions of "heterosexuality" and dating boys. She eventually started to question her sexuality after being exposed to the gay community in Chicago and after sleeping with "the girl" "it all made sense" to her. All her confusion 
about sex and its enjoyment was cleared upon her first time. Sexual interaction, for Jennifer, was key in the shifting of identity into that of lesbian. However, her first sexual experience with a woman happened after two years of questioning and burning a lot of bridges with men. Her first experience led her to the "light bulb" moment where everything in her life started to make sense and the her assumed heterosexuality shifted into the claiming of a lesbian identity shortly after.

As with many people, the influences of heteronormativity play a large role in Jennifer's own history of sexuality. She had had previous relationships with men, but discusses her feelings and thoughts about the impact of the social pressure of "one woman and one man." This pressure mostly came from her religious background and the lack of diversity she experienced in her life, until moving to Chicago. She reflects on her past and acknowledges now that she was in such a deep closet that she could not even acknowledge the possibility of a non-heterosexual identity. Jennifer shares:

I just really feel bad for them, actually in a lot of ways. I was, I was pretty bad, because I let their emotions get involved, and mine were just, there weren't any emotions at all, really. I mean there were, but it was like 'best friend' status. ...Yes to social pressures... it was social pressure in a way that was so, so, I was so blind to the social pressure, that I was just like this is, I mean this is just my only option [dating males.] I don't really think I want to be alone my whole life, so I just need to find the 'right guy.' And, and also from the religious standpoint that there is only one person out there. So I was sort of brainwashed into thinking that I had to find that 'perfect guy' and then it would all make sense, because I'm supposed to have sex with one dude. And so maybe it's just, say, I haven't found THAT guy yet. So I was in really deep. So I was trying to find... "in" as in deep in the closet. So I was trying to find that DUDE that was going to, that everything was going to fit together. And it wasn't until I was in Chicago, where I was like "oh maybe that's not, maybe that's not the issue.' It wasn't the fact that it's me, But that it is a 'GUY.' 
She believed that she needed to find "the right guy" based on what society and her family had "brainwashed" her into believing. However, that was not her reality, she needed to readjust her thoughts and acknowledge that the heteronormative construction of sexuality does not actually apply to her. In fact it may not even be the hegemonic construction of the heterosexual versus homosexual binary; after moving to Chicago she was able to construct her lesbian identity after experiencing sexual intimacies with "THE GIRL" who blew her mind. The hegemonic discourse of sexuality plays out in many coming out narratives, however, what is key is to locate where constructions of gender and sexuality link to identity. After having the "come to the light" moment about her sexuality, I was curious to see how her construction of gender played out. She had already been sharing notions of heteronormative gender and acknowledged her own femininity, but where did this pan out in her journey of identity development.

Jennifer shares a story with me about a night that recently occurred which provides insight into her own identity. In this story she compares both gender and sexuality and talks about the impetus for her to start really thinking about gender in ways that she had not before. What made her start to think about her gender was after a possible sexual experience, in which she was confronted with more open ideas of gender. In responding to the question, "Going back to your gender, you were saying that you are more traditionally feminine, do you say that because of your clothing? Do you see your clothing as connected to your gender? Or is it something else?" Jennifer states:

Here is the thing Kym, ...I have only been thinking about THAT part of my identity in the past couple of months. ...So I went on an OKCupid date with a trans-guy who, on OKCupid, his profile says 'female,' 'lesbian' everything. So I went with certain assumptions about the situation, and who I was going to meet and all this stuff. 
... But, yeah so that date was really, it was really great and I felt myself attracted to him in whatever. It ended up not going anywhere. But it left me with this like this whole 'wait!' I say that I'm a lesbian. And I've really clinged to that, rather than just saying I'm a queer woman. And I, yeah, but what does that mean to be a lesbian? And what does, 'cause that means that identify as a woman and I say that I am only attracted to other women. And that works in like almost all the cases, but then I started, so I met this gender queer individual who prefers male pronouns. And, but at the same time he doesn't identify as 'fully' male. So then I was like 'well what makes me think.'

This interaction had the guise of sexual attraction and led to a period of questioning herself because of whom she felt attracted to and what society says about labels. She shares her questioning: "how can I identify as a lesbian, if I found a male identified individual attractive?" For Jennifer, as well as others, there was the empowerment that comes with valuing the queer identity over the original constructions of categorized labels. Her lesbian identity does not allow for the attraction to 'other' sexed/identified individuals.

At the same time she continued her narrative and talked about the implications of her gender as connected to these sexual desires and her sexuality.

I would say that part of my questioning has come around my pornography preferences. I can't watch any videos. But I really like erotic literature and I really can only get off when I am reading straight erotic literature. So then I'm like 'where does the dude come into this' and I realized (awkward laugh) that, that when I am reading it, I'm identifying as the male, in those stories. And that's what gets me off! So then I'm like 'so what the $F^{* * *}$ does that mean?' I don't know what that means. I think it's more than just like wearing a dildo, or strap-on. (side comment) Although I do like to do that.

Jennifer talks about how porn has been utilitarian for her in he sexual experiences and "getting off" but more in how she has formed an identity around certain acts and people 
in the pornography that she is reading. Specifically she discusses how in "straight erotica" she imagines herself as the "male" in the story and that has enabled her to please herself. However, her narrative gives insight into her own thought process of how if she imagines herself as the "male" in porn, how does that affect the way she constructs her gender and her lesbian identity. For her she still see's herself as " $100 \%$ female" but enjoys the sexual pleasuring of others and sees herself as the penetrator.

Later in the interview she tells stories about her own sexual experience with partners and how it connects the ideas of her gender to sexuality. Though she says there are more pressures in her actual relationships, these pressures, according to Jennifer are based on her appearance. She says that she is typically attracted to the "more androgynous ladies" but it can pose a problem, since a majority of the women she has been in a relationship with tend to put her in the "female" position, or the one to receive the pleasure rather than give pleasure. In her own thoughts, she talks about how she thinks this is based on her gender presentation. The following is the story Jennifer told about her relationships:

The women I've dated ...there are things like 'paying for dinner' where I'm like 'No. This doesn't fall on you because you look more like a guy!' So I've been pushing back on things like that... I open doors for ladies all the time. And I don't expect that to happen to me. And so that's where I think some of the gender stuff/comments from my 'queer family' are coming from. That I'm ... 'don't pull out my chair. Don't take my coat. I can handle myself.' But I don't want that to be a gender thing...But YES I do have to; I definitely have to address that [expectations and roles] with people I've been dating. And it's caught more than one girl off-guard - that I want to wear the harness, literally (laughing) during 'sexy time' as much as I want the other person to wear it. And that is always sort of shocked me, well you have fun wearing it don't you? Because I DO TOO!! Like come on! ... Maybe that is not a 'norm' that I am 
more of an exception [that I present in a more traditionally

feminine way but also like to wear the harness].

Jennifer's narrative plays into what Foucault (1978) refers to as the regime of powerknowledge-pleasure and how it sustains the discourse of human sexuality. This regime structures her own sexual experiences. Most of the women Jennifer has dated have had specific expectation of her sexual desires based on her femme attire and presentation. The sexual discourse that plays out for Jennifer penetrates and controls her sexual experiences because the modern world is sexually constructed in a particular way that goes beyond just sexuality but also forms expectations and possibilities (Butler 2004; Eves 2004; Kimmel 2011).

She is often fighting or pushing back against the hegemonic structure by purposely blurring the gender lines in mannerisms and behaviors. She comments in her narrative that she often opens doors for ladies - instead of having the door opened for her - but acknowledges that this may be a "feminist thing."

Sexuality or sexual experiences, for Jennifer, has elucidated concerns about desire as it is connected to her gender presentation. Jennifer's identity is encircled by her gender and the fact that others place certain sexual expectations on her, especially during what she calls "sexy time." Her feminine appearance blends into her sexuality, but not because of her own construction, but rather because the women she is with often place her within a particular heteronormative construct in regards to sexual "positions" and options. She is generally shocked that individuals who are aware of the oppression of heteronormativity place the same confines on her sexuality based on her feminine appearance. 
Jennifer is forced to address the expectations/roles with those that she dates and actively constructs this identity that fights against the confines of hetero-gender expectations - both in appearance and mannerisms. It is interesting to note that when asking Jennifer to give a statement about her sexuality she continues to place gender and sexuality together. She sums up her sexual identity as the following:

I would say that I am a, (thinking) I'm a strong female lesbian who's looking for the same in a lady.

When asked to make the same statement about her gender she responds:

Jennifer: I think it would be the same

Kym:(clarifying) The same?

Jennifer: Yeah. I think it would be the same. A strong independent female lesbian.

She is aware of the fact that being "strong" and "independent" are traditionally masculine characteristics and that the cultural associations of gender may have "baggage that we haven't really shaken off' yet. However, what she fails to acknowledge is what happens when she utilizes the same summary statement for both her gender and her sexuality. How does this affect the way in which her gender and sexuality are constructed? And what are the implications that this construction has on the way in which she interacts with others around her?

The journey that Jennifer has been engaged with in her life has culminated her current understanding of her gender and her sexuality. At the same time, it has been her sexual experiences that have played a large role in how she has thought about both her gender and sexual desires. Specifically, her sexual experiences have sparked her own 
internal analysis of how her gender and sexuality may interact with one another and blend into other areas of her life.

\section{Charles: I'm Just Single}

Every one of my participants were able to discuss how sexual experiences with the samesex have caused a shift in identity for them, either gender or sexual orientation, except for Charles. Though he had a similar trajectory to those I interviewed he views his sexuality as something unsolved and identifies as "single" or sometimes "bisexual/questioning." Charles grew up in Southern California and said he felt like "the typical boy" who enjoyed playing sports until eventually he lost interest. As he reached high school, he followed the norm and participated in heterosexual expectations and dated female; however, he qualified his relationships with women: "There were only two girls that I was ever "WITH" and even then, not long term. ... We dated for a little way, and then I got bored and we became friends."

Charles attended a private Christian college and while he was there he began to think about same-sex attraction, but even then he is very clear that it is simply a sexual relationship. He shared that he could not see himself in the long run settling down with a male. His story, at this point, diverges drastically from all my other participants, and as such it is important to include the narratives that are surprising or unsolved. Most of my participants were able to discuss their gendered and sexualized identities and the journeys they went on in coming to their current conceptualizations; however for Charles, his sexual identity is still unresolved and he is somewhat apathetic to claiming an identity. 
While sharing his same-sex relationship Charles expresses his journey as he sees

it. He states:

There were times in high school that I would look at both straight and gay pornography. But for the most part, I didn't. There weren't ever...there wasn't anyone up until College that I was physically attracted to, or attracted to at all. There were some people that were attractive, but I never really, I can't say I ever dwelled on them too much. ... We had an on and off sex relationship for 2 or 3 years.

Charles is one of the few people I talked to who had experienced same-sex sexual

relations and did not have that "light bulb" moment. It was not similar to Jennifer where after her first sexual experience with a woman everything started to make sense. At the same time, he has spent some time thinking about his sexual identity and has clarified what the experience with Alex, his first and only same sex experience, has meant for his identity. He states:

I don't know. A lot of times, like because of the way I view my attraction to men versus women, I think of myself as straight, but that is only some of the time, I should say. Frequently I think of myself as bisexual, but even then...my attraction to men is just very physical. There is no emotional, or mental connection I've ever felt with a guy. And that was why I specified intimate versus sexual with him [Alex]. Because it was just sex. And I feel really bad saying that. ... It was up until, well there was obviously in high school when I was like "oh god I'm gay!” because I looked at gay porn. But realizing that I still had strong attraction to women, it wasn't I don't know, that was a confusing time in high school. But in college we, man I took basic psych classes and you know through those they reaffirmed like "it's okay. That is normal." Those kind of thoughts settled down. But it wasn't until my junior year, that I was involved with Alex. And so up until then, I didn't really think about my sexuality a ton. But I didn't really feel confused again, until Alex came along. So then when he did come along I didn't know really what the hell to make of it. 
Though this narrative addresses confusion about what exactly Alex meant to his identity, there was no change in identity as a whole. As similar with some of the other participants Charles talked about taking psychology classes as a way to try and intellectually understand himself. His narrative addresses specifically his relationship with Alex but not how that has played a large part in Charles history. At the same time his conceptualization is different compared to how the others I interviewed experienced their first same-sex relationships. In parts of Charles's narrative a secrecy has arrived in which he was adamant about concealing his same-sex experiences. In fact no one at the time, except best friend, who is gay, knew about his sexual relationship with Alex. Even now, while living in a more "queer friendly place" he mostly keeps his sexual attraction to men on the down low.

This may be, as someone who is also attracted to women, feeding into the dominant hegemonic constructions of homosexual versus heterosexual, and if you are not one than you have to be the other. Charles's narrative is rife with his story of falling in the middle, or living between the spaces of identity labels. His identity has been explicitly constructed with dominant narratives by both attempting to fight his visceral attraction to men and avoiding having relationships with women. He said towards the end of the interview that he is "just single" until he can figure everything out. Surprisingly though, he does not feel that having a non-dominant sexual identity is something to worry himself about. He explained

I guess I never really connected sexual identity to identity as a whole. I guess I just could say my sexual identity is one part of me. It doesn't have to be the whole thing. So I never really considered if I can't figure this out, than I can't figure me out. There is just 
one part, one piece of the pie that has a question mark over it, you

know? (laughing)

Charles's narrative was included in analysis as a way to see that the journey to a gendered and sexualized identity can diverge and be expressed in many ways. As different from some of the literature on same-sex experience, for his case, his experiences with Alex were not an impetus to claim an identity around these desires. He explicitly says, "it is just one piece of the pie that has a question mark" and for him this is his reality. His gendered identity was rarely discussed and his sexual identity is a question mark. Though his narrative of the relationship of sexual experiences to his identity is an outlier compared to the other participants, it sheds light on the possible stories for those who are questioning and how there is not much research in this area.

As has been noted throughout this section sexuality and sexual experiences have been pertinent in constructing these individuals' identities. I would even argue that Charles's identity as “single” was started by his questioning identity from college. Though he does not claim an identity around his sexuality, his sexual experiences have still played a large role in his overall identity. While focusing on the other participants it is notable to mention that many of the other males that I interviewed rarely discussed sexual experiences in the same detail as the females. However, when they did mention sex or sexual relations it was common that they addressed how they "felt" whether being a "top" or a "bottom." Especially for those that have experienced both roles in different relationships they mentioned how society has particular expectations of "bottom" and "top" and that these expectations are generally connected to an individual's gender enactment. Brandon in particular mentioned how when he was more "feminine" in 
appearance and presentation that it was expected that he was a bottom. The sexual

position of bottom connected to his femininity and is also deeply rooted in the patriarchal society that we live in. He stated how:

When you identify as the 'top' or 'bottom' that has a significant way of how people perceive you. I think that 'bottoms' are sometimes written off as being 'silly' or whatever, whereas 'tops' have more credibility in the eyes of some, which I think is ridiculous.

Brandon goes on to mention that in his previous relationships he was a "bottom" and that now being a "top" he thinks about himself differently. He states:

I think that is been in a way, of me feeling more competent, because NOW I'm THE TOP. And I'm more credible, which is I think, it's me playing into the very same judgments that I also, at the same time criticize. So yeah, I guess there's some hypocrisy even within myself. It's just those sorts of roles, you know 'bottoms' are perceived to be more feminine no matter how "butch" they are at the same time. They are playing the "woman" role. You know, those domestic roles and who's playing the 'women' and the 'man,' or who's wearing the pants. We're both two dudes and wearing pants.

Even between my partner and I, we, even recently, we have sat down to have a conversation about what 'role' we are going to play in the relationship. And I'm not talking about sexually, I'm talking about, oh I'm the 'breadwinner' right now at this point in my career. My partner still works, but I have the more traditional 9-5, a little higher paying job, and you know about family he is going to play the 'stay at home mom/dad.' You know it is interesting even between us we are framing it as "mom" and "dad" which is interesting.

The way in which Brandon constructs the different roles between male and male sexuality is as he says "hypocritical," because he acknowledges the limitations in furthering the hegemonic and patriarchal constructions of gender and sexuality. At the same time this view further delegitimizes the "feminine" and places them into the 
"passive" or "receiver" role, which translates into other aspects of life. As Brandon stated, he was not necessarily talking about sex, but he and his partner frame their conversation about family in the same heteronormative frame of "mom" and "dad" or "breadwinner" and "stay at home." These narratives are further damaging to the "female" or the "feminine" individuals in which they are rendered as "silly" or less than. Brandon is not trying to devalue women or femininity but acknowledges how when he is a "bottom" he tends to feel less competent, internalizing society's views of femininity and masculinity and the de-legitimization that occurs.

\section{Conclusion}

The way in which sexuality penetrates many aspects of an individual's life has been exemplified in this section, however, there is a similarity in which there are expectations placed on these individuals based on their outer gender appearance or enactment which infiltrates into their sexual experiences. The following chapter will take into consideration the role that the previous narratives shared had on the individuals who were interviewed and will address the explicit interplay of gender and sexuality. 


\section{Chapter Six: Connections of Gender and Sexuality}

\section{Introduction}

The interviews I conducted culminated with an array of narratives relating to the participants' identities and any attempt to separate and compartmentalize further aspects of these identities would render invisible the true complexities for these individuals. Though each individual has their own narrative and history the stories they told present a new dimension in understanding queer identities. Some of these narratives appear to relate to an essentialist view of sexuality, but in fact they highlight the lack of strictness for possible identities. The idea of an essentialness to sexuality seems to conflict with queer theory yet it still embraces an alternative view of sexuality. A majority of these stories address "the discovery" of their identity and the (re)structuring and (re)shaping that occurred based on this discovery. The histories that these individuals told address more than "coming out stories" but acknowledge the connection and interplay of gender and sexuality.

\section{Mia: I Was One of the Boys}

Mia is a 24-year-old white lesbian female whose parents are still married and represent the "traditional" idea of a family. Growing up in Southern California, Mia said her mother was the "traditional housewife" and instilled patriarchal Eurocentric ideas into her when she was younger. Her mom believed that as a woman, it was part of her duty to be a housewife. In fact, Mia shared a story of how when she was little her mother would say, "When you get older you're going to need to look for a man with money and looks... and 
stay within your own race." Not only were there heteronormative values being expressed, they were coupled with racism.

Mia is currently out to her family, though she informed me that her sexuality is disregarded and her parents act as though she never came out. In college, she lived in the pool house at her parents' house and her girlfriend would come over and stay the night. Her parents ascribed to "traditional" constructions of sexuality and regulated who Mia was allowed to have stay the night, though this had more to do with Mia's homosexuality. In (re)telling the story about her parents enforcing proper sexuality, Mia shared how once she asked them that if she had a "boyfriend," instead of her girlfriend, would they regulate his "sleepovers," and of course the answer was no. In their eyes, there was less a need to regulate her sleepovers with "boys" because as a "young adult" heterosexuality is assumed and "normal." This conservative view of sexuality acknowledges the prevalence of heteronormativity and as such the favoring of "opposite sex" attraction and relationships.

The values of heteronormativity stood out in Mia's narrative, though not in the way her mom intended. Mia's understanding of what the differences between "boy" and "girl" is mixed with her own feelings and stereotypes. In telling a story about her life she utilized the rhetoric of "tomboy" as a way to locate herself in the spectrum of gender. For Mia being a tomboy enabled her to transgress stereotypes of femininity as a child.

Mia: I felt like a tomboy but I didn't have a problem with it. Most of my friends were guys and I was just considered one of the boys. But I was a girl. I had long hair, thought I wore boy clothes, had a boyfriend even when I was like $3^{\text {rd }}, 4^{\text {th }}, 5^{\text {th }}$ grade. But I was still like a boy.

Kym: When you say that you felt like a tomboy what do you mean? 
Mia: Well I felt like they were all boys, and I was one of the boys, but they also saw me as a female. Which is why I think of "tomboy" because I was a boy. And I was so boyish that I fit right in. But they still recognized me as a female and I recognized myself as one too. So it was like, that's how I felt like a "tomboy." ... I never felt uncomfortable until later on in life.

Mia is expressing the dualism in her life in which she "is a boy;" however, at the same time is female because of her long hair. As Mia's narrative continued, her long hair is considered the sign of maintaining "femaleness." In recent scholarship on lesbian identity development, particularly that of butch identity development, Hiestand and Levitt (2005) acknowledge how as children women claimed a "tomboy" label, however that usually faded away as the women reached their teen years and that of their twenties. There was a transition of tomboy to butch, in which they were able to enact crossgendered stereotypes while maintaining a slight sense of femaleness, although not femininity. However, for Mia, she talks about being a "tomboy" and shies away from the identity label of butch. The favoring of opposite sex attractions is played out through Mia's experiences even though she has same-sex attraction and formed her lesbian identity around this attraction. The gendered language utilized highlights how Mia conceptualizes her desires - they are all structured through language and it is this language that (de)regulates Mia's gendered sexuality. Language is the secret in understanding how gender performativity not only structures, creates and performs one's gendered sexuality, it also highlights the ways in which there is no essential gender or sex that an individuals IS, rather gender is impossible to be separated out from other regulating modalities (Butler 1990, 1993a, 1993b, 2004). The construction of her gender and sexuality adheres to the current episteme of "opposites attract." 
Later in the interview the patriarchal and racial ideals her mom instilled in her became more apparent in how she understands her own sexual desires. The heteronormative notion of "opposites attract" also including the proper roles of females and males came through as she discusses whom she typically finds more attractive.

Mia: Well now I go for really feminine girls. I like long hair, and usually I like girls who wear dresses and that kind of thing.

Kym: and the long hair and dresses is feminine for you?

Mia: Yeah and I like, I guess, the social norm of "how a woman is supposed to look." BUT I'M NOT LIKE THAT. I'm still a tomboy. I mean I haven't worn a dress in four years. I mean I had to for a wedding.

Kym: How about your own gender, today?

Mia: Hmm... I would say, well maybe say I'm female bodied, but my mentality is like, I don't know I feel like I have the mind of a man (awkward laugh).

There is a struggle occurring within Mia and the values she was raised with. Though her adherence to the traditional dichotomy of masculine and feminine still exists, her notion of being a 'boy/man' occurs in her mentality and often sexually in which she is "always dominant, like in the bedroom." Mia informed me that her sexual fantasies often occur with her having a "dick" and that she is usually penetrating feminine girls. These sexual fantasies she said have been since she can remember, but struggles with the true meaning of them. As is true in a society that favors cisgendered individuals, the struggle of crossgender identification is often intertwined with gendered sexuality.

In her narrative of desire, she is not acknowledging a "trans" identity but rather utilizes the available discourse in trying to understand her own desires. She further discusses this dichotomy within herself: 
Mia: I mean like, (thinking) I don't, well yeah I'm more dominant in the bedroom and usually more dominant that people in general that I'm dating. I could never date someone who ...

Kym: And by dominant are you referring to positioning of "top" or "bottom"? or are you talking about...

Mia: AND personality wise. You know, I also like to be the caretaker. It's very traditional like the way I see it. You know. I like to be, you know, just the one who "let me be the one to put my coat down over the puddle so you can jump over it" - type of thing. (laughs)

Her narrative expresses similar notions that her mother instilled in her the only difference is that there are two females involved in the equation instead of the heterosexual coupling of a man and woman. Although there is the connection of sexual interaction, in her desire to be "more dominant" these notions stem from her childhood conceptualizations of the boxes of gender. What is the appropriate gendered behavior and how does that relate to the world? For Mia, it very much is the homonormative construction of butch/femme, or rather "tomboy"/caretaker and "feminine girls." In Mia's narrative there were notions of how her gender came to play with her sexuality, not only through hegemonic dichotomous constructions of gender but also how she understands herself which broke apart these identity categories.

\section{Geri: Concern of Intelligibility}

Meet Geri, she is a 31-year-old white self identified gay/lesbian female. She grew up in Maryland and moved to Portland in 2004, after college. She is highly athletic and played sports her entire life. Sports became an avenue for her to create community, both in her hometown and in Portland. When I asked her how she describes herself she said "neutral" but then laughed, thinking that she really is not "neutral" but that her clothing could be 
considered neutral because it is not "flashy." As similar to many of the participants she was raised in a religious household and spent a majority of her teenage years involved with the local Presbyterian Church and Young Life, a youth Christian organization.

Geri, as an individual who is gender typical, spent a longer time processing, questioning, and living a life that adhered to the "cultural expectations" of sexuality. Up through college, Geri maintained a hetero-gender identity; although she had thought about her same-sex desires during high school. She eventually came out after graduating from college and moving to Portland where she found and was introduced to the Portland queer communities. She considers herself to "really think things through prior to following through" with them and that is what happened when she acknowledged her same-sex attraction. She told me how she had to go through a deep self-analysis in order to grasp this new identity and what it means for her, especially compared to the heteronormative assumptions she grew up with.

While talking about moving to Portland, Geri discussed her excitement in finding a community. She said:

I moved [to Portland] right after college, I graduated in the fall and I moved in January, the $21^{\text {st }}$ of 2004. And I had a college friend out here that came out. We had a plan: "let's just go out there, I'll go out early and you can come out and it will be great!".... And I fell into the sports community pretty quickly and started reffing pretty quickly. And then just making friends around. And it did feel a lot like that, I often said to people, after the first few years here, that I had never been anywhere and met so many people that resonated with me so quickly. And in such quantity, that it was just amazing! So I was really excited about coming out here, it was very open and I was able to be "free" of a lot of boxes. You know? I went to college, did my college thing, right from high school, from church, you know? So.... IT WAS GREAT! 
Her excitement in finding and being a part of this "new" community is evident in the fact that Geri still knows to the day when she moved. This may have to do with the fact that she was able to find people "that resonated" with her quickly. It was the first time in her life in which she was able to build her community, but at the same time was able to explore her gendered sexuality. This exploration came in having a sense of community. In addition communities can serve as a space where identities can emerge and evolve (Eder, Staggenborg, and Sudderth; Fine and van den Scott 2011; Taylor and Whittier 1992; Weiss 2006). She discusses how moving to Portland enables her to live a life that is "free" from all the boxes and the expectations that her life previously had such as being involved in the Church and going directly to college after high school.

The narrative of her life before addresses the "normalcy" that a white, middle class, heterosexual, youth has laid out for them. With the changing social climate, race is becoming less of a factor in whether or not an individual attends college, though class still seems to be significant. For Geri, she does not necessarily acknowledge her place of privilege when telling this narrative. Her path, according to her, seems as though it is the same for everyone, and thus rendering invisible alternative trajectories. Her narrative normalizes the experiences but Geri felt restricted and confined by "what she was supposed to do." Moving to Portland enabled a huge shift in her identity by providing distance between her past and her future possibilities as a lesbian. She is living in a place that has a community of people that allow her the ability to be her true self.

Although Geri now has her community she focused on the struggles she had trying to finalize that community. Geri told shared how she struggles with forming that great queer community because of her appearance. Since she lives in the same society 
that she was raised in, the heterosexual matrix focusing on gender intelligibility stands out for Geri. As someone who adheres to cisgendered characteristics and specifically style she believes that she is not recognizably "gay." According to Irvine (2002) behavioral signifiers are key for queer individuals to identify and recognize one another. Talking about the "signifiers" the following narrative arose in her response to a question about whether or not she believes her gender presentation to be connected to her sexuality. She states:

That has been a really big struggle, for me. Not a huge struggle, it's all relative (laughing). But I don't look gay to a lot of people and I am gay (laughing). And I HAAVVEE, I don't know what to do about that. I don't want to change how I look, I feel really confident with my appearance, but I, it is an issue when I go into an environment where there's a mix of orientations and I'd like to identify with the "gay group" more because I want to be friend sand have that great community, but I just always tend to go back to "heterosexual" folks. And I think a lot of it is just 'cause that was my comfort zone growing up. And I can't, I don't know how to deal with that necessarily, but hopefully I don't have to.

In this discussion Geri is talking about "that great community" but at the same time feels somewhat isolated from it because of her appearance. For Geri, there was a real concern about intelligibility. She felt as though she would be "mis-read" by others and not seen as "gay," especially in a mixed crowd in which her "gayness" or the understanding of her gender as tied to her sexuality is rendered invisible by the fact that she appears to uphold normative constructions of femininity. As is explicated in this quote, her narrative further demonstrates how sexuality can be read through gender. Gender becomes one way in which cues of sexuality are passed to others around (Bradley 2013). Her gender presentation is connected to sexual desire in which she is not read as "gay" because of her looks. Her narrative provides a good example of the formation of a sexualized gender, it 
addresses, that though she is "really confident" in her appearance she is concerned that she is not read as gay - based on an outward appearance.

This is important in analyzing how gender and sexual desire are connected to one another for Geri. According to her, her sexuality, or at least the reading of her sexuality, is reliant upon her gender presentation and as a gender typical female she is concerned that she would be read as "heterosexual" instead of "gay." This is a concern for her because she sees it as possibly affecting her ability to fit in with that community that she loves in Portland. Geri talks about Portland as having such a great community and is still struggling with how to "fit in" the community without changing her appearance.

Later in our conversation Geri discussed how she connects to different communities in her life. One way in which Geri feels a connection to the queer community is through gender enactment, even amongst her heterosexual friends. Geri states:

When I hang out with my close hetero friends, I feel really bad calling them that, they are my close friends, Heidi and Brittany, I feel a little bulkier, like I take up more space. Not like physically bulky but just not clumsy, but do you know what I'm saying? You know when you walk kind of bulkier... I walk bulkier than them. But I guess for me from the outside it looks like the same... Well I feel more connected to the queer community when I'm "bulkier" when I walk "bulky" than when I don't. But it's too bad. Because I shouldn't have to feel that way. I mean whatever, we have lots of ranges and personalities, but yeah. ... It [walking bulky] makes me feel like I'm exuding more “queerness" (laughing).

In this narrative, Geri talks about how her connection to the queer community is through performativity. It is through her own understanding as how she presents herself - as neutral - but it changes based on her social location and who she is interacting with. Clarifying her own conception of herself she informs me of how she feels different on the 
inside, though it may not be visible on the outside. At the same time she is disconcerted about the fact that based on her outward appearance, she misses out on connecting further to the queer community. On the other hand she acknowledges how outward enactment is connected to her identity and how she feels. For her, her bulkier walk exudes her own "queerness" which in turn enables her to feel more connected to the queer community. Additionally, her doing of "bulky" not only addresses her gender, but also, at the same time, is connected to her sexuality and how she constructs her identity around potential queerness.

Geri's narrative gives insight in how she constructs her gendered and sexualized identity through 1) the desire to have that great community, 2) taking into consideration how she thinks she is being "read" by the local community while at the same time 3 ) enacting "bulkiness" as a way to exude a particular sexuality.

\section{Lauren: Part of Being a Woman is Loving Other Women}

Lauren, the 24-year-old gay woman from earlier had discussed how her sexual experiences impacted her identity but also told stories of how she experiences her gender and sexuality as connected. She kept (re)stating that part of being a woman, for her, is loving other women and that the two - gender and sexuality - are intrinsically linked. It is hard for her to extrapolate what aspect of her identity is only "sexuality" and which part is her gender. The following narrative is Lauren's response to the question "Do you think that you experience your gender?" Lauren had talked earlier in our interview about the fact that she does not notice her gender in a "normal way" but rather her focus on 
gender is in relation to growing up in a patriarchal society and the fear that that brings being a woman.

Depends on who I am around. (Thinking) I think, among queer people, I experience more ... unlike. I mean like being a lesbian. Like (thinking) uh, I don't know how to explain this. A third... like with strangers and stuff, I find that I get in trouble more. And I think that is because as a woman you are expected to be a little more, like you are supposed to defer and be quieter and not as outspoken about things. And I'm not that way. And I see boys get away with things that I get called out for, quite often. So I run across a lot of that...

And then, not being incredibly feminine and walking the line of androgyny in my aesthetic appearance. I 've walked into a room and watched people be very uncomfortable. I've also experienced the not fitting in to the gender that people expect you to and how uncomfortable everyone else gets.

Lauren's notion of experiencing her gender was when she was around queer people, but also about the lack of equality that exists in the world because of the patriarchal society. For her, gender is something that is evident when she acknowledges the stereotypes and expectations of what it means to be a woman. Particularly for her, this acknowledgement comes from feeling others around her be uncomfortable because of her lack of conformity to those stereotypes. Particularly she sees her self and being the opposite the "woman stereotype" because she does not defer to men and is also outspoken and louder than the stereotype calls for.

Lauren brought up that for her it was about how her gender enactment blurs the lines and she "walks the line of androgyny." Her androgyny is not just through her "unfeminine" characteristics but also her style, which she believes to be connected to her sexuality. As a queer woman she told me the following narrative of how the specific constructions of gender affect the way she is treated by others. In Lauren's life, at times, 
she has maintained hegemonic ideals of fashion and noticed the difference in treatment between presenting herself as feminine or masculine. This narrative arose when I asked her to clarify a response in which she discussed both sexuality and gender; specifically how she experiences her gender in the queer community.

They are so connected for me. As I said before, part of that, when I think about my gender, its like inseparable from the fact that I sleep with the same gender. That gender does, that my gender only comes out because of that. Well I kept saying within, experiencing my gender in the gay community kind of manifests in the fact that I only hang out with lesbians, pretty much. (Sigh) It's really hard to articulate these things. I think I like, I experience my gender in the gay community, as a companionship and in common play ground with other peers. Kind of similar to, they're totally, I can't separate them. They are one in the same.

Lauren grappled with trying to express her experiences as a gendered person separate from a sexual person. She explicitly stated how they are "one in the same" for her. However, when trying to answer the same question but utilizing sexuality, she says:

I'm having a really hard time with that because, the question, it is hard for me to pull out... like what my experiences with my sexuality and my experiences with my gender from my experience with my life. It is hard for me. It's hard for me to pick apart what's what, and say what is coming form where. I think it is easier for me to find ways in which I found ways my sexuality or my gender to be frustrating. Like I was telling you the cycle of discrimination, those things are easier for me to pic out but not my daily experience.

In this narrative Lauren informs how her sexuality plays a much larger role in her identity than her gender. At the same time she is unable to deconstruct each identity category from the other when talking about her own experiences, as is with an intersectional approach it is important to look at the ways in which matrices of identity create the individual and their experiences. As Collins (2000) states an individual does not and 
cannot experience one aspect of their identity as separated from the others. Though Lauren says she may experience her sexuality more, she still is cognizant of what role gender plays in her interactions with others, whether she is being treated differently or unequal.

Lauren is cognizant of the different treatment and as was stated earlier she is very aware of the gendering of the queer community. As a product of a patriarchal society members in this community are not strangers to the ways that gender have infiltrated everyday practices and interactions. The reward for her femininity comes with more attention and adheres to the heteronormative construction of (hetero)sexuality. One way in which she differentiates between genders is based on the reactions she gets from others around her. Lauren shares a narrative about clothing, aesthetics and desire.

I used to dress like everyone else in the room, I fit in pretty much. It was definite on the more... "masculine" side of normal, but after I came out, I was more willing to do things that match, mix and match things that I normally wouldn't wear. Push boundaries of style a bit more. I also started to go out more and wear dress shirts. Once I realized that I didn't have to wear dresses, changed the entire dressing up world for me.

I went through a huge tie phase. I have not donned a tie in 2.5 years, and I don't know what happened. I think I came here, and I hate walking into the room and wearing the exact same thing as everyone else with short hair. The thing about Portland, they know how to dress... I don't want to be one of everyone with a tie. I don't know. It's interesting how differently people will treat you when you are in a dress, when you're among gay people.

The use of aesthetics for reading gender becomes a way in which, according to Lauren, the gay community is gendered. The assumption that when she, or others are dressed more feminine, or feminine presenting, it becomes a site of passivity, or as the receiver. She noticed how when she used to dress more feminine, more people would hit on her, 
but especially people with short hair. It is interesting that Lauren, herself, genders her own reactions. She talks about gender aesthetics but specifically as it relates to her sexuality. Her acknowledgement of the impact of the gendered world is the way that people treat her depending on what she is wearing. When explaining in more detail what the "different" reactions were she says:

When I was in dresses, or wearing very girly tops, more people with short hair hit on you. I don't know more people hit on me in general.

The notion of femininity as connected to passivity translated into sexuality for Lauren. Her clothing style related to both her gender and sexuality but depending on what gendered appearance she express to the world may in fact gender her sexuality. Though she mentions how individuals, especially those with short hair, hit on her more, based on her feminine clothing and appearance. This illustrates one way in which gender can and is constructed with sexuality. Aesthetics and appearance played a large role in how Lauren interacted with people - the unequal attention, or "positive" attention, focused on her based on her gender performativity. As one who rarely dressed in "feminine" ways she was able to pin point the changes in interaction. This construction underscores the same hetero-normative construct of gender and sexuality placing those who appear more "feminine" in the passive position therefore making it normal for others to "hit on" them or make a remark about their appearance.

Lauren's journey of identity has been intertwined with her sexuality and her gender in which both play significant parts in her life. Nonetheless her identity is formed in the intersection of her gender and sexuality, which is at the same time constructed by her experiences with class and race. Lauren, was cognizant of her gender, but in ways 
that were unlike others that I interviewed, she acknowledges her gender when it comes to being the power struggle between females and males in a patriarchal society. Although Lauren constructs what it means to be female by loving other women, this connection of gender and sexuality play out in alternative ways.

\section{Mike: The Checklist in Childhood}

Mike shares a narrative about being feminine and wanting to be a "care taker." Mike is a 20-year-old white gay male who grew up in Portland, Oregon and was raised by his single mom. When talking about the interplay of his gender and sexuality he started in childhood; he explained that his mother is "definitely a feminine woman" and that he "had a lot of her mannerisms when I was younger." He has lived in Portland his entire life, except for the trips to visit his father in Tennessee. Mike talked about notions of gender enactment and analyzed his own behaviors connecting his gender and his sexuality. Mike new he was gay when he was in the third grade, which was a year after he moved to a new school. Although Mike recognized his queer sexuality at a young age, he, as similar to most queer youth, hid in a deep closet and utilizes the tools of masculinity to hide his sexuality. Mike's experience as a gay child was confronted with heteronormativity and frustration that led to a deep, deep depression. He relates his femininity, in his childhood, to the fact that he was raised by his mother and as such noticed how others treated him.

His retrospective construction of his childhood tries to connect hegemonic stereotypes of gender to his actual events. While utilizing this terminology the following is our conversation about Mike's childhood: 
Mike: I felt very different you know, before I was gay. People started treating me different, and I didn't know why. I was [a] very, very feminine little boy when I was younger. And there were a lot of repercussion.

Kym: can you give an example of how you were more feminine.

Mike: I guess, maybe I had a lisp or something. I wasn't as into sports, as most boys were. And obviously not as into the girls later on. And I, I'd rather be drawing or coloring or something, [other] than playing wall ball. It was much more passive, which is something that is [a] more feminine trait. And I was just shy and soft spoken. Not the normal boisterous little boy.

Kym: Feeling different, was it about your understanding of being more feminine? Or is that part of hindsight?

Mike: I mean no. I mean it was also, on the other hand, I was also, like most boys, where I liked Hot Wheels, and the typical gender specific things, but the things like the way I talked and acted, occasionally. I don't remember specifically because it was $2^{\text {nd }}$ grade. Little kids, like I had only one or two friends that year, and that was it. Being as innocent as I was, and wanting to be friends with everyone. I was also very friendly. I wanted to be everyone's friend, and care for everyone, which is another one [feminine characteristic]. It hurt me a lot. That definitely later on, it's a longer story, but it threw me into depression.

As a way to cope with being bullied, Mike started to censor himself. However, his narrative of his own story was self-analyzed in gendered ways. Some of the men I interviewed talked about being aware of their surroundings and starting to be more "selfconscious" about what it meant to be a "gay man," Mike's response was more in relation to the way he was being treated in school and by his peers. He talked about ways in which he tried to force "masculinity" out and hide the "femininity" in his behaviors. Now he acknowledges the androgynous tendencies within himself and that there are both masculine and feminine characteristics. This is the story he told: 
That as after the point I realized I was gay. I figured it out in $3^{\text {rd }}$ grade, the year after I moved to a new school. Then I was a completely different person. I forced the masculine traits to come out, or what little I had. I was still a sensitive guy, and that made all the girls like me instead, to my dismay. SO there was the awkward trying to be straight and date girls. Lie to myself and run away from that truth. And I was still, I mean, I still was definitely not competitive person. It was very seldom that I am, unless I'm with my family or [close] friends. But it is not a frequently occurring thing. And I wasn't, well I didn't talk about women, which is also not a masculine trait. And I had a lot more friends, like actual friends without any [sexual] interest, which is something that kind of threw my straight mail peers for a loop. "How can you just be friends with a girl?" well... I didn't tell them, but it was really easy for me. I see myself definitely, I have an androgyny quality to me, and I did then too. But I definitely have become more comfortable with that the more older [sic] I have gotten. And [after transferring to the new school] I tried to not to be too "girly" so I can make more friends. I didn't say things that often my mom would say like, 'That's really cute!' or 'That baby's cute!' My mom said [to me] "that makes you sound like a girl" and I was like "okay." It is hard to explain, I just, I just maybe even tried to walk differently. ... I mean at the same time I also lost all self-confidence. And that was when I started going into depression. And also completely going into the closet and sealing the door, and promise myself I would never tell anyone and never admit it. And other than that, I just became such an introvert that I was almost somebody nobody paid attention. Or if I was someone [that people] paid attention to, my femininity would come out occasionally and [I would] get defensive and be more masculine. But specifically how I did that, in the long run, I don't remember. I actually remember I did immerse myself in sports, I tried. But by then I was an overweight kid because of the depression and everything. So it was a little bit harder, I played kickball a lot. But that is a fairly androgynous sport, but a sport nonetheless. And so that is one more check for the "not-feminine" side for me. So I tried to do little things like that.

Mike had analyzed his past as part of dealing with isolation and depression and connecting his isolation as a child to the fact that he was more feminine. As a side effect of his isolation he completely immersed himself in "the closet and sealing the door, and promise[d] myself I would never tell anyone and never admit it!” He sees himself as 
someone who disappears in and was someone nobody paid attention to; however, there were moments of his own frustration around his cross gender behavior of being more feminine that led others to notice him, which he then over compensated with masculinity and competitiveness. Part of disappearing or trying to fit in Mike tried to walk differently but also at the same time "played kickball a lot." Even though Mike acknowledges that kickball is not a "traditionally masculine sport" it was still "a sport nonetheless" which gave him "one more check for the 'not-feminine' side." This doing of gender for Mike became a real part of his identity - for him he performed a particular type of gender in situations, but he saw is as a performance within himself, something that was unnatural and forced. Mike's construction of masculinity is prescribed from society's constructions of hegemonic masculinity. Mike's checklist was something as a tool in order for him to keep his own identity in check and to hide his femininity. This hiding of gender atypicality during childhood is important in Mike's (re)construction of his current identity. He still sees/analyzes himself by the dichotomous categorizations of gender, but is more willing to express what he feels inside which is both femininity and masculinity. Though at the same time he told me stories of how he wished that his gender fluidity was more readily accepted and could be connected to his queer identity.

For Mike, playing sports became the symbol for "proper" gender conforming, in which he tried to fend off feelings of "otherness" and hide his "feminine side." Mike wanted "to be everyone's friend" and was hurt by the stigmatization he faced as a child based on his gender performativity. His narrative was filled with gendered categorizations that came to represent how he felt about where his identity started. As stated, he is aware of the privileges associated with heterosexuality and therefore the 
social, political, and legal repercussions associated to homosexuality. He expressed narratives of trying to reconcile the differences between how he sees himself and the expectations based on his gender. These struggles started in childhood and had they not experienced this conflict, their identities today might be different. Many individuals still spend a majority of their lives in the closet and as much as our society has progressed we are not in a post-sexuality world. The differences between heterosexuality, homosexuality, and other forms of sexuality are placed firmly upon a hierarchy in which power and privilege are given to those on the top.

\section{Gabby: The Journey of Desire}

Gabby is a 27-year-old self-identified pansexual queer who grew up in New York and moved to Portland to attend graduate school. She was raised in a heterosexual two-parent household whose mother was a stay-at-home mom, while her father worked outside of the house. She told stories about her large extended family and the fact that she was the "girl" in the family. Surrounded by males, she said she often felt polarized as a child for constantly being left out of "boy things." She has a brother who she described as very stereotypically masculine, jumping off vans, grunting and started weight lifting at a young age. She said he was the leader of the under-class gang of males in their hometown.

She was highly cognizant of how gender was shaped in her childhood and that what options were available to her as a female have shaped both her gender and her sexuality. She explained how she never felt as though the strict gender stereotypes that she was forced to follow fit her at the core. Gabby had learned later in life that 
alternative constructions of gender and sexuality were available to her. As a way to avoid being further pushed into the "feminine" box she asserted herself in her own ways. As she grew up she grasped onto feminism as a way to explore her own fluid identities at the same time participated in what she considers "gender nonperforming behavior." She explained this as utilizing masculine traits in order to advance her femininity. She participated in sports and did well in school throughout her entire life. Gabby shared with me her narrative of discovering her queer identity.

Gabby told a narrative about how she believes gender and sexuality are "more fluid than traditional understandings" and therefore she claims a "queer" identity. When reflecting back to her college years, she realized that is when her journey of this queer identity really began. She originally claimed a "bisexual" identity, which is common in the "coming out" process (Kaufman and Johnson 2004; Rust 1992). As different from the coming out process, she claimed this identity prior to having sexual relationships with women. She further clarifies:

The desire appeared as that relationship ended [her long term childhood love who happened to be male], the idea that it [queer] could be a real part of who I was came, I feel like I sort of sought it out. Because I never felt unhappy with my life and my sexual life, and my gender, and gendered relationships... I had to conceptualize it intellectually before I could understand it as an experience. Does that make sense? ... Yet still have identification with and enjoy relationships that were "straight," perceivably heterosexual because I'm not heterosexual, and even than that was true for me, but I didn't have the label for it. So yeah, classes in college that gender and sexuality is more fluid and yeah "I CAN DO THAT, " and it's not something that will redefine me because I didn't wasn't to be redefined. I just wanted a better definition of who I am. ME. 
In this narrative Gabby shares a time in her life in which she had a bisexual identity, which is different than her current identity, she is very clearly articulating her process of transitioning into a queer identity. For her, she acknowledged that in retrospect her identity as never heterosexual, though she may have been perceived to be in heterosexual relationships. Although, as with most things, hindsight is twenty-twenty and so the narrative here expresses her view of what was occurring as she started her journey in becoming queer. She never experienced the frustration as most did about sexuality or gender, but still participated within the heterosexual matrix of society. However, as one way to counter-act the hegemonic understandings of her own gender she had to intellectually understand the concepts of gender and sexuality. This was necessary in order for her gendered and sexualized experiences to be "legitimate."

Gabby states how with her current identity she feels her "gender enactment is a very masculine personality that is presenting in a very feminine way." For Gabby, she sees her gender as connected to her sexuality, but that her gender has many facets. Explaining her identity to me, she shared that her gender is more than clothing, but it is gendered attitudes, gender enactment, as well as prescribed from sex. Her narratives express notions of intersectionality in which she shared stories of constructing her identity through the use of dominant discourses. She adheres to a queer identity because for her, queer is "an umbrella term that allows for the most openness and fluidity and because [my] sexuality and gender have been fluid for as long as I have been able to conceptualize those things as tangible things that are moveable."

Her own construction of masculinity and femininity strays away from both hegemonic masculinity and emphasized femininity (Connell 1995; Connell and 
Messerschmidt 2005; Kimmel 2011). These constructions point to the ways in which identities are complex and fluid instead of static and stable. In explaining Gabby's identity as masculine but presenting in feminine ways, it provides insight into the ways in which individuals utilize the discourses available in order to constitute an identity entrenched in the processes of discursive subjectification regulated by discursive coercion (Bradley 2013; Foucault 1977). It is the discourses in society that provide avenues for the complexity of identity while simultaneously creates the ability of a queer identity. Although Gabby is not free from cultural and structural implications, she utilizes the traditional modeling - feminine and masculine - and incorporates them into her conceptualization of her identity. In essence, in forming her queer identity she queers dominant discourses of gender to better explain and "fit" her gendered sexuality.

\section{Sarah and Audrey: Dyke Conceptualizations}

Sarah and Audrey both utilized notions of sexualized gender when talking about their identities. Both Sarah the 27-year-old pansexual from earlier and Audrey explicitly utilize sexuality labels in constructing their gender. Both of the following narratives stray from the narratives that Gabby and Lauren told about connections of gender and sexuality; however, they provide insight into alternative constructions of the interplay of gender and sexuality. Sarah beyond talking about her queer sexuality talked about how she had wanted a change when she was 21-years-old. This change was in reference to her understandings of her own gender. She had been in a transition period in her life, meeting new people and creating new friends, but she knew something was not settling with her. 
She told a narrative about the importance of change in her life. It started when she "cut off all my hair, I looked more DYKEY!!!" When I asked her for clarification she continued, "I've been always very fluid and at that moment I wanted to look rough, ... I no longer wanted to look feminine appearing." In this narrative there is an explicit link of her gender to her sexual desire for women. Dyke is a particular label associated with women who love women, and a connection of a particular look, in Sarah's case "rough" or not feminine. This led to an identity entrenched in sexual desire. The following narrative arose when I asked Sarah to discuss "dyke" and what it means to her.

Kind of dykey to me, is when I say I'm looking dykey or when me and Amelia are "dykey" today. It is like, not showing your boobs (laughs) just to be literal. Not like...Presenting your form in a more less curved way. And then, generally short hair, though it doesn't have to be short. But a lot of it is posturing. I would really say that a lot of it is body posturing (puffs her shoulders up and out)... An aesthetic of toughness. It's more like, it's just looking dressed down, no real form, no form, like feminine for per se, and physical posturing. ... I think that being dyke is super awesome... Oh man, I communicate with the way I dress. If I, because I'm very fluid in my mind, I've never really been feminine, but sometimes I feel more sassy or slutty. ...

Sarah is talking about her gender aesthetics in connection to her gender presentation. She wanted to be less "feminine" in form, shape and posturing, and she used a sexual identity label to express this conceptualization. This understanding of her gender presentation is conflated with a label of "dykey-ness/dykiness" in which "dyke" is culturally associated to the lesbian label, especially historically and in some cases currently as an epithet. In addition it can be associated with "butch" lesbians, or "butch" in general. Furthermore, Sarah's own understanding of having this dyke identity is connected to gender, and as she stated, "doesn't have to mean that you are cis-bodied female who is [in a relationship] 
with a female person." Nonetheless, the imagery that the word "dyke" provokes is constructed in our minds through the use of identity language, which Sarah utilized to express her gender presentation. Sarah has restructured her presented identity as "dyke" in connection to gender, though still address a sexual orientation, which is dyke (or "butch" lesbian).

Sarah's own construction of dyke sexuality is has more to do with attitude and sexuality - in general - rather than a label. In further explaining where "dyke" comes into the picture for her she talks about her sexual desires.

And I say that [being sassy or slutty] in a positive way, ... And sometimes I want to put it out there. That I, I'm frisky and sexy. And then sometimes I want to communicate that I'm together and strong-minded, like or "butch" in my mind. That's a communication to people that I want to have sex with, the people that I'm dating, because sometimes, depending on who I'm dating, I'll switch it up, but sometimes there are certain roles that I like with certain people.

Sarah has been able to reclaim this dyke identity and use it to express not only her gendered performativity but at the same time her positive constructions of sexuality. Her dyke identity is something that occurs in her mind, but allows her to have a strong sexuality that is "out there." Sarah, throughout telling her narrative, constructs a journey that not only focused on the role of sexual experiences but also explains herself as a combination of gendered sexualities. Sarah's dominant discourse is one of fluidity in which both her gender and sexuality are constructed through a queer discourse.

Audrey was another woman who utilized the "dyke" identity when talking about her gender. Audrey is a 26-year-old self identified cis-female queer dyke. Audrey was raised on the West Coast, in northern California, and lived in Massachusetts for college. 
After living in both Connecticut and Massachusetts Audrey moved to Portland about three or four years ago. As a child Audrey felt like an outsider and that she "wasn't a normal girl." She told narratives about how she always felt comfortable being assertive and talking about sex, and feels that these attributes are highly connected to her dyke identity. Although Audrey came out an early age, she still had sexual relations with men afterwards and did not end up having a positive sexual experience with a woman until her senior year of college. Upon initially coming out Audrey, as similar to others, utilized the "bisexual" label, but than realized that "bisexual doesn't fit because I'm much more butch than that." Audrey's understanding of identity, in this case, the difference between bisexual and her current queer identity, relies on a gendered presentation of butch-ness. This assumes that a bisexual female could not be "butch" or "mannish." In the narratives she shared, she continued to link gender aesthetics to sexuality.

Understanding Audrey's own journey, the following narrative sheds light on the particularities of her gendered sexuality.

Audrey: I identified as bisexual, from the middle of high school to the middle of college. And I finally realized that "BISEXUAL" doesn't fit, because I am much more butch than that! ... I'm burly, I'm kind of mannish in a lot of ways.

Kym: And by butch you mean? You're referring to?

Audrey: Gender presentation... like I had long, long hair until my senior year of high school and then I briefly identified as a lesbian and I cut it all off and I had this spikey thing! And it was bangs in the front; it was very cool. Very "dyke" sort of thing, and I wore mostly men's clothes. It was great! I stopped getting lots of male attention, and then well I found myself a boyfriend (laughing) and he was, he was very girly. It was the closest thing I could get to a woman at the time... But I sort of held that internalized homophobia for a long time. And I acted in ways that made me seem more "straight" than I was... I would wear sort of typical 
"girly" stuff; I went through a few phases where I would wear make-up and heels... And how I felt like a big fat phony the whole time. As if "this is not who I am!" But even when I did wear baggy men's shirts, I felt good in my own gender identity because it is comfortable and what I wanted to wear. I would still feel like "Well... Being a dyke makes me an outsider, and being feminine makes me feel like I'm an imposter," and so I was torn between those two identities. And having boyfriends, and having sex with men did not help the situation. I knew I was a dyke, but I kept on having sex with men.

Audrey speaks about how "dyke" for her is being both a gender presentation, for example in the first part of this excerpt, and her sexuality. She addresses how her gender, as burly or mannish or butch, relates to her hair length and how at the same time it speaks to her feelings of "internalized" feelings. For example, she had the internalized homophobia, and though she presented herself in a more gender atypical way, she was sleeping with men, but knew she wanted to be sleeping with women. However, the ability to address her "true" identity and the aspects of herself that revolve around the desire to be with women was expressed as her "dyke" gender understanding, even though her sexual life at the time was contradictory.

Audrey, in a later part of the interview informs me how playing with gender is essential in her identity, and gender can be, for her, something that is manipulated in order to express the sexual desires. This conceptualization arose after Audrey moved to Portland. In the narrative she described the differences between Massachusetts and Portland, and how sexuality can be read through gender enactment. The following narrative does not explicitly address her "dyke" identity, as the previous narrative, but it addresses how for her gender presentation was something that enabled her to further explore her sexuality. While discussing her gender, at the time of the interview, she 
states that her current gender is the most stable it has ever been and Portland, and the community here, has a lot to do with it. Audrey explains:

I feel like Portland in general allows people to play with gender. Playing with gender is part of the culture here and it is totally okay... You know my whole life I have seen gender as something to be played with. It is something it is fun to dabble here and there with certain gendered things. And maybe that is what made me feel different growing up, I was okay playing with gender and no on else was. And it made me look different and everyone saw me as different because I was wearing things only boys wear, or doing things that only boys do. So yeah I think playing with gender has been a theme my entire life, but the community in Portland just makes it much easier.

Audrey understands the importance of place in her own identity construction, specifically the stability of her gender. Her narrative relates how the culture and community of Portland offers her the ability to play with traditional understandings of gender, specifically in appearance.

Audrey acknowledges how playing with gender plays a large part of who she is today, and that Portland plays a large part in it. Portland is known for being a queer utopia and for some this preforms how these individuals address constructing their identities. In fact, gender aesthetics, for Audrey, appears to play a large part. Though she diverges slightly from others I interviewed, by not being concerned for her own intelligibility, but rather she is able to construct her identity with a more fluid understanding. Audrey's current conceptualization of her identity is that of dyke, but acknowledges that Portland was important in her journey of gender exploration. The queer community here in Portland, can help enable the shift in identities that addresses the fluidity between gender and sexuality and as Audrey states "Portland gives people the opportunities to play with gender." 


\section{Conclusion}

Some of the narratives shared moments of childhood in which it was and is important for these individuals in how they began to construct their gendered sexuality and looking at the interplay between these two axes of identities. Many of the narratives connected gender and sexuality either through cross gender behaviors and how gender intelligibity is deeply in effect in our society, in which certain gendered characteristic and enactments if with the "proper" sexed body denotes a certain sexuality. The connections to gender intelligibility were expressed through notions of "not fitting in" with this hegemonic model. In many cases the individuals I interviewed discussed how their gender atypicality led to a feeling of difference, or rather as they got older they started to understand that they themselves were not the same as everyone else. This feeling of difference started their journeys in constructing the interplay between gender and sexuality in their lives. Childhood and young adult gender and sexual performativity became a place for resistance, strength and sadly also the closet. The narratives about childhood address the ways in which participants' understanding of their current identity started years ago. They made sense of their past as it relates to the present and in doing so utilized a particular discourse that was recognizable and true for them. While other narratives of the interplay of gender and sexuality expressed the snapshot of identity at the time of the interview.

Conceptions of gender and sexuality are often constructed as separate entities of identity; however as has been apparent through the narratives above, individuals narrate their own journeys of identity as it relates to both gender and sexuality. Individuals have multiple facets of identity (Collins 2000; Crenshaw 1989, 1991; hooks 1989) and as such 
experience those as intersecting components of themselves. The individuals I interviewed utilize heteronormative constructs of identities that play into the regulatory regimes in which society has a specific discourse available to discuss and construct identities. These individuals share moments of their journeys that give insight into how gender and sexuality are interconnected in their lives. Whether they explain their identities as interchangeable such as Lauren, in which she was not able to extrapolate one part from the other, or Jennifer who utilized the same descriptor for both her gender and sexuality. On the other hand, concerns for intelligibility became a large aspect of individual's identity and how they utilized gendered cues to try and assert their queer identity. All in all invisibility and intelligibility were important concepts in understanding how gender and sexuality are intersecting in these narratives. 


\section{Chapter Seven: Discussion}

\section{Introduction}

This chapter reintroduces the research question in light of the findings and the narratives presented in the previous chapters. The narratives were grouped in organizational categories to get a snapshot of how these individuals constructed their identities and the journeys they went on during the process. The previous chapters discussed the importance of race, sexual experiences and the interplay of gender and nonheterosexuality in constructing gendered sexualities. Throughout these narratives it became increasingly clear that the language they used shaped the individuals' perceptions of their gendered sexualities. Language has the power to shape and preform what our minds are drawn to (Lakoff 2008) and as language is shaped by the institutional and structural implications so too becomes our identities. Language has the ability to be split into notions or intention to mean or to signify (Derrida 1991). It presents the opportunity to represent some form of mental thought or communication but also in a sense of representing something, in this case particular forms of identity. In providing a representation there is the connection to repetition and/or a reproduction of an original (Butler 1990, Derrida 1991).

This reproduction is explored in this research by the ways in which the twenty participants represented their identities in relation to forms of power. According to Butler (1990) the juridical structures of language and politics constitute the contemporary field of power and it is this power that structures the way in which individuals present/enact their gendered sexualities because it shapes the culture in which people 
learn and do and limits the opportunities for individual expression. Language holds the power to verbalize but at the same time language is limiting in understanding because it points and names and therefore one loses alternative options of being, thinking, and expression. Throughout the narratives shared it became apparent that language was the crux of identity but there was also a journey that occurred therefore their narratives will be analyzed through two different lenses: 1) the deconstruction of or resistance to hegemonic discourse and labels and 2) through a linear social constructivist view of identity while ending with a discussion about how these two lenses can work together.

\section{The Deconstruction of or Resistance to Traditional Labels and Hegemonic Discourse}

Language is both reality and a representation and must be treated as such. The question to ask is how does an individual's use of language reflect their positionality in society. Throughout the narratives it was clear that childhood becomes the location in which the individuals started to understand themselves in relation to the world around them and an understanding of labels that followed them through their lives. There is a resistance to labels such as boy or girl, or rather the associations with those labels. Since language is purely a representational structuring aiming to communicate to others, these individuals told narratives about how they understand their own identities as separate from the label. It became clear that there were notions of parody in which the constructions of the true lived experience is compared to an 'original' (Butler 2000: 175) and that original is resisted by the individuals. These individuals expressed concerns of difference in which they utilized labels and specific worlds to categorize their feeling and their identities, but it was always as a comparative. 
Hegemonic discourses were rampant in the narratives these individuals shared. They, through the commonality of language, chose terms that would relay particular messages to their audience. The narratives involved the participants trying to make sense of the past, they focused on their relationships with friends and peers and attempted to fit their experiences within the structure that language creates and provides. The current language is set within dichotomous binary terms that create mutually exclusive categories and if an individual does not fit into one category then it is assumed that they are the "other." At the same time these categories are ranked hierarchically in which hegemonic masculinity and heterosexuality are placed on a pedestal. In heteronormative societies masculinity and maleness are rewarded and upheld as the norm compared to other (re)presentations such as femininity and femaleness (Connell and Messerschmidt 2005; Kimmel 2011). In the narratives shared there were feelings of difference but more specifically their understanding of being became structured through a hegemonic discourse within our gendered society.

\section{Race, Gender and Sexuality}

In the narratives regarding race, the individuals had complicated views in what their race and/or ethnic background meant in constructing their gender and sexuality. Specifically, those that shared narratives about their race discussed how race was something that bound them to particular stereotypes and how they themselves wanted to resist being boxed in by those confines. They deconstructed what it meant to them in constructing their gendered sexuality. Even those that came from a place of racial privilege there were explicit narratives about the expectations placed on them, specifically by religion. Those 
who were identified as white or Caucasian shared similar stories of the gendered expectations for girls and boys but their stories, for the most part, were not connected to race. Lucky to be the "norm" their journeys reflect the invisibility of whiteness in which it is not viewed as an identity status per se. Whiteness was not something that restricted their ability to be who they are but rather was rendered invisible in shaping their narratives. The privilege to freely construct a gendered sexuality appeared to only be in the narratives of those participants who were white; there was not necessarily the notion that their whiteness played into the dominant constructions of identities.

Those who held a racialized marginalized status were cognizant that their racial/ethnic makeup interconnected with other axes of identity providing a matrix of domination (Collins 2000; Crenshaw 1991; Espiritu 1999). Racial identities not only formed boundaries on both gender and sexuality but also acted as the connector for families, communities, and religion to be socializing institutions (Lorde 1970). For example, when looking at the narratives from Jay and Brandon it is very clear the role that both race and religion play in constructing particular boxes, they are cognizant that race and religion go hand-in-hand, however there were similar stories shared by the white individuals, but they only discussed the role of the church completely negating the racial aspect. Though the two types of narratives were almost identical the white individuals did not experience it as a fact of being white, because it was just "normal." Jennifer, also raised in a Baptist home, and others in their narratives ignored their racial identity as white for the most part, while those of a racial minority status were very clear on what 
being a racial minority meant in trying to break from those traditional boxes, labels, or stereotypes.

Those of racial minority status had similar but different narratives of both resisting labels and the use of hegemonic discourse in narrating their stories. For example, Andrew discussed how as "Asian" it is expected that he excels in math, does not disrespect his elders etc. He shared how he himself “doesn’t like labels" but knows that they play a part in his identity while he actively tries to resist them. The way in which he uses language is creating a particular (re)construction of his identity that is based on resisting the stereotype of "the model minority" or even that of being "gay." In his narrative he shares events and moments in his life that deal with the deconstruction of boundaries for what it means to be "Asian" and what it means to be white and also what it means to be a half-white/half-Asian gay boy. He is aware of the damage that stereotypes have played in his own life but is frustrated by the lack of openness that categories present. As an Asian American, he is placed against the racial stereotypes in which there is a forced heterosexualization of desire, specifically placed on him by his family and his culture, in which as a male there are particular expressive attributes expected and that those attributes attract the "other" which in this case is feminine and female (Bradley 2013; Butler 1990, 1993a, 1993b; Hatfield 2010; Ingraham 2004; Lorber 2004). Andrew's narrative of the role of race in his construction of identity plays in well with Butler's ideas and how discourses peformatively create the categories where people locate their identities. Through his narrative, he shares how he explored his identity through regulatory discourses, which he attempted to resist, while at the same time 
expressed both a gendered and sexualized identity as a notion of being which diverged from the "truth" of himself.

Specifically through the resistance to/or deconstruction of the specific labels these individuals expressed narratives of how labels have been constructed by the dominant group and that they themselves are held accountable to those standards. As Collins (1986) argues controlling images and being an "outsider within" these individuals resisted the labels attached to them, but at the same time they understood both worlds that they constructed their identities within - that of marginalized as well as from the "outsider" in. These individuals are capable of seeing the construction of labels as placed by dominant society while they take pride in self-defining their identities (Collins 1986). The racial minorities who shared stories of their race, not only faced specific constructions of their gender and sexuality those identities were also racialized. Both Brandon and Jay shared narratives filled with how being African American placed specific "traditional" understandings of identity labels on to them. However, in their narratives they shared how they resisted these categories and understood that their performances of identity are not always intelligible - the notion that there might be a "truth" of sex, as Foucault ironically terms it, in which it is produced precisely through the regulatory practices that generate a coherent identity through the matrix of gendered norms.

One of the participants, Tyler, is Korean but had been adopted by a Danish family and grew up in a predominately "white" town and was the only person of color in his town, that he can remember. His understanding of race differed from the other narratives. 
Race became something that was stigmatized, but did not necessarily impact his own construction of gender or sexuality. He shared how since a "white" family adopted him they did not know how to address the racial differences between him and them and they did not understand why it would matter for him. His narrative about constructing his gendered sexuality was a resistance to both stereotypes of race and specifically of gender. He shared the deconstruction that occurred as an adult in how for him the dominant messages sent about gender and sexuality were far to rigid and as such he had to break away from those.

Race in this case places specific constructions on those gendered categories that also become racialized; however, the narratives that the participants told addressed how they resisted those racialized and gendered categories in relation to their sexuality. Valocchi (2005) acknowledges that queer theory tends to fall short on broadening its analysis in focusing on identity categories, however by focusing on the narratives of identity construction it become clear that there is a specific deconstruction of existing label categories in telling their own stories. Race is something that is both invisible and visible in the construction of these narratives. Though most of the narratives shared in the race category were those of minority status that does not mean that race is only a viable identity for those that are non-white. Specifically what is the impact of race on identity? Is it the color of one's skin, the culture that they grew up in or something entirely different? The narratives shared expressed how there are multiple aspects that make up the role that race plays in constructing their identities. 


\section{Sexual Experiences}

Through both the (de)construction of and the resistance to hegemonic discourse these individuals highlighted the fluidity of understanding gendered sexualities. Sexual experiences, specifically, became a site in which deconstruction occurred. There were narratives relating to how sexual relationships were pertinent to the identity that these individuals claimed. A majority of the participants spoke about how the labels that exist within our language do not allow for a comprehensive view of who they are and instead took agency over the labels - broke them down and through language reconstructed the label so that it better explained their experiences and who they are. Disciplinary regimes and the construction of bounded epistemologies limit not simply the recognition, but the very articulation of alternative ways of knowing and being which is why assimilated labels as connected to queer can lead to a perpetual understanding of "outsiderness." This state of marginality may not be viable, but at the same time produces opportunities to resist marginalization itself through the deconstruction of those epistemologies.

Stories of sexual experiences spoke about how for some these experiences became the impetus for a redefining or reimagining their queer identity, taking on a new label that better encompassed who they are. At the same time, the narratives of sexual experience was described within existing labels in such that the way that these individuals talked about how they experienced sex were shaped by the labels attached to it. For many the labels around gender, desire, and sex were originally restraining their identities and so until they reframed the meaning of those labels through deconstruction they were not able to have the "full queer experience." Even focusing just on desire, the 
identity label structured or superimposed ideas of who they could be sexually attracted to, this was specifically the case for the female participants.

Previous constructions of identity categories such as sex, gender, and desire have been conflated with one another however there is a "whole range of sexual desires, dispositions, and practices that constitute sexuality" as separate from part of other identity categories, and by focusing on the performative aspect of sexuality and desire identity labels become deconstructed (Valocchi 2005, p. 751). Even in the case of the male participants, specifically Charles, he discussed how the identity label does not work and so he casually identifies as "single." The deconstruction of a bisexual identity came to him as based upon the specific expectations that were associated with the labels and he did not understand specifically the importance of keeping a label that was not true to his own experience.

Queer theory has enabled me to analyze these stories in a way in which if one was to continue to separate gender from sex from sexuality it reifies the belief that an individual has only one of those categories and that that identity is static and fixed through life. Separating gender and sex reaffirms the notion of the fixed core self that is isolated from other matrices of identity; however as is apparent through these narratives dimensions of identity overlap with one another in which gender can be sexualized, racialized, classed, etc. In fact shows how dominant taxonomies fail to address the true "complexity of individual gender and sexual subjectivities and practices" (Valocchi 2005, p. 253). Therefore the further compartmentalization of identificatory categories negates the existing fluidity and complexity within individuals. 
The narratives of sexual experiences specifically address the ways in which dominant labels do not address the complexity of identity. Sexual experiences were an impetus for many to start to claim a queer identity but as demonstrated through the narratives those experiences the individuals broke down the specific assumptions of identity labels which were then (re)constructed around their experiences. Specifically in the case of those that were gender typical there was an alignment of their appearance to their gender in which their ever-evolving identities are connected the confounding of gender and sexuality. These narratives complicate the categorical simplicities within culture to show that there is a continual movement to challenge the hegemonic ordering of the sex/gender binary in which individuals deconstructed specific labels. By deconstructing these labels and focusing on sexual experiences it highlights the ways in which current conceptualizations of individuals' gendered sexualities can be connected to the opening up of "new pathways for self-development and life satisfaction that were previously unimaginable or unforeseeable" (Green 2010, p. 317). Furthermore sexual experiences are important in connecting ideas of identity to the understanding of being structured through a hegemonic discourse.

\section{Connections of Gender and Sexuality}

As has been apparent through out the narratives gender and sexuality are not separated aspects of an individual's identity. The narratives presented in the gendered sexuality aspect address how labels do not adequately address multiple layers of identity. Specifically looking at the relationship of gender and sexuality there is the notion of intelligibility that was a large concern for many of my participants. In discussing their 
gendered sexuality and how these aspects "are not separate" the participants focused on what labels they used in order to construct their identities and how those labels became a place for deconstruction. They shared stories about how the identificatory labels themselves required a deeper break down of how it applies to their own lives in order to catch a snapshot of their identity narrative.

When listening to Mia's narrative, she talked in relation to "butch" but at the same time there was a resistance to that label as she continued to talk. Her adaptation of tomboy to her adult identity, though formed in childhood, becomes the point of resistance. Tomboy is not only her gender but also addresses a multitude of concepts such as being a girl, but at the same time "being a boy" and this notion of being for her was wrapped up in the label of tomboy. At the same time her use of tomboy informs a specific time in her life and others with similar pasts; tomboy is generally associated to a particular stage in development and childhood that is connected to gender atypicality (D'Augelli et. al. 2008, Hiestand and Levitt 2005).

Discourses surrounding gender and sexuality are connected to that of generation (i.e. early or middle childhood) in which children's gendered and sexualized childhoods are placed in the larger context of having normative identities that are intelligible (Renold 2006). She utilizes "tomboy" as a way to address her gendered sexuality in which she sees her attraction to femininity but at the same plays out heteronormative desire in which her "tomboy" identity allows her to "be one of the boys." Here the parodic signification (Butler 1990, 1993a, 1993b) of tomboy better reflects her inner connection of herself than that of "butch" which is what some may ascribe to her gendered sexuality. The pairing of the tomboy identity to her feminine desire allows Mia to conceptualize her own desires in 
a way in which normative labels would not allow or address. However, through the use of language Mia deconstructs these identificatory assumptions about her gender and her sexuality so that through the regulating modalities of society and labels, her narrative addresses the essentialness of being. Mia expressed her childhood as connected to the current identity and though she was cognizant of the heteronormative discourses and interpretations of labels, she resisted normative meanings and (de)constructed her own labels to accurately highlight her journey in a gendered sexuality.

Notions of intelligibility were key in understanding the ways in which these participants broke through regulatory regimes of gender and sexuality. Resisting dominant modalities these participants discussed the ways in which in order to narrate how they enact gendered sexualities there is the need for the breakdown of boxes and expectations. How do notions of gendered sexuality relate to the breakdown in expectations and boxes? For many of the participants they discussed how their (re)presentations of their selves were within the dominant label however they broke down the boundaries between categories in sharing their narratives. Specifically the few women who utilized the label of "dyke" to address their gender, not only focuses on the interplay between their gender and sexuality but also the ways in which that label is reconfigured as a way to address both gender and sexuality. Through the deconstruction of labels these individuals address the fluidity within identity categories and point to the ways that constructions of identity are complex than previously conceptualized.

Language became a large part of the narratives specifically relating to the interplay between gender and sexuality. Many of the participants explained how they felt restrained, constrained, and wrongly defined by the use of language. Since it was an 
important aspect for them, they focused on what language they could use to better explain their selves. It also became an aspect to analyze in order to focus on what conscious construction of language was used for the participants to discuss their gendered sexualities. Overall through the use of language these individuals deconstructed traditional labels of identity in order to narrate their own identity formation as connected to stories of race, gender, sexuality, and sexual experiences.

Specifically for Mike and John, they focused on how traditional labels could be manipulated in order to better accommodate their feelings and conceptualizations. More or less, for both of them, they aimed to understand how hegemonic masculinity could apply to their lives, and they found that it applied by resisting the specific understanding of what it means to be a man. It became increasingly clear that for them sports was the avenue in which they attempted to be masculine, but even with that, they did not fit the label and thus resisted it. Mike told narratives about keeping his personal checklist of characteristics as a way to monitor his own behavior and try to fit the model of boy or man; however he soon realized that his identity and who he is connects his gender atypicality to his non-heterosexuality and that he is both feminine and masculine and is going to resist the normative construction of male which in this society equals hegemonic masculinity.

Queer theory enables an individual to analyze the data in a way that acknowledges constitutions of power, privilege, and notions of being as connected to the power of language. Notions of identity, with a focus on reiteration and repetition allow for the deconstruction of and resistance to both hegemonic discourses labels and allows for the identificatory labels to be understood with a notion of fluidity. Specifically 
understanding how desire may be a better way to conceptualize sexuality but also acknowledges that desire is and can be gendered.

\section{From a Linear Constructivist Lens}

Constructivist developmental perspectives focus on individuals' abilities to develop by constructing the meaning of and relationships among multiple identities through internally defined perceptions. The emerging constructs of an individual's identity starts at the stages of infancy and can build into a crisis by adolescence (Erikson 1968). I focus

on the development of gendered sexuality and this section will re-analyze the data honing in on the journey that the participants went on in regards to coming to terms of their unique identities. By highlighting the journey, some participants discuss milestones or stages that individuals go through in order to reach their identity. These individuals shared narratives in relation to how they constructed their identities in relation to interacting with others and incorporating their social experiences.

This analysis will construct narratives based on milestones in relation to stage theories of sexual minority development. Childhood became the first point in which almost all of the participants shared stories of being different. However, during the retelling of their story it may have been superficially connected to their non-normative sexuality. Specifically focusing on the narratives relating to the interplay of gender and sexuality, Mike shared with me his childhood which was strife with gender atypicality in which case he was "very effeminate and not a normal boy." This effeminacy for him led to the over emphasis of masculinity in order to hide his gender performativity. The 
linear models generally focus on how gender atypicality as a child is often related to homosexuality as an adult (D'Augelli et. al. 2008).

Notions of difference are apparent for the participants and they all constructed narratives in relation to this difference. However, there was one participant - Charles, who identified as questioning or "single" - who did not follow this same path or did not share his notion of difference at any point of his narrative. Since Charles diverges from this first stage it supports the understanding that linear models are far from universal and are based on a specific normative gay identity, which is often male and white (SavinWilliams and Diamond 2000).

Some linear stage developmental models address the differences between groups of individuals, specifically the role of gender in the stage development (Rust 1995; SavinWilliams and Diamond 2000). Women who identify as "lesbian" usually first come out as "bisexual" as a way to acknowledge their same-gender attraction but still perform heteronormative desire. In understanding the process for claiming a particular identity many of the females in this project shared this trajectory. They shared how they had realized their sexual attraction to women but felt as though, depending on age, they were still constrained by society and felt as though coming out as a "lesbian" was not acceptable and thus claimed a bisexual identity. However, for Sarah it was after she claimed her lesbian identity that she realized her love for a male-bodied individual and was fraught over it and so changed to an identity label that better addressed her sexual desires. On the other hand, this was not a trend that I saw within the male participants that of coming out as bisexual and then claiming a gay identity. By honing in on the 
journey of identity development the males came out as gay and for the most part maintained a salient gay identity.

The existing stage developmental models of sexual minorities places linear construction and restrains how 'identity" is formed and though some suggest the changing of identity (Rust 1995) it still does not quite accurately reflect the fluidity of identities as suggested by others (Diamond 2003, 2008; Savin-Williams and Diamond 2000).

The stage models address milestones in a multitude of ways but all are generally focused on that first feeling of difference and then tend to move into understanding sexual experiences. Although same-gender sexual experiences are not necessarily required in claiming a queer identity this has shown to be important in both coming out models and for my participants (D’Augelli et. al. 2008; Kaufman and Johnson 2004; Savin-Williams and Diamond 2000). The impetus for claiming an identity is often seen as connected to sexual experiences; however if one was to reverse the sexual categories that are being discussed, I would argue that those who identify as heterosexual do not necessarily have a sexual experience prior to claiming that identity nor does everyone in this study. There was a consensus from the participants that sexual experiences with the same-gender are important to their identity as queer but not necessarily the cause of their queer identity. This consensus arose from individuals sharing narratives about their first time or in retrospect the understanding of their desires away from experience. Even those that had not necessarily had their first experience during development they had talked about the hypothetical if they had had sexual experiences with the same gender they might have come to their queer identity sooner. Specifically those who adhered to traditional 
stereotypes of gender often shared how they did not, because of fitting into the norm, question their sexuality until having the opportunity to have same-gender sexual experiences.

Upon experiencing sexual encounters with the same gender, the next step collectively in these models is the claiming or self-labeling a non-heterosexual identity. Many of the participants focused on different reasons for claiming their particular queer identity. For many this identity preceded sexual relationships, or it coincided through exploration. As is consistent with Savin-Williams and Diamond (2000) and Kaufman and Johnson (2004) females often self-label themselves based on the emotional relationships they had instead of sexual ones. Specifically in constructing their narratives many of the participants talked about that "special friend" or the best friend and how in retrospect that "friend" relationship stood in for emotional relationships that are usually connected to sexual desires. Sarah's narrative addressed this in the clearest way in which she talked about how she had cried and was depressed for weeks after her best friend had moved away, and it was not until later that she realized she had been in love with her. She had shared how in that relationship they used to cuddle when they had sleepovers, and spent all their free time either "hanging out" or talking on the phone. Either way, whether it is sexual relationships or emotional relationships it is clear that particular types of relationships with same-gendered individuals are key, in relation to the stage development models, in the formation of a salient identity.

The final stages of sexual minority development models addresses the salience of a "homosexual"/queer identity. According to Cass (1984) those final stages address the searching for community as well as when there is no longer a separation of the 
homosexual identity and other aspects of the individual, in which they come out of the closet completely. The search for community was apparent in a majority of the narratives told; though discussed in a myriad of ways. For many the notion of a community is a way for them to better conceptualize their "new" identity. Some of the participants discussed how after coming out they initially sought out resource centers, support groups, or just other queer people in order to understand what being queer means. As one of the participants put it "It is not as though you get a letter from Hogwarts that says 'Hey! Welcome to the club!" that was then followed up with a list of everything you need to know about being queer. There was a consensus amongst participants, specifically the females, in which they discussed how the learned to be gay which was connected to this idea of community. They discussed it in relation to either having people, other queer people, introduce them to "queer culture" through, music, movies, books, bars, clubs, neighborhoods etc. or by being introduced to other queer people. It is said that communities often emerge in specific places, typically where there is a ghettoization, such as the Castro in San Francisco, or Greenwich Village in New York and is key in the formation of a salient gay identity (Adam 1995; D’Emilio 1983; Seidman 2002; Stein 1977). Having this community is important for the journey that these participants went in developing their queer identity.

By working through the linear stage developmental models it is clear that there are particular processes involved in constructing a salient identity. By the time an individual is open and out about their sexual identity it is believed that, based on these linear models, they have progressed through the multiple stages in their development. 


\section{An Interplay of Resistance and Linear Constructivist Lens}

The first step to integrating these two different theoretical perspectives, queer theory and sexual minority development, is to recognize the strengths that each bring to the discussion. Depending on the focus for analysis, queer theory brings the ability to deconstruct existing categories and recognizes the problems with having static and compartmentalized categories. While on the other hand, the sexual minority development lens allows an analysis that focuses on the journey or the process involved in forming an identity. Each lens has its own strengths, which can compliment each other. For example identity theories highlight the journey but it does not necessarily recognize the possible nuances in identity. Additionally, through a queer theory framework it allows for an evolution of performativity. Though, queer theory has been critiqued in which it is said to fall short in functioning within hegemonic categories and does not necessarily create an understanding based on consensus. This is where the strength of sexual minority development can be used in order to better understand these social phenomena.

For this study, I am not extensively utilizing identity theory or linear social constructivist models however as a researcher, I feel as though they both are valuable forms of analysis. As was exemplified in the linear constructivist model section it can be commonly used for telling "coming out stories" or analyzing the process involved in an individual's sexual development. This has allowed for the analysis on the role of community to be highlighted, and how community is important in forming a salient identity, which was missing from the queer theory approach. The linear social constructivist model can be adequate to supplement queer theory and makes this research better translatable to other theoretical foci such as identity theory. The linear 
constructivist model highlights more of the journey or stages of identity development that the participants went through. Focusing on this approach creates a model in which individuals can be held to a standard enabling a comparative approach to be utilized.

By queering sociological research the use of performativity of identity is highlighted and the nuances of the participant's constructions of identity are deconstructed. Specifically, a queer discourse of performativity elucidates the invisibility and fluidity of identity categories in which certain enactments of gendered sexuality arises. Queer is always an "identity under construction, a site of permanent becoming: utopic in its negativity, queer theory curves endlessly toward a realization that its realization remains impossible" (Jagose 1996: 4). Nonetheless, it has been critiqued at the level in which its endeavor to deconstruct the existing categories at the same time constructs those categories. Queer individuals can utilize the discourses available in order to constitute an identity entrenched in the process of discursive subjectification that are regulated by "disciplinary coercion" (Foucault 1977). This is exemplified in the section "Deconstructing or Resistance to Hegemonic Discourse and Labels." Specifically, the section that addresses how labels of gender, sex, and desire were originally constraining individual's identities, specifically Sara's label of "lesbian” preformed expectations of how she could express her sexuality. It was not until after she deconstructed that label she created a better understanding of her queer identity. Or in the case of the some of male participants such as Brandon there was a clear connection of his gender to sexuality in which, based on hegemonic understandings of gender, depending on his position, that of "top" or "bottom" there was a construction relating to 
the binary of gender; however, he utilized these "universal" labels but modified them and broke down the assumptions surrounding them, in order to have a fuller queer experience.

All in all both the queer theory lens and the linear constructivist lens enables different areas of analysis and can be seen to complement one another by picking up different nuances within identity. Additionally by placing an identity approach next to queer theory it broadens the ability for analysis and may make it more accessible.

\section{Chapter Eight: Conclusion}

In this chapter I will provide the overall message and argument of this thesis, or the "so what?" part, an overview of what was discussed in the previous chapters, the limitations of my research, as well as suggestions for future research.

\section{Performativity and Gendered Sexuality}

Throughout my interviews it is clear that narratives of identity, specifically gendered sexuality are more complex than originally perceived. It is important to note that postmodern and queer theories acknowledge that gender, when utilized as a way to organize society is the "the repeated stylization of the body, a set of repeated acts within highly rigid regulatory frame that congeal over time to produce the appearance of substance of a natural being" (Butler 1990: 43-44). When connected to performativity "performative acts are forms of authoritative speech: most performatives, for instance, are statements which, in uttering, also perform a certain action and exercise a binding power" (Butler 1993b: 17). As was exemplified in the analyses, the individuals in this project, through the performative power of language, declared and (re)constructed their gendered desires. Therefore, it is with this acknowledgment that language is power, as a structure, but also 
as structuring, which enables the static categories of identity to slowly deconstruct and become destabilized.

The individuals shared stories about their gendered expectations and by uttering/naming/performing "feminine" or "masculine" there were expectations in which certain behaviors, roles, and performances were expected to follow. However, what was discovered is that the modernist construction of identity labels does not address the complexities and nuances that reflect the true unique lived experiences. In fact through queering these notions of identity categories it signifies the importance of actions (including those that are performative) and not necessarily the actors/individuals.

Through the previous analysis of identity and performativity an individual's identity can only work to the extent that it is recognizable and can only be recognizable "to the extent that it draws on and covers over the constitutive conventions by which it is mobilized" (Butler 1993: 19). What this means is that the identities discussed are only intelligible through cultural categories. However, what the individuals, through their narratives, try to explain is how they use hegemonic discourse but muddle the categories in order to construct their identities. They shared stories about how their race and sexual experiences are critically important in understanding their gendered sexuality. In addition, how the ascribed categorizations as attached to their identities restrict and confine their possibilities until they acknowledged their inner "queerness." This thesis argues that the current categorical structures for gender and sexuality do not adequately encompass the true lived experience and are not sufficient to stand-alone.

Furthermore, there is interplay between gender and desire that opens up new pathways for understanding identities. The interplay can be read through performative 
acts in which individuals through repetition construct specific identities unique to them. These identities have been preformed with a lens of intersectionality in which axes of identity interconnect to create a multidimensional approach. The assumptions connected to categories of identity construct an expectation of normative characteristics assigned to both gender and sexuality. However, as was displayed through the narratives, the expectations of the "norm" are insufficient and harmful because it continues to reproduce inequalities as connected to language and societal inequalities.

This research highlights how language shapes this field of gendered sexuality and it can be used as a way to underscore the importance of an amalgamated identity. Currently the structure of our language does not allow for the real fluidity of identities and as such needs to be retransformed to enable the full understanding and thus with a claiming of a queer identity the narratives shared by the individuals prefigures that queer is the understanding of both a gender and a sexuality - not one or the other - and gives depth to the front of both gender and sexuality. This research highlights the importance of language and furthermore when connected to notions of identity development focuses on how identities are changing and are a dialectical processes in the development of an individual's self concept. This adds to the queer theory literature adding constructivist models as well as acknowledging the power of language as a way to begin to change the language that one uses in order to understand identities.

\section{Limitations}

This study is not without limitations and as such is important to acknowledge them. Due to the small sample size and qualitative nature of this study the results cannot be 
generalizable to others beyond those who were interviewed. This study was also limited to the fact that Portland is quite racially homogenous and so connections of race in terms of intersectionality may have been slightly underdeveloped in the case of how individuals understand and analyze their own race, specifically that of whiteness.

Additionally, as this study focused specifically on self-identified Lesbian, Gay, Bisexual and/or Queer individuals and that these identificatory labels have unique understandings that may not have been addressed clearly as a way to truly explain what it means for the participants. Individuals' identities are constantly in a state of evolvement and therefore the narratives in this study only shed light on the identities at the time of the interviews. Additionally, I have been informed that after interviewing some of my individuals shifted in identity and started to claim a trans identity, which was specifically precluded from this research which may have skewed their own understanding of gendered sexuality.

At the same time, the geographic location of this research can be a limitation to this study. Portland, Oregon is known as queer friendly place also has more "queer consciousness" comparatively to other cities and thus may have skewed the findings in how individuals in this project were able to understand the fluidity between gender and sexuality. Furthermore individuals, as being surrounded by a "queer consciousness" may have been able to have more of an intellectual understanding and utilize the words, ideas, and theorists, associated with the queer movement in academia. 


\section{Suggestions for Future Research}

In order to expand on this research and to consider geography a sample of participants should be obtained from other cities in order to analyze the differences that locations create between populations. I found that location was significant to the individuals in their journeys of gendered sexualities; however since all the participants lived in the Portland area at the time of the interview it was not appropriate to analyze the role of location. Expanding this research to be a multi-cite study would further allow development of theories presented. Specifically what is the role of geographic regions on identity? In order to analyze this, I would suggest gathering participants from each of the regions in the United States and compare how geography plays a role in the development.

Additionally, expanding the ideas of the complex identity as connected to transgender individuals would allow the analysis to be brought to a different population with possibly a more complex development of their identities. Since transgender research is often tied to areas of identity and gender, would analyzing transgender individuals offer a deeper focus on the compounded identities? Or be a project all along itself.

Furthermore, I think that future research could expand more on the claiming of identity labels for both gender and sexuality, i.e. dyke, to focus on the complexities within this identity category. How does the $d y k e$ identity transfer claims of gender and sexuality while at the same time differentiating between these aspects of identity?

It is my goal that this project adds to the discussion of both identity and queer theory literature by combining two distinct theoretical perspectives that are usually kept as separate. Also by highlighting the fluidity that queer theory allows when analyzing 
identities and understanding that there are multiple axes within individuals that need to have the "traditional" understandings deconstructed in order to make sense of their selves. 


\section{References}

Abes, Elisa S. and David Kasch. 2007. "Using Queer Theory to Explore Lesbian College Students' Multiple Dimensions of Identity." Journal of College Student Development 48(4): 619-636.

Adam, Barry D. 1995. The Rise of a Gay and Lesbian Movement: Social Movements Past and Present. New York: Twayne Publishers.

Anzaldua, Gloria. 2007. Borderland/La Frontera ( $3^{\text {rd }}$ ed.) San Francisco, CA: Aunt Lute Books.

Armstrong, Elizabeth A. 2002. Forging Gay Identities: Organizing Sexuality in San Francisco, 1950-1994. Chicago: University of Chicago Press.

Armour, Ellen T. 1999. Deconstruction Feminist Theology and the Problem of Difference: Subverting the Race/Gender Divide. Chicago: The University of Chicago Press.

Ashforth, Blake E. and Fred Mael. 1989. "Social Identity Theory and the Organization." The Academy of Management Review 14(1): 20-39

Atkinson, D. R., G. Morten, and D.W. Sue. 1979. Counseling American Minorities: A Cross-Cultural Perspective. Dubuque, IA: W.C. Brown.

Becker, Alton. L. 1979. "The Figure a Sentence Makes: An Interpretation of a Classical Malay Sentence in Discourse and Syntax" Syntax and Semantics Ann Arbor, MI 12: 245-259.

Becker, Alton, L. 1984. "Biography of a Sentence: A Burmese Proverb." in Edward Bruner (ed.) Text, Play, and Story: The Construction and Reconstruction of Self and Society Washington, DC: American Ethnological Society.

Bem, Sandra Lipsitz. 1975. "The Measurement of Psychological Androgyny" Journal of Personality and Social Psychology. 31: 634-643.

Bem, Sandra Lipsitz. 1981. "Bem Sex-Role Inventory" Consulting Psychologists Press Inc.

Bettie, Julie. 2000. "Women without Class: Chicas, Cholas, Trash, and the Presence/Absence of Class Identity." Signs: Journal of Women in Culture and Society. 26:1-35.

Bettie, Julie. 2003. Women without Class: Girls, Race, and Identity. Berkeley: University of California Press.

Bilodeau, Brent L. and Kristen A. Renn. 2005. "Analysis of LGBT Identity Development Models and Implications for Practice." Gender Identity and Sexual Orientation. Wiley Productions

Blumer, Herbert. 1969. Symbolic Interactionism: Perspective and Method. Los Angeles: University of California Press.

Blumer, Herbert. 1979. Critiques of Research in the Social Sciences: An Appraisal of Thomas and Znaniecki's The Polish Peasant in Europe and America. New Brunswick, NJ: Transaction Books (Original work published in 1939).

Bonilla- Silva, Eduardo. 2001. White Supremacy and Racism in the Post-Civil Rights Era. Boulder: Lynne Rienner Publishers.

Bonilla-Silva, Eduardo. 2010. Racism without Racists: Color-Blind Racism and Racial Inequality in Contemporary America $3^{\text {rd }}$ edition. Plymouth: Rowman and 
Littlefield Publishers.

Bowles, Gloria and Klein, Renate Duelli. 1983. Theories of Women's Studies. Routledge and Kegan Paul publishing.

Bradley, Kym. 2013. "(Mis)representations of (Hetero)Sexuality in Two and a Half Men: A content analysis" Journal of Gender Studies. DOI:10.1080/09589236.2012.752348

Bradley, Kym and Lubitow, Amy. 2013 "On the Margins: Identity Development in the Context of Sexual Minority Practices" Manuscript under review at Sexualities.

Bridger, Jeffrey C and Maines David R. 1998. "Narrative Structures and the Catholic Church Closings in Detroit" Qualitative Sociology. 21(3): 319-340.

Brown, Marni. 2011. Coming Out Narratives: Realities of Intersectionality. Retrieved October 2012, from http://digitalarchives.gsu.edu/sociology diss/63

Bruner, Jerome. 1986. Actual Minds, Possible Worlds. Cambridge, MA: Harvard University Press.

Bucholtz, Mary and Kira Hall. 2004. "Language and Identity" A Companion to Linguistic Anthropology (pp. 369-394).

Bullough, Vern L, Vicki Eakor and Robert R Meek 2006. Bringing Lesbian and Gay Rights into the Mainstream: Twenty Years of Progress. New York: Routledge.

Burke, Peter. 1991. "Identity Process and Social Stress." American Sociological Review. 56(6): 836-349.

Butler, Judith 1988. "Performative Acts and Gender Constitution: An Essay in Phenomenology and Feminist Theory" Theatre Journal 40(4): 519-531.

Butler, Judith. 1990. Gender Trouble: Feminism and the Subversion of Identity. New York: Routledge.

Butler, Judith. 1993a. Bodies that Matter. New York: Routledge.

Butler, Judith. 1993b. "Critically Queer." GLQ. 1: 17-32.

Butler, Judith. 2004. "Bodily Inscriptions, Performative Subversions" (1990) in Judith Butler and Sara Salih The Judith Butler Reader (pp. 90-119). Malden, MA: Blackwell Publishing.

Butler, Judith, Ernesto Laclau and Slavoj Žižek. 2000. Contingency, Hegemony, Universality: Contemporary Dialogues on the Left. London: Verso.

Callero, Peter. 1994. "From Role-Playing to Role-Using: Understanding Role as

Resource” Social Psychology Quarterly 57(3): 238-243.

Callero, Peter. 2003. "Sociology of the Self." Annual Review of Sociology. 29: 115-133.

Case, Sue-Ellen. 1993. Towards a Butch-Femme Aesthetics. In H. Abelove, M.A. Barale, and David M. Halerin (eds.) The Lesbian and Gay Studies Reader (pp. 294-306) New York: Routledge.

Cass, Vivienne. 1984. "Homosexual Identity Formation: A Theoretical Model." Journal of Sex Research 20: 143-167.

Census. 2012. quickfacts.census.gov/qfd/states/41/4159000.html; accessed on 5 September.

Charmaz, Kathy. 2006. Constructing Grounded Theory. Los Angeles: Sage Publications Ltd. 
Chase, Susan E. "Narrative Inquiry: Multiple Lenses, Approaches, Voices" in Denzin, Norman K., and Lincoln, Yvonna S (eds.) The Sage Handbook of Qualitative Research third edition (pp. 651-679). Thousand Oaks: SAGE Publications.

Chauncey, George. 1994. Gay New York: Gender, Urban Culture, and the Making of the Gay Male World, 1890-1940. New York: Basic Books.

Civil Liberties. 2012. http://civilliberty.about.com/od/gendersexuality/g/heteronormative.htm accessed 17 November.

Cochran, Bryan N. Angela J. Stewart, Joshua A. Ginzler, and Ana Mari Cauce. 2002. "Challenges Faced by Homeless Sexual Minorities: Comparison of Gay, Lesbian, Bisexual, and Transgender Homeless Adolescents With Their Heterosexual Counterparts." American Journal of Public Health. 92(5): 773-777.

Coffey, Amanda and Paul Atkinson. 1996. Making Sense of Qualitative Data: Complementary Research Strategies. London: SAGE Publications Inc.

Cohen, Cathy J. 1996. "Contested Membership: Black Gay Identities and the Politics of Aids" in Steven Seidman (ed.) Queer Theory/Sociology (pp. 362-394) Malden, MA: Blackwell Publishers Ltd.

Coleman, E. 1982. "Developmental Stages of Coming Out Process." in J. Gonsiorek (ed.) Homosexuality and Psychotherapy: An Introduction. Cambridge, MA: Cambridge University Press.

Collins, Patricia Hill. 1986. "Learning from the Outsider Within: The Sociological Significance of Black Feminist Thought.” Social Problems 33(6): S14-S32 (special theory issue).

Collins, Patricia Hill. 1988. "Toward a New Vision: Race, Class, and Gender as Categories of Analysis and Connection.” In R.F. Levine (ed.) Social Class as Stratification: Classic Statements and Theoretical Debates (pp.231-247). Lanham: Rowman and Littlefield.

Collins, Patricia Hill. 1989. "The Social Construction of Black Feminist Thought." Signs. 14(4): 745-765.

Collins, Patricia Hill. 1990/2000. Black Feminist Thought: Knowledge, Consciousness, and the Politics of Empowerment. New York: Routledge.

Collins, Patricia Hill. 1993. "Black Feminism in the Twentieth Century" Black Women in America: An Historical Encyclopedia. 2: 418-425.

Collins, Patricia Hill. 2004. Black Sexual Politics: African Americans, Gender, and the New Racism. New York: Routledge.

Collins, Patricia Hill. 2008. "Shifting the Center: Race, Class, and Feminist Theorizing about Motherhood." In Coontz, S., Parson, M. and Raley, G. (eds.) American Families: A Multicultural Reader $2^{\text {nd }}$ edition (pp. 173-187). New York: Routledge.

Connel, R.W. 1987. Gender and Power: Society, the Person and Sexual Politics. Stanford Press.

Connel, R.W. 1992 “A Very Straight Gay: Masculinity, Homosexual Experience, and the Dynamics of Gender." American Sociological Review 57: 735-751.

Connel, R.W. 1995/2005. Masculinities. Berkeley: University of California Press.

Connel, R.W. and Messerschmidt, James W. 2005. "Hegemonic Masculinity: Rethinking the Concept" Gender and Society. 19(6): 829-859. 
Crenshaw, Kimberlé. 1989. "Demarginalizing the Intersections of Race and Sex: A Black Feminist Critique of Anti-Discrimination Doctrine, Feminist Theory, and AntiRacist Politics" University of Chicago Legal Forum 139-167.

Crenshaw, Kimberlé. 1991. "Mapping the Margins: Intersectionality, Identity Politics, and the Violence Against Women of Color" Stanford Law Review 43(6): 12411299.

D’Augelli, Anthony, Grossman, Arnold H., and Starks, Michael T. 2008. “Gender Atypicality and Sexual Orientation Development Among Lesbian, Gay, and Bisexual Youth: Prevalence, Sex Differences, and Parental Responses." Journal of Gay and Lesbian Mental Health. 12(1/2): 121-143.

D'Emilio, John. 1983. Sexual Politics, Sexual Communities: The Making of a Homosexual Minority in the United States 1940-1970. Chicago: University of Chicago Press.

D’Emilio, John. 1993. "Capitalism and the Gay Identity." in Abelove, Henry, M. A. Barale, and D. Halperin (eds.) The Lesbian and Gay Studies Reader (pp. 467-476). New York: Routledge.

D'Emilio, John. 2002. The World Turned: Essays on Gay History, Politics, and Culture. Durham, NC: Duke University Press.

D'Emilio, John and Estelle Freedman. 1997. Intimate Matters: A History of Sexuality in America $2^{\text {nd }}$ edition. Chicago: The University of Chicago Press.

Daniels. Jessie. 1997. White Lies: Race, Class, Gender and Sexuality in White Supremacist Discourse. New York: Routledge.

Dauite, Colette and Lightfoot, Cynthia. 2004. Narrative Analysis: Studying the Development of Individuals in Society. London: Sage Publications.

DeBeauvoir, Simone. 1952. The Second Sex. New York: Alfred A. Knopf.

Denizet-Lewis, Benoit. 2003. "Double lives on the Down Low" NY Times August 3. Found in Collins, Patricia Hill. (2004) Black Sexual Politics: African Americans, Gender, and the New Racism. New York: Routledge.

DeLauretis, Teresa. 1993. Sexual Indifference and Lesbian Representation in H. Abelove, M.A. Barale, and David M. Halperin (eds.) The Lesbian and Gay Studies Reader (pp. 141-158) New York: Routledge.

Derrida, Jacques. 1991. "From Speech and Phenomena." in Peggy Kamuf (ed.) A Derrida Reader: Between the Blinds (pp. 6-30). New York: Columbia University Press.

Diamond, Lisa M. 2003. "What Does Sexual Orientation Orient? A Biobehavioral Model Distinguishing Romantic Love and Sexual Desire." Psychological Review 110(1): 173-192.

Diamond, Lisa M. 2008. Sexual Fluidity: Understanding Women's Love and Desire. Cambridge, MA: Harvard University Press.

Dow, Bonnie. 2001. "Ellen, Television and the Politics of Gay and Lesbian Visibility." Critical Studies in Media Communication 18(2): 123-140.

Duggan, Lisa. 1993. "The Trials of Alice Mitchell: Sensationalism, Sexology, and the Lesbian Subject in Turn-of-the-Century America" Sign 18(4): 791-814.

Duggan, Lisa. 2002. "The New Homonormativity: The Sexual Politics of Neoliberalism." In R. Castronovo and D. D. Nelson (eds.) Materializing Democracy: Toward a Revitalized Cultural Politics (pp. 175-194). Durham, NC: Duke University Press. 
Dull, Diana and Candace West. 1987. "Accounting for Cosmetic Surgery: The Accomplishment" in Sarah Fenstermaker and Candace West (eds.) Doing Gender Doing Difference: Inequality, Power and Institutionalized Change (pp. 119-140).

Eder, Donna, Suzanne Staggenborg and Lori Sudderth. 1995. Journal of Contemporary Ethnography 23: 485-515.

Epstein, Steven. 1996. "A Queer Encounter: Sociology and the Study of Sexuality" in S. Seidman Queer/Sociology (pp. 145-167). Malden, MA: Blackwell.

Espiritu, Yen Le. 1999. "Gender and Labor in Asian Immigrant Families." American Behavioral Scientist. 42(4): 628-647.

Espiritu, Yen Le. 2010. "All Men Are Not Created Equal: Asian men in US history.” In Kimmel, Michael, and Messner, Michael (eds) Men's Lives $10^{\text {th }}$ edition (pp. 4457) Boston: Allyn Bacon.

Esterberg, Kristin. 1996. “'A Certain Swagger When I Walk': Performing Lesbian Identity" in Steven Seidman (ed.) Queer Theory/Sociology. Oxford: Blackwell.

Eves, Alison. 2004. "Queer Theory, Butch/Femme Identities and Lesbian Space." Sage Publications 7(4): 480-496.

Ewick, Patricia and Silbey, Susan. 2003. "Narrating Social Structure: Stories of Resistance to Legal Authority." The American Journal of Sociology. 108: 13281372 .

Felson, Richard B. 1985. "Reflected Appraisal and the Development of the Self" Social Psychology Quarterly 48(1): 71-78.

Fine, Gary Alan and Lisa-Jo van den Scott. 2011. "Wispy Communities: Transient Gatherings and Imagined Micro-Communities." American Behavioral Scientist 55(10): 1319-1335.

Franks, David D. and Viktor Grecas. 1992. "Autonomy and Conformity in Cooley's SelfTheory: The Looking-Glass Self and Beyond." Symbolic Interaction 15(1): 49-68.

Foucault, Michèl. 1977. Discipline and Punish: The Birth of the Prison. New York: Vintage.

Foucault, Michèl. 1978. The History of Sexuality: An Introduction. Vol 1. Translated by Robert Hurley. New York: Vintage Books.

Gamson, Joshua. 1997. "Messages of Exclusion: Gender, Movements, and Symbolic Boundaries." Gender and Society 11(2): 178-199.

Gamson, Joshua and Dawne Moon. 2004. "The Sociology of Sexualities: Queer and Beyond." Annual Review of Sociology 30: 47-64.

Gecas, Viktor and Peter J. Burke. 1995. "Self and Identity." in KS Gook, GA Fine, and JS House (eds.) Sociological Perspectives on Social Psychology (pp. 41-67). Needham Heights, MA: Allyn and Bacon.

Gecas, Viktor, and Michael L. Schwalbe. 1983. "Beyond the Looking-Glass Self: Social Structure and Efficacy-Based Self-Esteem.” Social Psychology Quarterly 46(2): 77-88.

Georgakapoula, Alexandra. 2006. "Thinking Big with Small Stories in Narrative and Identity Analysis. Narrative Inquiry. 16(1): 122-130.

Ghaziani, Amin. 2011. "Post-Gay Collective Identity Construction." Social Problems 58(1): 99-125. 
Green, Adam Isaiah. 2010. "Remembering Foucault: Queer Theory and Disciplinary Power" Sexualities 13: 316-337.

Gramsci, Antonio. [1971] 1999. "Selections from the Prison Notebooks of Antonio Gramsci" in Hoare, Q and Smith, G.N. (eds.) New York: International Publishers.

Green, Adam Isaiah. 2010. "Remembering Foucault: Queer Theory and Disciplinary Power" Sexualities 13(3): 316-337.

Gubrium, Jaber F. and Holstein, James A. 1997. The New Language of Qualitative Method. New York: Oxford University Press.

Gubrium, Jaber F. and Holstein, James A. 1999. "At the Border of Narrative and Ethnography." Journal of Contemporary Ethnography. 28:561-572.

Gumperz, John. 1982. Discourse Strategies: Studies in International Sociolinguistics 1 Cambridge, UK: Cambridge University Press.

Hall, Stuart. 1993. "Cultural Identity and Diaspora." In Patrick Williams and Chrisman (ed.) Colonial Discourse and Post-Colonial Theory: A Reader (pp. 392-401). London: Harverster Wheatsheaf 1994.

Hatfield, Elizabeth F. 2010. " "What it Means to Be a Man': Examining Hegemonic Masculinity in Two and a Half Men." Communication, Culture and Critique 3: 526-548.

Hiestand, Katherine R. and Levitt, Heidi M. 2005. "Butch Identity Development: The Formation of an Authentic Gender." Feminism and Psychology. 15: 61-85.

Hinchmen, Lewis P. and Hinchmen, Sandra K. (eds) 2001. Memory, Identity, Community: The Idea of Narrative in the Human Sciences. Albany: State University of New York Press.

Hogg, Michael A., Deborah J. Terry, and Katherine M. White. 1995. "A Tale of Two Theories: A Critical Comparison of Identity Theory with Social Identity Theory." Social Psychology Quarterly 58(4): 255-269.

hooks, bell. 1989. Telling Back: Thinking Feminist, Thinking Back. Boston: South End Press.

Ingraham, Chrys. 1994/2004. "The Heterosexual Imaginary: Feminist Sociology and Theories of Gender." Sociological Theory, 12(2): 203-219.

Ingraham, Chrys. 2008. Romancing Heterosexuality in Popular Culture $2^{\text {nd }}$ edition. New York: Routledge.

Irvine, Janice, N. "A Place in the Rainbow: Theorizing Lesbian and Gay Culture" in Seidman, Steven (ed.) Queer Theory: Sociology (pp. 213-240). Malden, MA: Blackwell Publishers Ltd.

Jackson, Stevi. 2006. "Interchanges: Gender, Sexuality and Heterosexuality: The Complexity (and Limits) of Heteronormativity." Feminist Theory 7: 105-121.

Jagose, Annamarie. 1996. Queer Theory. Melbourne: The University of Melbourne Press. Johnson, Allan G. The Gender Knot: Unraveling Our Patriarchal Legacy. Philadelphia, PA: Temple University Press.

Jones, S. R. and M. K. McEwen. 2000. "A Conceptual Model of Multiple Dimensions of Identity" Journal of College Student Development 41(4): 405-414.

Kaufman, J. M. and Johnson, C. 2004. "Stigmatized Individuals and the Process of Identity." Sociological Quarterly 45: 807-833. 
Keller, Reiner. 2005. "Analysing Discourse: An Approach from the Sociology of Knowledge" Qualitative Social Research 6(3): Article 32.

Kerfoot, Deborah and David Knights. 1994. "Into the Realm of the Fearful: Power, Identity and the Gender Problematic" in L.H. Radtke, and H. J Stam (eds.) Power/Gender (pp. 67-89). London: SAGE Publications Ltd.

Kimmel, Michael. 2011. The Gendered Society $4^{\text {th }}$ edition. New York: Oxford University Press.

King, Deborah W. 1988. "Multiple Jeopardy, Multiple Consciousness: The Context of Black Feminist Ideology." Signs: Journal of Women in Culture and Society. 14: 42-72.

Kinsey, Alfred, Wardell Pomeroy and Clyde Martin. 1948. Sexual Behavior within the Human Male. Bloomington, IN: The University of Indiana Press.

Kinsey, Alfred, Wardell Pomeroy and Clyde Martin. 1953. Sexual Behavior within the Human Male. Bloomington, IN: The University of Indiana Press.

Kopelson, Karen. 2002. "Dis/Integrating the Gay/Queer Binary: 'Reconstructed Identity Politics' for a Performative Pedagogy." College English 65(1): 17-35.

Labov, William. 2001. "Uncovering the Event Structure of Narrative.” In Tannen, Deborah and Alatis, James E. (eds.) Linguistics, Language, and the Real World: Discourse and Beyond (pp. 63-83). Washington D.C.: Georgetown University Press.

Lakoff, George. 2008. The Political Mind: Why You Can't Understand $21^{\text {st }}$ Century Politics with an $18^{\text {th }}$ Century Brain. New York: Penguin Group.

Laslett, Barbara. 1999. "Personal Narratives as Sociology" Contemporary Sociology, 28:391-401.

Lorber, Judith. 1990. “ 'Night to His Day': The Social Construction of Gender” in S.E. Case (ed.) Performing Feminisms: Feminist Critical Theory and Theatre. (pp. 5368). Baltimore, MA: The Johns Hopkins University Press.

Lorber, Judith. 1994. Paradoxes of Gender. Bimington: Yale University Press.

MacKinnon, Katherine. 2003. Sex and Gender: Maleness and Masculinity. New York: Oxford University Press.

Maines, David R. 1993. "Narrative/s Moment and Sociology's Phenomena: Toward a Narrative Sociology." Sociological Quarterly. 34(1): 17-38.

Maltz, Daniel N. and Ruth A. Borker. 1982. "A Cultural Approach to Male-Female Miscommunication.” in John J. Gumperz (ed.) Language and Social Identity (pp. 196-216) Cambridge, UK: Cambridge University Press.

Marshall, Catherine and Rossman, Gretchen B. 2011. Designing Qualitative Research Fifth edition. London: Sage Publications, Inc.

McIntosh, Mary. 1996. "The Homosexual” in Seidman, Steven (ed.) Queer Theory/Sociology (pp. 33-40). Malden, MA: Blackwell Publishers Inc.

McIntosh, Peggy. 1988. "White Privilege: Unpacking the Invisible Knapsack." In Disch, E. (ed.) Reconstructing Gender $5^{\text {th }}$ edition (pp. 78-83). Boston: McGraw Hill.

Mead, George H. 1934. Mind, Self, and Society: From the Standpoint of a Social Behaviorist. Edited with an introduction by C.W. Morris. Chicago: University of Chicago Press. 
Meeks, Chet. 2006. "Gay and Straight Rites of Passage." in Seidman, S., N. Fishcher, and C. Meeks (eds.) Introducing the New Sexuality Studies (pp. 6-12). New York: Routledge.

Minton, H. L. and G. J. McDonald. 1984. "Homosexual Identity Formation as a Developmental Process" Journal of Homosexuality 9: 91-104.

Owens, Timothy J., Dawn T. Robinson, and Lynn Smith-Lovin. 2010. "Three Faces of Identity." Sociology 36(1): 477.

Plummer, Kenneth. 1975. Sexual Stigma: An Interactionist Account. London: Routledge and Kegan Paul.

Plummer, Kenneth. 1995. Telling Sexual Stories. New York: Routledge.

Polkinghorne, Donald E. 1995. "Narrative Configuration in Qualitative Analysis" in Hatch, J. A. and Wisniewski, R. (eds.) Life History and Narrative (pp. 5-23). Bristol, PA: The Falmer Press.

Pyke, Karen D. and Denise L. Johnson. 2003. "Asian American Women and Racialized Femininities: 'Doing' Gender across Cultural Worlds." Gender and Society 17(1): 33-53.

Renold, Emma. 2006. “ 'They Won’t Let Us Play... Unless You're Going out with One of Them': Girls, Boys and Butler's 'Heterosexual Matrix' in the Primary Years." Journal of Sociology of Education 27(4): 489-509.

Rupp, Leila and Verta Taylor. 2003. Drag Queens at the 801 Cabaret. Chicago: Chicago University Press.

Rupp, Leila, Verta Taylor and Eve I. Shapiro. 2010. "Drag Queens and Drag Kings: The Difference Gender Makes" Sexualities 13(3): 275-294.

Rust, Paula C. 1993. " 'Coming Out' in the Age of Social Constructionism: Sexual Identity Formation among Lesbian and Bisexual Women." Gender and Society 7(1): 50-77.

Savin-Williams, Ritch C. Lisa M. Diamond. 2000. "Sexual Identity Trajectories Among Sexual-Minority Youths: Gender Comparisons." Archives of Sexual Behavior 29(6): 607-627.

Sedgwick, Eves. 1990. Epistemology of the Closet. Berkeley: University of California Press.

Seidman, Steven. 1996. Queer Theory/Sociology. Blackwell Publishers Ltd.

Seidman, Steven. 1997. Difference Troubles Cambridge, UK: Cambridge University Press.

Seidman, Steven. 2002. Beyond the Closet: The Transformation of Gay and Lesbian Life. New York: Routledge.

Seidman, Steven, Chet Meeks, and Francie Traschen. 1999. "Beyond the Closet? The Changing Social Meaning of Homosexuality in the United States." Sexualities. 2:9-34.

Shankar, Shalini. 2008. Desi Land: Teen Culture, Class, and Success in Silicon Valley. Durham, NC: Duke University Press.

Sophie, J. 1985/1986. “A Critical Examination of Stage Theories of Lesbian Identity Development" Journal of Homosexuality. 12: 39-51.

Stein, Arlene. 1977. Sex and Sensibility: Stories of Lesbian Generation. Berkeley: University of California Press. 
Stein, Arlene and Ken Plummer. 1996. “' I Can't Even Think Straight': 'Queer' Theory and the Missing Sexual Revolution in Sociology" in Steven Seidman (ed.) Queer Theory/Sociology. (pp. 129-144). Malden, MA: Blackwell Publishers Inc.

Stets, Janet and Peter Burke. 1988. "Femininity/Masculinity." in Edgar F. Borgatta and Rhonda J. V. Montgomery (eds.) Encyclopedia of Sociology, Revised Edition. (pp. 997-1005). New York: Macmillan.

Stryker, Sheldon and Richard T. Serpe. 1982. "Commitment, Identity Salience, and Role Behavior." in W. Ices and E. Kneels (eds.) Personality, Roles, and Social Behavior (pp. 199-218). New York: Springer-Verlag.

Tannen, Deborah. 1994. Gender and Discourse New York: Oxford University Press.

Taylor, Verta and Nancy E. Whittier. 1992. "Collective Identity in Social Movement Communities.” In A.D. Morris and C. McClurg (eds.) Frontiers in Social Movement Theory (pp. 104-129). New Haven: Yale University Press.

Tjafel, Henri and John C. Turner. 1979. "An Integrative Theory of Intergroup Conflict." in W. G. Austin and S. Worchel (eds.) The Social Psychology of Intergroup Relations (pp. 33-47). Monterey: Books/Cole.

Trautner, Mary Nell. 2005. "Doing Gender, Doing Class: The Performance of Sexuality in Exotic Dance Clubs" Gender and Society 19(6): 771-788.

Troiden, Richard R. 1988. Gay and Lesbian Identity: A Sociological Analysis. Dix Hills, NC: General Hall.

Troiden, Richard. R. 1989. "The Formation of Homosexual Identities.” Journal of Homosexuality 17(1-2): 43-73.

Vaid, Urvashi. 1995. Virtual Inequality: The Mainstreaming of Gay and Lesbian Liberation. New York: Anchor. s

Valentine, David. 2003. " 'I Went to Bed with my Own Kind Once': The Erasure of Desire in the Name of Identity." Language and Communication 23(2): 123-138.

Valocchi, Stephen. 1999a. "The Class-Inflected Nature of Gay Identity." Social Problems 46(2): 207-224.

Valocchi, Stephen 2005. "Not Yet Queer Enough: THE Lessons of Queer Theory for the Sociology of Gender and Sexuality." Gender and Society 19(6): 750-770.

Van Dijk, Teun A. 2001. "Critical Discourse Analysis" in D. Schiffin, D. Tannen and H.E. Hamilton (eds.) The Handbook of Discourse Analysis (pp. 352-371) Malden, MA: Blackwell Publishers Inc.

Ward, Elijah G. 2005."Homophobia, Hypermasculinity and the US Black Church." Culture, Health and Sexuality 7(5): 493-504.

Warner, Michael. 1991. "Fear of a Queer Planet" Social Text 9(14): 3-17.

Warner, Michael. 1999. The Trouble with Normal. New York: Free Press.

Weber, J. 1986. "Symposium: On West and Fenstermaker's 'Doing Difference'," Gender and Society 9:499-503.

Weeks, Jeffrey. 1977. Coming Out: Homosexual Politics in Britain from the $19^{\text {th }}$ Century to the Present. London: Quartet.

Weeks, Jeffrey. 1986. Sexuality. London: Routledge.

Weeks, Jeffrey. 1996. "The Construction of Homosexuality" in Steven Seidman (ed.) Queer Theory/Sociology. (pp. 41-63) Malden, MA: Blackwell Publishers Ltd. 
Weiss, Margot D. 2006 "Working at Play: BDSM Sexuality in the San Francisco Bay Area." Division II Faculty Publications, Paper 47. http://wesscholar.weleyan.edu/div2facpubs/47.

West, Candace and Don H. Zimmerman. 1987. "Doing Gender." Gender and Society. 1(2): 125-121.

Weinberg, T. S. 1984. "Biology, Ideology, and the Reification of Developmental Stages in the Study of Homosexual Identities." Journal of Homosexuality 10: 77-84.

Wilson, Ara. 2004. The Intimate Economies of Bangkok: Tomboys, Tycoons, and Avon Ladies in a Global City. Berkeley, CA: The University of California Press.

Wodak, Ruth and Norman Fairclough. 1997. "Critical Discourse Analysis." in Teun A. van Dijk Discourses as Social Interaction (pp. 258-284). London: Sage 
Appendix A: Recruitment Flyer

\section{LESBIAN, GAY, BISEXUAL AND QUEER INDIVIDUALS NEEDED}

\section{ONE-ON-ONE IN-DEPTH INTERVIEWS: "DISCURSIVE ANALYYSES OF QUEER SEXUALITY AND GENDER PERFORMATIVITY"}

Kym Bradley, a Master's Candidate in the Department of Sociology at PSU, is conducting interviews to learn more about the experiences of gender for queer individuals. If you are between the ages of 18-35 and are self-identified as LGBQ, you are invited to join a study that aims to discuss these issues through one-on-one interviews. The information gathered in the interviews will help shed light on the processes involved in the daily enactment of gender for queer individuals.

\section{TO FIND OUT MORE INFORMATION AND/OR \\ TO BE CONSIDERED FOR AN INTERVIEW, PLEASE CONTACT KYM BRADLEY AT KABRADLEQPDXX.EDU OR 503.725.5820}




\section{Appendix B: Preliminary Questionnaire}

Please answer the following questions to the best of your ability. Feel free to stop or skip questions at any point if you feel uncomfortable.

1. How did you hear about this research study?

2. What city do you currently live in?

3. What is your age?

4. What is your race/ethnicity?

5. How long have you lived in Portland, OR?

6. Are you currently in College? If so where?

7. What is your sexual orientation?

8. What is your current gender identity?

9. Have/Are you involved in a long-term romantic relationship with someone of the same sex? 


\section{Appendix C: Bem Androgyny Test}

\section{Bem Androgyny Test}

Sociology

This test is a way of judging how masculine or feminine you are. Answer questions as the term best fits you according to the following scale: (put the scale number next to the question number below)

\begin{tabular}{|c|c|c|c|}
\hline \multicolumn{4}{|c|}{$\begin{array}{c}1=\text { Never or almost never true } \\
2=\text { Usually not true } \\
3=\text { Sometimes but infrequently true } \\
4=\text { Occasionally true } \\
5=\text { Often true } \\
6=\text { Usually true } \\
7=\text { Always or almost always true }\end{array}$} \\
\hline \multicolumn{4}{|l|}{ Questions: } \\
\hline 1. Acts as a Leader & \multicolumn{2}{|l|}{ 21. Feminine } & 41. Makes decisions easily \\
\hline 2. Adaptable & \multicolumn{2}{|l|}{ 22. Inefficient } & 42. Shy \\
\hline 3. Affectionate & \multicolumn{2}{|l|}{ 23. Defends own beliefs } & 43. Masculine \\
\hline 4. Conceited & \multicolumn{2}{|l|}{ 24. Flatterable } & 44. Solemn \\
\hline 5. Aggressive & \multicolumn{2}{|l|}{ 25. Dominant } & 45. Soft-spoken \\
\hline 6. Cheerful & \multicolumn{2}{|l|}{ 26. Jealous } & 46. Tactful \\
\hline 7. Ambitious & \multicolumn{2}{|l|}{ 27. Gentle } & 47. Self-reliant \\
\hline 8. Conscientious & \multicolumn{2}{|l|}{ 28. Likable } & 48. Sympathetic \\
\hline 9. Childlike & \multicolumn{2}{|l|}{ 29. Forceful } & 49. Self-sufficient \\
\hline 10. Conventional & \multicolumn{2}{|l|}{ 30. Gullible } & 50. Theatrical \\
\hline 11. Analytical & \multicolumn{2}{|l|}{ 31. Has leadership abilities } & 51. Tender \\
\hline 12. Compassionate & \multicolumn{2}{|l|}{ 32. Moody } & 52. Truthful \\
\hline 13. Assertive & \multicolumn{2}{|l|}{ 33. Loves children } & 53. Strong personality \\
\hline 14. Friendly & \multicolumn{2}{|l|}{ 34. Reliable } & 54. Understanding \\
\hline 15. Does not use harsh language & 35. Independent & & 55. Willing to take a stand \\
\hline 16. Happy & 36. Loyal & & 56. Unpredictable \\
\hline 17. Athletic & 37. Individualistic & & 57. Warm \\
\hline 18. Eager to soothe hurt feelings & 38. Secretive & & 58. Unsystematic \\
\hline 19. Competitive & 39. Sensitive to the needs & f others & 59. Willing to take risks \\
\hline 20. Helpful & 40. Sincere & & 60. Yielding \\
\hline Answers: & & & \\
\hline 1. & 3. & 5. & 6. \\
\hline 7. & 10. & 11. & 12. \\
\hline 13. & 15. & 17. & 18. \\
\hline 19. & 21. & 23. & 24. \\
\hline 25. & 27. & 29. & 30. \\
\hline 31. & 33. & 35. & 36. \\
\hline 37. & 39. & 41. & 42. \\
\hline 43. & 46. & 47. & 48. \\
\hline 49. $\square$ & 51. & 53. & 54. \\
\hline 55. & 57. $\square$ & 59. & 60. $\square$ \\
\hline 1. & 3. & 5. & 6. \\
\hline
\end{tabular}




\section{Appendix D: Interview Guide}

- Thinking about your childhood how did you feel compared to others around you?

- While you were growing up did you ever feel that you were "different" from other kids? If so what about you felt different? Do you remember when you started feeling like this? Did the feeling sort of happen all at once or was it gradual?

- Did anyone suggest that you were different from other kids your age? If so who and when?

- Did you talk to anyone about your feelings? If so, how did they respond? Did you talk to any others?

- How old were you when you realized you were attracted to the same sex? And how old when you realized these feelings were sexual? Can you talk about how and when you started to question your sexuality?

- How old were you when you considered a non-heterosexual identity?

- Were you every called sissy/tomboy as a kid? And if so can you explain how this identity came to you?

- Did you ever think of your gender as having an emphasis on sexuality? If so, can you talk about that?

- Can you talk about how you see your gender and how you think others see your gender? And your sexuality?

- How old were you when you adopted this understanding of your gender? And sexuality? Can you explain this in detail?

- Has this understanding changed since you first came out? If so, in what ways? Can you tell me a little about this?

- Have you noticed changes in your gender style, for example the way you carry your mannerisms or the way you interact with others, or talk about yourself in relation to your gender. Has this happened before or after coming out? Can you tell me about this?

- Do you see style of clothing as related to your gender and if so can you talk about how? 
- Do you see your walking style, how you stand, or compose yourself connected to sexuality or gender?

- Do you change how you enact your gender based on whom you are surrounded by? Or where you are going to be going? Such as school, work, the bar, hanging out with friends? Can you tell me a little about this.

- Have you had a long-term serious relationship of the same-sex? If so, do you think the relationship solidified or somehow reinforced your sexual identity? Did you have changes in your gender presentation while in this relationship or directly after a break up?

- Did you perceive your significant other to have a similar gender style to you? A different style? If so how?

- How would you define gender enactment? And how would you define your own gender enactment.

- How do you describe/experience your gender? How do you experience others' genders and sexualities? Do you react off it? Can you explain this? 